\title{
The development of a diesel injector experiment to study the combined effects of oxidation and shear on lubricating oil viscosity
}

\author{
by \\ Frédéric Laforge \\ A Thesis submitted to \\ the Faculty of Graduate Studies and Research \\ in partial fulfilment of \\ the requirements for the degree of \\ Master of Applied Science \\ Ottawa-Carleton Institute for \\ Mechanical and Aerospace Engineering \\ Department of Mechanical and Aerospace Engineering \\ Carleton University \\ Ottawa, Ontario, Canada
}

September 2015

Copyright (C)

2015 - Frédéric Laforge 
The undersigned recommend to

the Faculty of Graduate Studies and Research

acceptance of the Thesis

\title{
The development of a diesel injector experiment to study the combined effects of oxidation and shear on lubricating oil viscosity
}

\author{
Submitted by Frédéric Laforge \\ in partial fulfilment of the requirements for the degree of \\ Master of Applied Science
}

Prof. Ronald Miller, Supervisor

Prof. Metin Yaras, Department Chair

Carleton University

2015 


\section{Abstract}

An experimental test rig was needed to apply high rates of shear strain on lubricating oil molecules and study the effects these may have on the degradation of the lubricant. The result was the development of a diesel injector experiment where the degraded oil from a bench-top oxidation apparatus could be stressed and cycled effectively. Viscosity measurements were used to determine whether or not the oil had degraded. A change in viscosity in high molecular weight compounds is evidence of chain scission. The results show that cycling a $128 \mathrm{ml}$ volume of oil 12 times has no effect on fresh, unaltered lubricating oils, even at low oxidation times up until 48 hours. However, the results show that heavily degraded lubricating oils near and beyond their usability limit, do exhibit a viscosity loss of up to $19 \%$. 


\section{Acknowledgments}

I would like to thank GasTOPS and Professor Ronald E. Miller, my supervisor, for this project.

Of course there are too many of you to underline but equally too important to ignore.

I wish to thank all who have supported me throughout this process. 


\section{Table of Contents}

Abstract $\quad$ iii

Acknowledgments $\quad$ iv

Table of Contents $\quad$ v

Nomenclature viii

1 Introduction 1

2 Literature Review $\quad 6$

2.1 Lubricating Oils and their Composition . . . . . . . . . . . . 7

2.1.1 Lubrication Modes Encountered in Machinery . . . . . . . . . 11

2.1.2 Lubricating Oil Viscosity . . . . . . . . . . . . . 14

2.1.3 Lubricating Oil Degradation: Its Impact on Viscosity . . . . . 16

2.1.4 Mechanical Degradation of Base Oils . . . . . . . . . . . . . . 19

2.1.5 Mechanical Degradation of VIIs . . . . . . . . . . . . . . 21

2.2 Experimental Methods in the Mechanical Degradation of Polymers . . 24

2.3 Diesel Injector Shear Rate Estimation . . . . . . . . . . . . . . . . 28

3 Test Plan \& Experimental Apparatus 32

3.1 Accelerated Lubricating Oil Oxidation Method . . . . . . . . . . . . 34

3.2 Diesel Injector Apparatus Description . . . . . . . . . . . . . . . 38 
3.2 .1 Injection System _ . . . . . . . . . . . . . . . . . . 38

3.2.2 Injection Nozzle . . . . . . . . . . . . . . . . . . . . . . . . . . 40

3.2.3 Atomization Chamber . . . . . . . . . . . . . 42

3.2.4 Injection Actuation Program . . . . . . . . . . . . . . . 43

3.2.5 Diesel Injector Apparatus Installation . . . . . . . . . . . . . . 44

3.2.6 Experimental Program . . . . . . . . . . . . . . 46

3.2.7 Injector Nozzle Flow and Shear Rates . . . . . . . . . . . . . . 51

4 Results \& Discussion $\quad 57$

4.1 Preliminary Results . . . . . . . . . . . . . . . . 57

5 Future Work $\quad 64$

5.1 Artificial Oxidation Method - Suggested Improvements . . . . . . . . 65

5.2 Experimental Diesel Injector Apparatus - Improvements \& New Research Direction . . . . . . . . . . . . . . . . . 66

6 Conclusion $\quad 69$

$\begin{array}{ll}\text { List of References } & 71\end{array}$

$\begin{array}{ll}\text { Appendix A Manufacturing Drawings } & 75\end{array}$

A.1 Atomization Chamber . . . . . . . . . . . . . . 76

A.2 Injector Rig Mobile Table . . . . . . . . . . . . . . . 77

$\begin{array}{lll}\text { Appendix B Experimental Data } & 79\end{array}$

B.1 Viscosity and Shear Stress Data . . . . . . . . . . . . . 80

B.2 Rheometry Testing Temperatures . . . . . . . . . . . . . 91

$\begin{array}{lll}\text { Appendix C Derivation of Equation ?? } & 92\end{array}$ 
Appendix D Measurement System

D.1 DG42/Q1 . . . . . . . . . . . . . . . . . . 94 


\section{List of Tables}

4.1 Tabulated average viscosities $(\bar{\mu})$ of oxidized-unsheared samples, oxidized-sheared samples and their difference $(\delta \bar{\mu})$ according to their respective oxidation times. . . . . . . . . . . . . . . . . 60

4.3 Average starting and final temperatures of each viscosity tests. . . . . 62

B.1 Average starting and final temperatures of each viscosity tests. . . . . 91 


\section{List of Figures}

2.1 Examples of a) paraffinic, b) aromatic and c) cycloparaffin molecular structures. . . . . . . . . . . . . . . . . .

2.2 The Figure shows a top and bottom surface, each having roughness where asperities come into contact and the low lying areas are filled with lubricant. Without an anti-wear additive, the lubricant cannot protect the surfaces as the loads encountered in boundary lubrication are too high for an oil film to develop. (Adapted from [1]) . . . . . . 10

2.3 Schematic representation of a typical journal bearing under steadystate running conditions [2]. The line running through the bearing and journal centers(the perpendicular distance seperating the centers is called the eccentricity, e) separates the converging zone of the bearing with the diverging region. The converging zone starts at $\theta=0^{\circ}$ where the pressure begins to build-up. At $\theta=180^{\circ}$ the oil film is at its minimum thickness and is denoted by the attitue angle, $\psi$; the angle formed by the load line and, the journal and bearing centers. Note the pressure profile that develops due to the generation of the oil film [2].

2.4 Depiction of the elastically deformed contact zone that develops between two loaded rollers.(Adapted from [3]) . . . . . . . . . . . 
2.5 Schematic representation of the events leading-up to the breaking of a VII molecule. The Figure shows the VII molecule at rest in the top-left corner of the Figure, undergoes elongation under stress, more so as the stress increases, which leads to bond breaking resulting in two smaller VII molecules. Note the two arrows showing that if the molecule does not break, it may return to its previous structure (i.e. shearing does not always have a permanent effect on the molecules structure) [4]. .

2.6 Theoretical representation of a polymer molecule breaking in the vicinity of a collapsing cavitation bubble. The topmost sketch represents the start of the collapsing event at time zero. As time marches forward (shown going down on the Figure), the bubble completely collapses and causes the polymer molecule to break [5] . . . . . . . . . . . . . . 27

2.7 Partial mass flux choking of an injection nozzle caused by cavitation [6]. 31

3.1 Bench-top oxidation testing apparatus. 1) Temperature Controller; 2) Thermocouple; 3) Air-Line; 4) Partial Immersion Thermometer; 5) Heating Jacket; 6) Hot Plate/Magnetic Stirrer; 7) Boiling Flask. . . . 37

3.2 Injection Pump details $[7] \ldots \ldots$. . . . . . . . . . . . . 39

3.3 Nozzle and pintle geometry as specified by the ISO 4010 standard. Note the 'neck' of the pintle by the grayed-out area. . . . . . . . . . . 41

3.4 Atomization chamber mounted to diesel injector interface plate. The drain-hole, overflow outlet and thermocouple port are visible. . . . . . 42

3.5 Diesel injector nozzle needle lift trace as a function of time (NOP:276 bars, back-pressure: 21.1 bars), modified from [8]. . . . . . . . . . . .

3.6 Experimental installation featuring: 1) Accumulators; 2) Air Amplifier; 3) Diesel Injector Calibrator; 4) Injection Tank; 5) Injector Nozzle/Atomization Chamber Assembly; 6) Sample Collection Jar; 7) Injection Pump; 8) Exhaust Muffler; 9) Mobile Table. . . . . . . . . . 
3.7 Schematic of diesel injector apparatus. . . . . . . . . . . . . 46

3.8 Expected viscosity of oil samples based on preliminary sample data. The legend denotes aging time in hours. . . . . . . . . . . . . 48

3.9 Plots of viscosity vs. shear rate for mineral oil viscosity standards RTM10 and RTM19, for 3 different tests on each. . . . . . . . . . 49

3.10 Calibration data for RTM10 and RTM19 with corresponding linear fits for interpolation. . . . . . . . . . . . . . . . . . 51

3.11 Minimum flow area (circled) encountered by injection fluid at various needle-lift positions. . . . . . . . . . . . . . . . . . . . 52

3.12 Typical air flow rate curve for a calibrated pintle-type injector nozzle [9]. 53

3.13 Schematic representation of important dimensions in annular flow. . . 54

4.1 Plot showing the viscosity difference between the sheared and unsheared oxidized lubricating oil samples. . . . . . . . . . . . . . 59

4.2 Plot showing the $\%$ viscosity change in viscosity. It clearly singles out the influence of shear on oil viscosity after 72 hours of oxidation where a $19 \%$ change was observed. . . . . . . . . . . . . . . . 59

4.3 Plot showing the viscosity difference between the sheared and unsheared oxidized lubricating oil samples. . . . . . . . . . . . . . 62

B.1 Viscosity and shear stress data plotted against the shear strain rate for oxidized and oxidized \& sheared samples after 8 hours of oxidization.

B.2 Viscosity and shear stress data plotted against the shear strain rate for oxidized and oxidized \& sheared samples after 12 hours of oxidization.

B.3 Viscosity and shear stress data plotted against the shear strain rate for oxidized and oxidized \& sheared samples after 16 hours of oxidization.

B.4 Viscosity and shear stress data plotted against the shear strain rate for oxidized and oxidized \& sheared samples after 24 hours of oxidization. 
B.5 Viscosity and shear stress data plotted against the shear strain rate for oxidized and oxidized \& sheared samples after 36 hours of oxidization. 84

B.6 Viscosity and shear stress data plotted against the shear strain rate for oxidized and oxidized \& sheared samples after 40 hours of oxidization.

B.7 Viscosity and shear stress data plotted against the shear strain rate for oxidized and oxidized \& sheared samples after 48 hours of oxidization.

B.8 Viscosity and shear stress data plotted against the shear strain rate for oxidized and oxidized \& sheared samples after 56 hours of oxidization.

B.9 Viscosity and shear stress data plotted against the shear strain rate for oxidized and oxidized \& sheared samples after 60 hours of oxidization.

B.10 Viscosity and shear stress data plotted against the shear strain rate for oxidized and oxidized \& sheared samples after 64 hours of oxidization.

B.11 Viscosity and shear stress data plotted against the shear strain rate for oxidized and oxidized \& sheared samples after 72 hours of oxidization. 


\section{Nomenclature}

\section{Symbols}

$\begin{array}{ll}a & \text { Outer radius of annulus, } m \\ b & \text { Inner radius of annulus, } m \\ C_{d} & \text { Discharge coefficient, dimensionless } \\ d \hat{p} / d x & \text { Pressure gradient across injector nozzle, } \mathrm{Pa} / \mathrm{m} \\ \dot{\gamma} & \text { Shear strain rate }\left(\mathrm{s}^{-1}\right) \\ \mu & \text { Absolute viscosity, } \mathrm{Pa} \cdot \mathrm{s} \\ \bar{\mu} & \text { Average absolute viscosity, } \mathrm{Pa} \cdot \mathrm{s} \\ Q & \text { Volume flow rate, } \mathrm{m}^{3} / \mathrm{s} \\ r & \text { Radial distance between } a \text { and } b, \mathrm{~m} \\ r_{c} & \text { Capillary tube radii, } \mathrm{m} \\ \rho_{l} & \text { Liquid density, } \mathrm{kg} / \mathrm{m}^{3} \\ \tau & \text { Shear stress, } \mathrm{N} / \mathrm{m}^{2} \\ \mathrm{~W} & \text { Load, } \mathrm{N}\end{array}$




\section{Abbreviations}

$\begin{array}{ll}\text { amu } & \text { atomic mass units } \\ \text { ASTM } & \text { American Society of Testing and Materials } \\ \text { KOH } & \text { Potassium hydroxide (basic compound) } \\ \text { PAO } & \text { Polyalphaolephis } \\ \text { TAN } & \text { Total acid number } \\ \text { VII } & \text { Viscosity index improver } \\ \text { zddp } & \text { Zinc dialkyldithiophosphate }\end{array}$




\section{Chapter 1}

\section{Introduction}

In spite of significant advances in machine health monitoring over the last decades, industries still rely on experience to schedule maintenance on specialized equipment. Currently, servicing machinery is done in either of two different ways; it is repaired preventively or it is repaired correctively following a failure. An example of preventive maintenance is the oil change in a car which is prescribed every 5, 000 or 8, 000 kilometers, whereas a headlight is usually changed correctively after it no longer switches on.

In lubrication, the tendency is to service equipment in a preventive manner because the cost of a failure is high and in some extreme cases, necessitates replacement of the entire unit. Performing a maintenance operation preventively or correctively can be seen as the two extremes, as the latter implies maintenance that could have been avoided while the former implies maintenance done on a conservative basis. Although preventive maintenance is not as costly, it often overestimates or ignores entirely the actual parameters describing the oil's condition. Anticipating possible machine problems through preventive maintenance does allow the user to operate machinery safely without worrying about excessive repair costs, but it is still not optimal. If better knowledge of the processes affecting the lubricant's deterioration is available and predictive lubricant life models can be developed, the user may be able 
to perform an oil change a few days, a few months, perhaps even years later than anticipated. For large industry this translates into fewer shut-downs and increased revenues.

Today's highspeed machinery cannot operate without proper lubrication. The purpose of machinery comes down to the transformation of power into a form that is useful to accomplish a task. That power is transformed into mechanical power which means that machine elements come into contact, slide and rotate with respect to a fixed support and so on. The geometries, motions and forces involved give rise to friction; it causes the rubbing surfaces to wear and dissipates itself in the form of heat. The energy required to overcome friction is often large and the rubbing components deteriorate rapidly. The most effective way of minimizing the losses due to friction and to protect the surfaces against wear is to lubricate them with a base oil blended with special additives.

When two surfaces touch, the contact zone can take several different forms and experience different levels of stress. The nature of these contacts brings two important lubrication aspects into play. First, for some lubrication modes, such as hydrodynamic and elastohydrodynamic, the production of an oil film is essential [10]. The oil film insures that the two surfaces will never come into direct contact with one another. However in order for the oil film to form, there needs to be active lubrication (a constant lubricating oil flow to the bearing) of the components and at least one surface needs to be in motion. An oil film does not produce itself under static conditions and viscosity is essential to its formation. Another lubrication mode known as boundary lubrication operates independently from viscosity [11]. In this case the additives of the lubricating oil are responsible for the successful lubrication of the sliding surfaces, as the load is too heavy and the sliding speed is too slow for 
an oil film to generate itself. In this case the viscosity is still important but to a lesser extent as its main function is to bring a constant supply of additives to the contacting surfaces. These additives protect the surfaces by reacting with the latter to produce a soft, attached and shearable polymer layer.

Over the years a good deal of research has gone into the understanding of the lubricant degradation process. Some reaction pathways have been identified; specific phenomena have been understood and as a result additives have been developed to protect the lubricant against changes in its molecular structure which would degrade its thermal properties and its viscosity. Most of the research work that has gone into lubrication is focused on the thermo-chemical processes that take place.

Over the span of the last twenty years, interest in the lubricating oil's response to high stresses has grown but it is still incomplete [12]. In this spirit, this research attempts to shed light on the contribution of shearing forces to the degradation of the lubricating oils. How do the forces generated by the combined effects of shear and pressure in a contact zone contribute to the change in molecular structure of the oil?

The motivations behind this work stem in part from the shortfalls of current analytical tools. For example, the automotive sector has developed a smart sensing oil condition device however, it is limited to oils on which extensive testing by the car manufacturer has been performed [13]. Although it has proven itself useful, a thorough chemical analysis of the lubricant, requiring several different instrument readings, is still essential to developing a clear picture of the lubricant's current condition. Tests can be made to ascertain the oxidation levels, viscosity, presence of certain functional groups, contaminants, wear particles, and so on. These analytical 
tools have been developed for the laboratory environment, making off-site analysis almost inevitable. However, if there is a problem, the turnaround time with off-site analysis can slow the operator's access to the results and his ability to take corrective actions. There are ongoing efforts to develop portable or in-line monitoring versions of some of these tools, but they are few [14].

The on-line monitoring of an oil is essential because it is a system that is undergoing constant change throughout its service life. Taking an instrument reading on an oil in-service is akin to taking a picture at a very precise moment in time. Without the history of the lubricant, the picture can perhaps tell the operator what is happening now but it cannot account for its history or what the next reading will be at the following test interval. A change in viscosity strictly means that the chemical structure of the lubricant has changed without indicating to what it will evolve next or where it evolved from.

To start answering the questions outlined in this section, this work describes a modified diesel injection/combustion testing apparatus that has been adapted to shear lubricating oils of differing oxidation levels, using different injection pressures over a range of consecutive injection cycles. The sheared oil's viscosity is then verified against its unsheared equivalent. Preliminary results show that there is little or no effect from shear at low oxidation times but beyond an oxidation time of 48 hrs, a trend develops showing that indeed, mechanical shear does decrease the oil's viscosity.

In the following chapter, a discussion of the literature that brought about the proposed experiments is reviewed. In Chapter 3, the diesel injector apparatus is discussed along with the preparation of the lubricating oil samples, followed by the experimental test plan. Finally the preliminary results are presented and discussed 
in Chapter 4 followed by the future work to be undertaken in Chapter 5 and a brief conclusion in Chapter 6 . 


\section{Chapter 2}

\section{Literature Review}

Lubrication is an important research branch of the field of tribology, which concerns itself with the study of friction and wear. Researchers from the fields of physics, chemistry, surface chemistry, fluid mechanics, contact mechanics and materials science have all made contributions [11] to its advancement. With the ever increasing sizes and speeds of modern machinery along with the rising costs of crude oil, a macroscopic understanding of lubrication is no longer sufficient. Understanding lubrication at the microscopic and atomic scale is critical to maximizing the useful life of a lubricating oil.

One important question for mechanical engineers is whether the mechanical stresses imparted on the oil contribute to the degradation of the lubricant. Conducting this study requires an experimental apparatus capable of generating high rates of shear on the oil. Doing so requires a thorough understanding of lubricating oils to build the experiment, but also to detect the effect it will have.

In the ensuing literature review, lubricating oils will be discussed in general terms on their composition, with a closer look at the importance of viscosity on lubrication, how these oils degrade and how viscosity is affected, and finally, how mechanical 
action can change them. The focus then changes to additives, in particular a class of additives that is affected by mechanical forces. The mechanical degradation of these additives will be outlined which will lead into the means by which they are studied. Certainly, this latter part of the literature review is the keystone to the development of the shear degradation apparatus, but without the accompanying discussion of the base lubricants, too much background knowledge would be neglected.

\subsection{Lubricating Oils and their Composition}

The most effective way of minimizing energy losses due to friction and to protect the surfaces against wear is to lubricate them. Lubricating oils are complex mixtures of hydrocarbon molecules formed by two parts. One part is the base oil that is either derived through synthesis or refined from petroleum. The former is identified as a synthetic base oil while the latter as a mineral base oil. Typical lubricating oil basestocks refined from petroleum are made of molecules containing from 18 to 40 carbon atoms and are present in a mixture of paraffins (saturated hydrocarbons), aromatics (cyclic hydrocarbons) and naphthenes (cycloparaffins) [15] (see Figure 2.1). The molecules do not necessarily appear as one type but rather as a mixture of two or more of the aforementioned basic hydrocarbon structures. At the very core of lubrication, the most important property of the base oil is its viscosity. Basestocks tend to be stable but react quite readily in the presence of oxygen and temperature from $30^{\circ} \mathrm{C}$ on and up $[4,16]$. Oxidation leads to a thickening of the oil.

The mineral base oil is made from solvent refining or hydro-treating of crude petroleum extracted from the Athabasca tar sands, off-shore drilling platforms or other oil fields. The distillation and refinement methods employed to extract the 


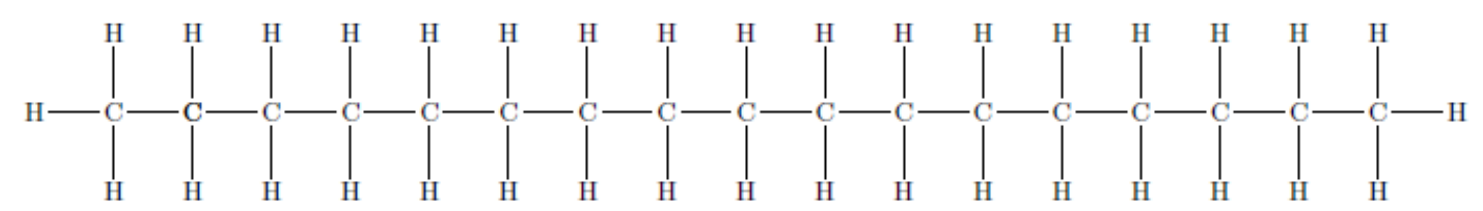

(a) Heptadecane

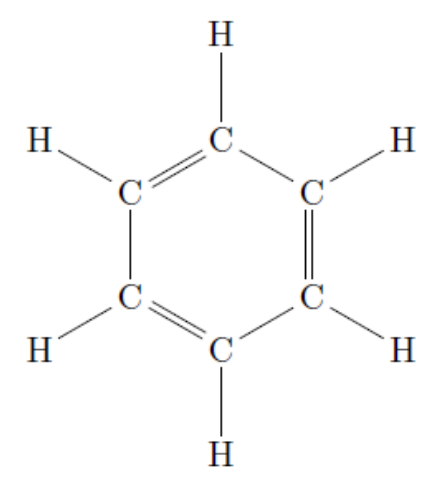

(b) Benzene ring<smiles>CC1(C)CCCCC1</smiles>

(c) Cyclohexane

Figure 2.1: Examples of a) paraffinic, b) aromatic and c) cycloparaffin molecular structures.

useful distillates from crude oil remove most of the harmful species but several remain in the final lubricating oil stock [17]. Synthetic base-stocks on the other hand result from the Fischer-Tropsch process developed by Germany between World War I and II. Produced from small, pure molecules in several steps where purification of the intermediate products routinely takes place, synthetic base oils are purer, in addition to having better properties than mineral base oils. For example, polyalphaolephins $(\mathrm{PAO})$, which are obtained by synthesis, are noted for having improved high temperature viscosity retention, shear stability, low volatility and good responsiveness to additives [17].

The second part of a lubricant is its specially formulated additives where their major 
role is to prevent an increase in the oil's viscosity. Lubricating oils are not limited to one or two additives. Often, they are blended with several different types. These blends largely depend on the operating environment and application such as a marine engine, turbine, bearings, gear boxes, piston/cylinder interfaces, cams, transmissions and other machine components.

Additives fortify and enhance desirable characteristics in the oil (like oxidation stability for example), but they can also impart properties that are otherwise non-existent. For example, an oil basestock is insufficient to lubricate the piston/cylinder wall interface where an oil film cannot form (It is what was referred to as a boundary lubricated contact earlier.) Boundary lubrication is the name associated with surfaces moving relative to one another, that are too heavily loaded for a lubricating oil film to develop and completely seperate the latter. In this case, the anti-wear, extreme-pressure additives provide the lubricating properties.

In our macroscopic understanding of mechanics, it is easy to forget that there is no such thing as a full contact between two surfaces. Instead, the contact is partial because no surface is perfectly flat; there is always some roughness to a surface. Figure 2.2 shows that the true contact occurs at the tips of the mating surface asperities. One can intuitively imagine that the actual contact area is much smaller than the one used in typical engineering calculations. In such contacts, the lubricating oil will easily fill the low lying areas of the surface, but it will not adhere to the asperity tips. Wear will inevitably occur as a result of adhesion and stick-slip motion at the asperities. Successfully lubricating these surfaces requires an interfacial film that is adsorbed on the surfaces. The solution was to develop what is categorized as an anti-wear additive. 


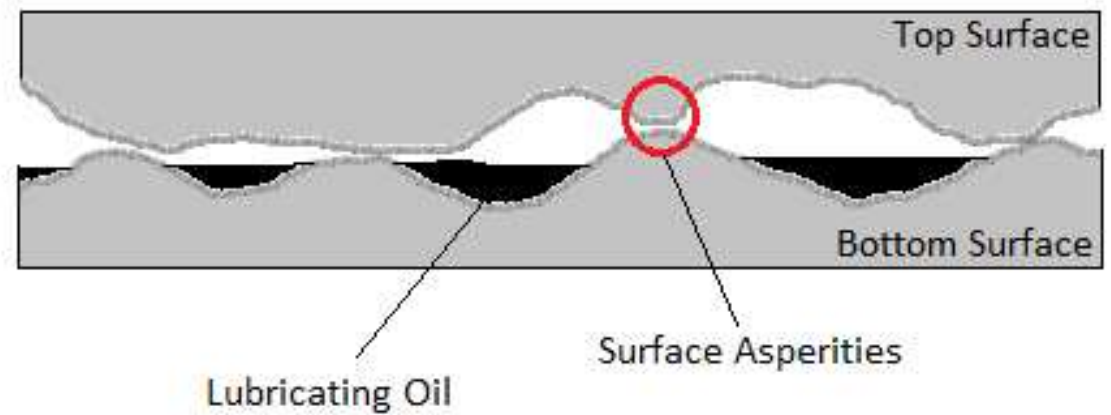

Figure 2.2: The Figure shows a top and bottom surface, each having roughness where asperities come into contact and the low lying areas are filled with lubricant. Without an anti-wear additive, the lubricant cannot protect the surfaces as the loads encountered in boundary lubrication are too high for an oil film to develop. (Adapted from [1])

One of the better performing anti-wear additives is zinc dialkyldithiophosphate (commonly known as zddp). The lubricating oil is acting as its carrier and it successfully introduces it to the piston/cylinder wall interface where under the exposure of extreme heat and pressure developed in an internal combustion engine, this additive undergoes a molecular change that enables it to produce a hard film [18]. The resulting film is softer than either of the piston or cylinder walls; it can thus be easily sheared away during each piston stroke, thereby preventing wear of the otherwise contacting surfaces.

Overall, additives are normally not present in sufficient quantities to influence the physical properties of the lubricant with the exception of viscosity index improvers (VII), which will be discussed further in Section 2.1.5. Key lubricating oil properties like viscosity, specific heat and specific gravity are derived mostly from the base oil. Finally, additives are present to conserve these properties for as long as possible by delaying, preventing and even promoting chemical reactions in the lubricant. 
Irrespective of how contacts are lubricated, viscosity is extremely important and will be a recurring topic in the following section.

\subsubsection{Lubrication Modes Encountered in Machinery}

For a lubricating oil, viscosity is its most important property. As stated previously, a lubricating oil's main function is to reduce friction and transport heat away from surfaces that are in sliding contact. Regardless of the lubrication mode, the base oil serves as an additive carrier and, for it to be successful in this role, it has to have the ability to flow in the narrowest of gaps within the machinery it must protect from wear.

Lubricating systems feed oil to a variety of machine components and they often include all lubrication modes, with the exception of extremely large machinery where an entire system may be dedicated to lubricating a single component. Lubrication is understood to occur under three distinct categories: hydrodynamic, elasto-hydrodynamic and boundary lubrication.

Hydrodynamic lubrication separates the rubbing surfaces with a film of oil. Figure 2.3 shows a journal bearing running in steady-state. The hash-marked area is the bearing sleeve and within it, a shaft (journal) is rotating with a load, $W$ acting down on it. The rotating motion of the shaft entrains the lubricant between the shaft and bearing, thus producing a pumping action, which lifts the shaft in an eccentric position, $e$, relative to the bearing's centerline, hence, producing an oil film [19]. In

this lubrication mode, the surfaces will never come into contact except perhaps as a result of sudden angular accelerations which may cause the film to fail [20] or during start-up when the lubrication is effectively of the boundary type. The film thickness 
(usually between $5-25 \mu \mathrm{m}[1]$ is dependant on the lubricant's viscosity to a larger extent, and to a lesser extent on the load and sliding speed. Journal bearings can be found in cars where the lubricating oil will encounter shear rates of up to $5 \times 10^{5} \mathrm{~s}^{-1}$ and loads of up to $34 \mathrm{MPa}$ [19].

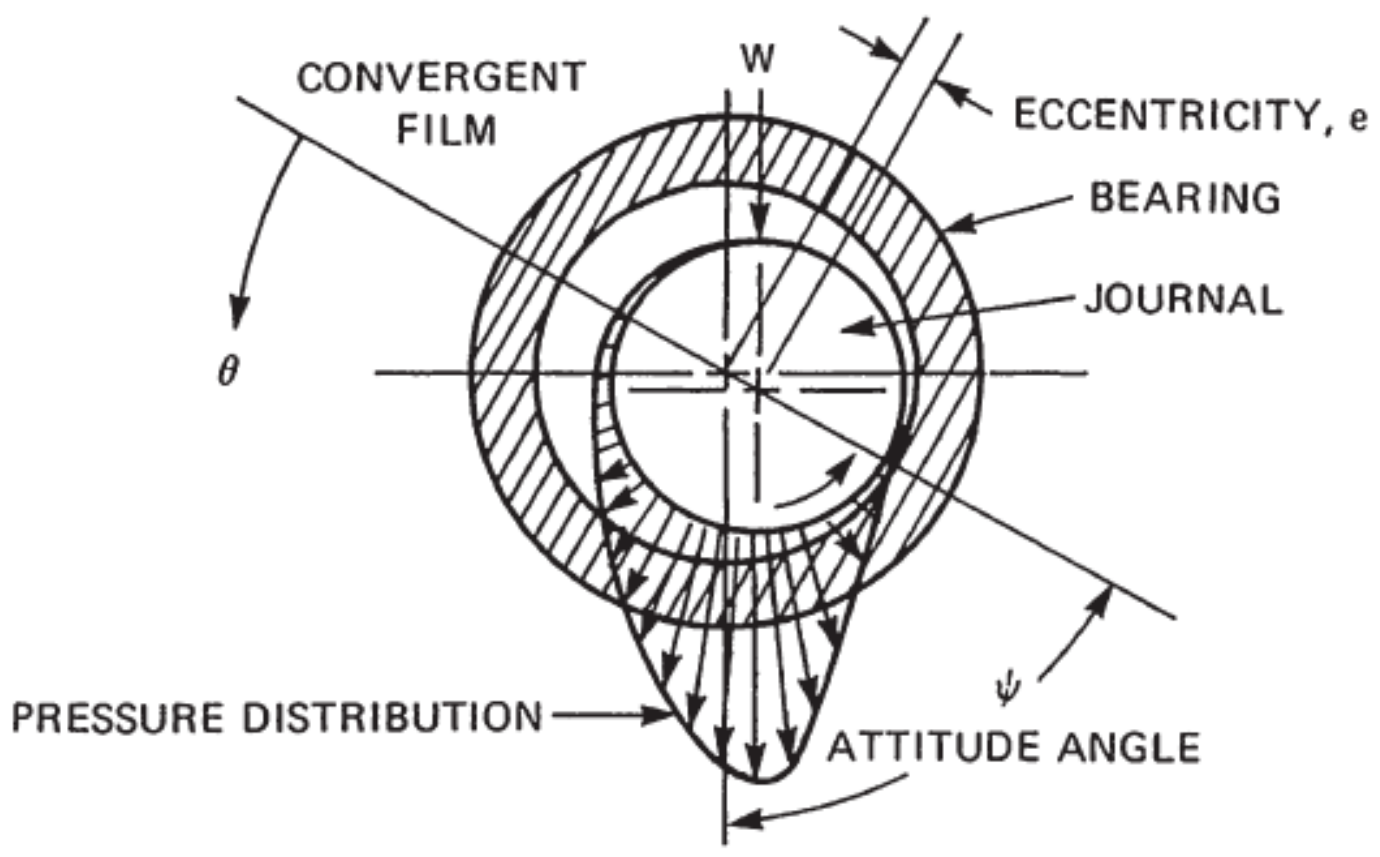

Figure 2.3: Schematic representation of a typical journal bearing under steady-state running conditions [2]. The line running through the bearing and journal centers(the perpendicular distance seperating the centers is called the eccentricity, e) separates the converging zone of the bearing with the diverging region. The converging zone starts at $\theta=0^{\circ}$ where the pressure begins to build-up. At $\theta=180^{\circ}$ the oil film is at its minimum thickness and is denoted by the attitue angle, $\psi$; the angle formed by the load line and, the journal and bearing centers. Note the pressure profile that develops due to the generation of the oil film [2].

Elasto-hydrodynamic lubrication is characterized by surfaces that move relative to one another in rolling or combined rolling and sliding contacts, where the surfaces are elastically deformed in the loaded zone as shown in Figure 2.4. These are more accurately known as Hertzian contacts which require knowledge of contact-mechanics 
for a proper evaluation [10]. The pressures within these lubricated contacts are in the $0.5-3 \mathrm{GPa}$ range of magnitude [19]. The stresses developed therein exceed the yield stress of the material just below the surface and inevitably, spalling wear [21] ensues. Like hydrodynamic lubrication, viscosity is primarily responsible for separating the surfaces, but load and sliding speed also play important roles. These films can be as small as $0.5-1.0 \mu \mathrm{m}[1]$ and encounter shear rates in the $10^{6}-10^{7} \mathrm{~s}^{-1}[22]$.

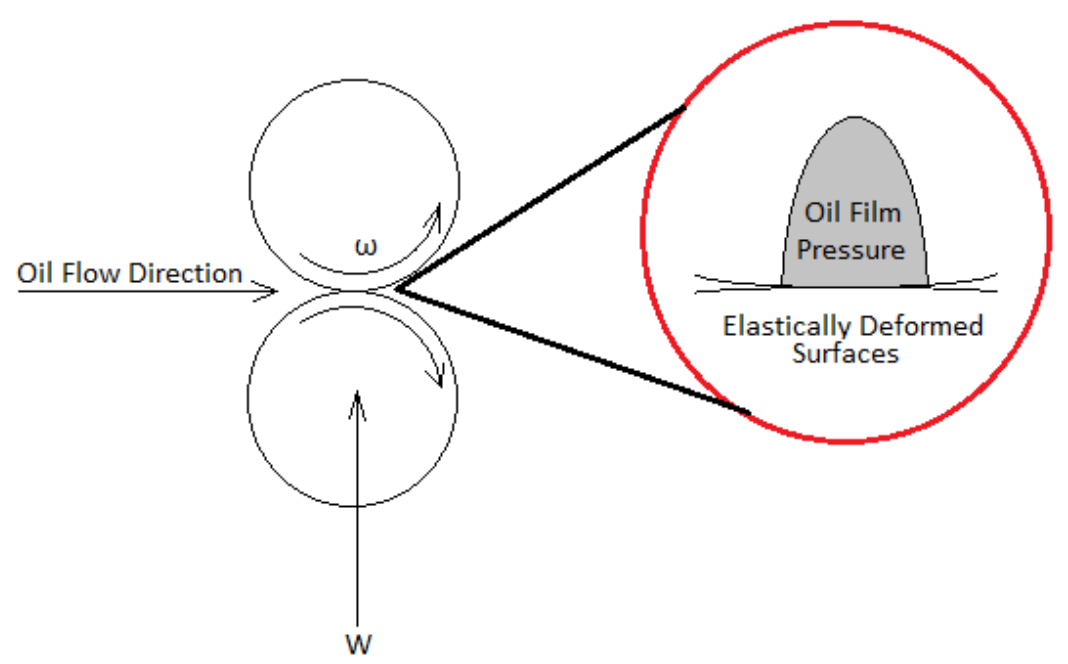

Figure 2.4: Depiction of the elastically deformed contact zone that develops between two loaded rollers.(Adapted from [3])

Boundary lubrication was discussed in Section 2.1 when the zddp, anti-wear addivite was introduced. However, the reader should take note that the viscosity of the lubricant is incapable of separating the surfaces completely; instead, the essential role of the lubricant in this case is to have sufficient viscosity so that the additives can reach the boundary lubricated interfaces. The lubricant needs to seep through the narrowest of gaps in this case where the distance separating the surfaces is of the $0.0001-1.0 \mu \mathrm{m}$ range [1]. 
All these forms of lubrication have their pros and cons, but what they have in common is that they will all inevitably wear; the heat they produce requires a high volume flow rate of lubricant and therefore a large volume of oil. Lubrication can only retard the wear processes but it cannot prevent it. Wear is most severe for boundary lubricated, elasto-hydrodynamic and hydrodynamic contacts. The implications from wearing surfaces are that frictional heat is produced, asperity to asperity contact will generate flash temperatures, nascent surfaces, the emission of electrons, all of which are favourable to chemical reactions with the lubricant as outlined by Hsu [11]. These effects cannot be classified as mechanical but they nevertheless affect viscosity, the most important property in lubrication.

\subsubsection{Lubricating Oil Viscosity}

To the mechanical designer, viscosity is the most important physical property of the lubricating oil. After carefully sizing and specifying the components that need lubrication, the lubricant is selected primarily based on viscosity. As stated previously, a lubricating oil's main function is to separate sliding surfaces with an oil film, reduce friction and transport heat away from these contacts. Regardless of the lubrication mode, the base oil serves as an additive carrier and, for it to be successful in this role, it has to have the ability to flow in the narrowest of gaps within the machinery it must protect from wear.

Fundamentally, viscosity is a macroscopic measurement that describes the resistance or internal friction between molecules moving relative to their neighbours $[4,16]$. In fact, molecular dynamics simulations have shown that the particular location and size of a functional group, branched on an alkane chain, has an impact on viscosity [23]. 
Viscosity, $\mu$, is a thermodynamic property formally defined as the resistance of a fluid to motion. It is a proportionality constant that relates shear stress, $\tau$, to the shearstrain rate (the rate of deformation of the fluid expressed as the velocity difference with respect to the vertical distance separating the fluid layers), $\dot{\gamma}$ as:

$$
\tau=\mu \dot{\gamma}
$$

This proportionality constant conveniently lumps all the molecular interactions within a fluid into a single number. The viscosity of a lubricating oil may vary due to three different factors: temperature, shear rate and pressure. Increasing the fluid's temperature will reduce its viscosity while decreasing the temperature will do the opposite. If the pressure in the oil is brought high enough a phase change to a solid can occur [19]. Although, in practice such pressure is not reached, an increase will cause a rise in viscosity just as lowering the temperature does. Viscosity variations due to pressure are important to journal bearings and more so to the lubrication of gears, cams and roller element bearings that operate in the elasto-hydrodynamic range. Lastly, oil viscosity can change due to shear rate which brings about the notion of a very important fluid category. A fluid whose viscosity is independent of shear rate at constant temperature is known as Newtonian. Usually, the departure from Newtonian behaviour or the start of shear-thinning occurs at high shear rates. Even fluids that are classified as Newtonian will start to exhibit non-Newtonian behaviour if the shear rate is high enough [24].

Synthetic and mineral oils like the one used in the forecoming experiments are known to be Newtonian but their character changes to non-Newtonian with the addition of VIIs (Section 2.1.5 will elaborate more on the VIIs). These long chain, high molecular weight hydrocarbon molecules are additives used in lubrication to lower the viscosity drop of a lubricant at higher temperatures. VII containing lubricants 
have been shown to exhibit shear-thinning [19] behavior in turbines where the oil sustained shear rates in excess of $10^{6} \mathrm{~s}^{-1}$. They have also been reported to show non-Newtonian behaviour [14] as they degrade over time.

VII augmented mineral oils exhibit non-Newtonian behavior at both high and low shear-strain rates. Constant temperature flow curves (viscosity - shear rate relationship) show shear-thinning when the shear rate reaches a critical value in the 5, 000 and $10,000 \mathrm{~s}^{-1}$ range. The viscosity then decreases linearly up to a value of shear rate in the range of $10^{4} \mathrm{~s}^{-1}-10^{6} \mathrm{~s}^{-1}$ after which a second Newtonian plateau is reached $[19,25]$. This implies that the viscosity needs to be measured over a wide range of shear rates, pressures and temperatures to fully characterize the lubricating oil's response to shear.

\subsubsection{Lubricating Oil Degradation: Its Impact on Viscosity}

The goal of this research was to build a device capable of imparting high shear rates to a lubricating oil to eventually study the effects that mechanical shear has on lubricating oil degradation. An oil's viscosity is tied to its molecular structure and shearing can have an effect on that structure. A change in viscosity should appear in measurements before and after shearing if shearing has imparted molecular change.

A fluid's viscosity will change as a result of a change in its molecular structure as has been demonstrated experimentally and through molecular dynamics simulations $[23,26]$. As was discussed in the previous section, varying the temperature, pressure, and shear will also cause changes in the lubricating oil's viscosity. These effects are often temporary and localized to the contact zones of sliding contacts, they cause changes in the motions, conformations and orientation at the molecular 
level, thus reflecting themselves as a change in viscosity [22]. Over time, viscosity also changes from the lubricating oil's regular exposure to heat and contaminants (i.e. oxygen, soot, metal particles).

A lubricant can be thought of as a dynamic system. Its behavior will change over its useful life as a result of its exposure to heat and oxygen which is essentially transforming the molecular makeup of the lubricant from its starting composition. The self accelerating thermo-oxidative degradation of lubricants has been identified as the most important form of deterioration that a lubricating oil can undergo and results in a significant increase in its viscosity as it ages. Many of the experimental methods developed to investigate lubricant degradation focuses on bulk oxidation tests since most lubricating oil systems are large and the molecules will spend most of their time in the sump [21]. The sump conditions are benign compared to the extreme conditions to which they are exposed to in a contact zone where the dwell time is extremely low, but the long exposure to molecules containing oxygen and other contaminants in the sump is a major source of oxidation.

In the context of this research, attention will be given to the one cause of degradation that is inevitable; the thermally induced, self-accelerating autoxidation degradation process as is well described in [4]. In the presence of heat and oxygen, the hydrocarbons will oxidize slowly at temperatures over $30^{\circ} \mathrm{C}$ and faster at temperatures over $120^{\circ} \mathrm{C}$. Note that metal catalysis will facilitate this process, but it will not be covered here.

The oxidation of the lubricant is driven by the formation of free radicals, which drive the polymerization process that will eventually increase the lubricating oil's viscosity. Below 120 degrees Celsius, the free radical mechanism can be summarized 
as follows: 1) initiation of the radical chain reaction, 2) propagation of the radical chain reaction, 3) chain branching and 4) termination of the radical chain reaction.

Above $120^{\circ} \mathrm{C}$, the process can then be categorized by a primary and secondary phase. The primary phase is identical to the one described earlier but is less selective ${ }^{1}$ due to hydroxy and primary alkoxy radicals which readily form above this temperature. Consequently, this reduced selectivity leads to the formation of carboxylic acids and in turn drives the condensation polymerization reactions, leading to higher molecular weight products.

Typically, these condensation polymers are bi-products of a lower molecular weight than those created by the addition polymerization resulting strictly from the free radical mechanism. However, at these elevated temperatures and with sufficient viscosity to cause the reaction to become diffusion controlled ${ }^{2}$, the condensation polymers now polymerize to make both soluble and insoluble products in the oil. These oil-soluble products contribute to further increase the lubricant's viscosity while the insolubles contribute to sludge which accumulates at the bottom of the sump. At the same time, varnish $^{3}$ forms on the hot metallic surfaces such as the contact zones within a bearing.

An indicator of the oxidation level of an oil is through the measurement of its acidity. This is done through a total acid number (or TAN) analysis. In fact, for an additive-free mineral oil a TAN of $2 \mathrm{mg} \mathrm{KOH} / \mathrm{g}_{\text {oil }}$ (the meaure indicates the

\footnotetext{
${ }^{1}$ Hydrogen abstraction may occur anywhere along the hydrocarbon chain whereas at low temperature, the hydrogen atom is stripped near or at the secondary carbon atom along the chain.

${ }^{2}$ In chemistry a diffusion controlled process is one where the chemical reactions are limited by the movements of the reactants due to their individual diffusivities [27], which are affected by the viscosity of the solvent, which in this case is the oil. For example, if reaction rates are lower for a solution at rest than the same agitated solution, the reaction is then diffusion controlled.

${ }^{3}$ Varnish is a hard film that deposits on hot metallic surfaces and will not dissolve just like a thermoset plastic.
} 
amount of base required to neutralise the acidity measured in the oil) is deemed a good indicator that the oil needs to be changed [21] or that it is close to the end of its useful life. This measurement however would not be useful in the context of a lubricating oil protected with a suitable additive package, where the acidity of the oil may be high but the polymerization process is well under control [4].

Experiments [28] aimed at understanding the high temperature oxidation stability of automotive mineral based lubricating oils, with and without additives, has shown that the base oils reached this TAN target of $2 \mathrm{mg} \mathrm{KOH} / \mathrm{g}_{\text {oil }}$ after 65 hours after having a $250 \mathrm{ml}$ sample of base oil subjected to a temperature of $180^{\circ} \mathrm{C}$ while having $1 \mathrm{~L} / \mathrm{min}$ of air pumped into it at the same time.

The literature is unclear as to the molecular weights achieved by the polymerized molecules which result from this degradation process, although some products are known to produce molecules weighing as much as 2,000 amu. The molecular weight of the oxidate is dependent on the conditions and the starting lubricant composition. For example, degradation of n-hexadecane has produced a hexadecane trimer [29] which is $750 \mathrm{amu}$. Mineral oil, which has a much higher carbon number, can produce much larger molecules.

\subsubsection{Mechanical Degradation of Base Oils}

In the previous section, the thermally induced, self-accelerating autoxidation process was discussed. It is clearly a thermo-chemical process. As shown before, mechanical forces can be very high in machinery when the lubrication modes were discussed. In the case of the boundary lubrication, anti-wear additives and friction modifiers (an anti-wear additive used in less severe contacts like journal bearings) produce soft, 
shearable films on the rubbing surfaces. Shearing of these films can be classified as a mechanical degradation, where covalent bonds are broken by shearing forces. This can happen to base oil molecules as well, but only under very specific conditions.

The mechanical breaking of bonds in small organic molecules like those found in mineral base oils is thought to only take place under severe friction, where they may get caught between the asperities of rapidly moving contacting surfaces [30]. Fundamentally, bonds ${ }^{4}$ are not rigid [5]; they can rotate, translate and vibrate and through these motions which are not mutually exclusive from one another a molecule dissipates energy. Base oil molecules can therefore rearrange themselves quickly when mechanical energy is applied, dissipate the energy, return to equilibrium and thus avoid bond scission.

Base oil molecules have only been successfully cleaved by shearing action and observed in a Bridgman Anvil, under $10 \mathrm{GPa}$ of pressure; however, the conditions therein far exceed the conditions ever experienced by a lubricating oil. At these pressures, the fluid may very well have undergone a phase change. The experimental difficulties with the detection of the mechanical breakup of small molecules arise from the means by which the phenomena can be observed, and how it can be differentiated from the thermo-oxidative degradation. We have seen in the previous section that the conditions inside the contact zone, though extreme, are short-lived for any molecule going through compared to the time they spend under bulk conditions in the sump. Furthermore, the oxidation process has the effect of reducing the size of the base oil molecules in the intial steps, an effect that is intuitively expected of the mechanical degradation if it were to occur. Inadvertently, all forms of mechanical

\footnotetext{
${ }^{4}$ Only the atoms move however, rotation, translation and vibration are easier to visualize if the bond is thought as the moving component when considering a stick and ball diagram as a molecule's descriptor.
} 
contacts generate heat and short molecules have a lower boiling point than long ones. As such, it is highly likely that thermal effects could mask mechanical bond breaking.

Molecules that do break-up with the application of mechanical forces are long chain polymers of high molecular weight molecules, and these can be found in oil (e.g. friction polymers [11] and VIIs). As such, the investigation of shear effects on VIIs is an important area of study. Indeed, this is the long-term goal of the research program within which this thesis is an important first step.

\subsubsection{Mechanical Degradation of VIIs}

Lubricating oil viscosity drops with rising temperatures. So much so that in certain applications the oil may not be able to provide the required protective film for the rubbing surfaces. The relationship between the temperature and the viscosity of an oil is inherent to its molecular structure, which is the result of the refinement process and the oil field it came from. The preferred method of improving this characteristic is to combine VII molecules to the base oil.

VIIs are long chain, high molecular weight polymers that range in weight from 10, $000-100,000 \mathrm{amu}$ [19] and are of course oil-soluble. Indeed $100000 \mathrm{amu}$ appears to be the limit of solubility for high molecular weight polymers in lubricating oils [15]. In terms of behaviour, VIIs tend to be entangled when the fluid is at rest. They are long molecular chains which fold upon themselves in their minimum energy state. Because these molecules are so large, they tend to interact with the surrounding solvent molecules and thereby alter the flow of the molecules which represent the bulk of the fluid. When the lubricant starts to flow, whether it be due to the rotation 
of a cylinder or pumping pressure, the VII molecules start to unfold and align in the flow direction, thereby interacting to a greater extent with the lubricating oil molecules. Similarly, when the temperature increases the polymer chain untangles itself and moves more freely within the oil, causing the individual VIIs to interact more with the base oil molecules. This greater interaction between the VII and the base oil molecules leads to an increase in viscosity.

Unlike the base oil molecules, VIIs form a large and rather complex three dimensional structure akin to a ball of sticky spaghetti noodles. When a shear stress is applied, the molecule cannot find structural equilibrium. Recall that molecules dissipate energy through bond rotation, elongation and bending. If the shear stress is strong enough, VII molecules will not be able to rearrange themselves to dissipate this energy, thus causing a bond to break. Figure 2.5 shows how a polymer molecule responds to an external stress. At the top of the Figure, the molecule is shown tangled and in a bulkier form in its relaxed state. When a shear stress is applied, the molecule remains tangled, but it is stretched out in the direction of the applied stress. When bond breaking occurs, the molecule is halved [31].

Some of the polymer molecules that have been investigated [31-34] are poly methyl methacrylate, polystyrenes, lauryl stearyl hydroxymethacrylate, polyacrylamide, dextran and other commercially available polymers ranging in weights from 80,000 to 5,830,000 amu. There is consensus however that polymer molecules breakdown at the mid-point of the chain on the $\mathrm{C}$-C backbone and that the probability that a polymer chain will break decreases as the molecular weight of the molecule decreases. Interestingly, no one has really put effort in identifying what the limiting molecular weight of mechanical degradation really is. There is some research that has shown polystyrene molecules having a molecular weight of 3,420 to have broken down to a 


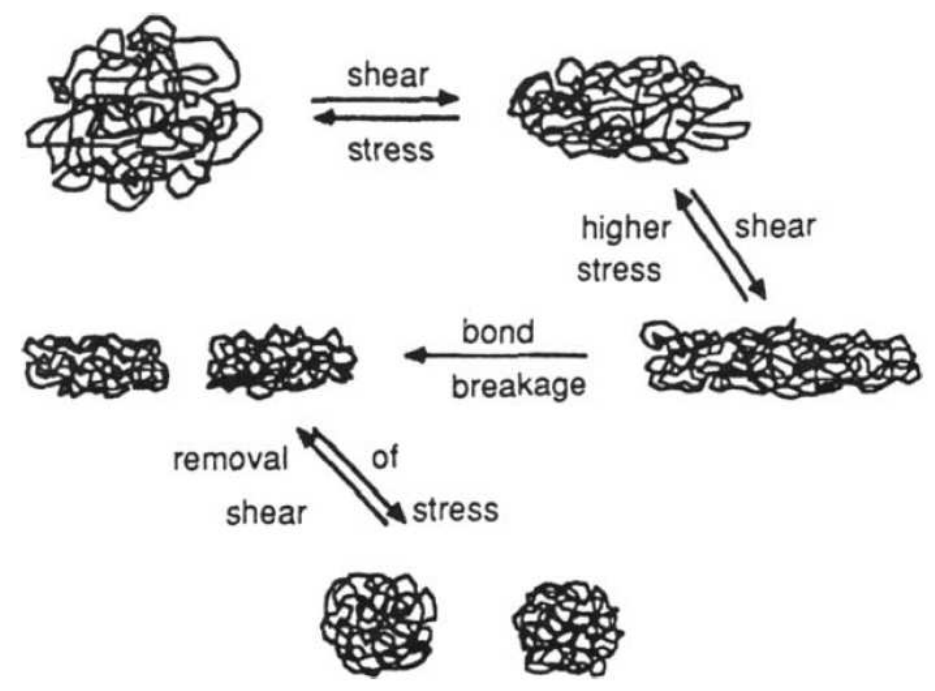

Figure 2.5: Schematic representation of the events leading-up to the breaking of a VII molecule. The Figure shows the VII molecule at rest in the top-left corner of the Figure, undergoes elongation under stress, more so as the stress increases, which leads to bond breaking resulting in two smaller VII molecules. Note the two arrows showing that if the molecule does not break, it may return to its previous structure (i.e. shearing does not always have a permanent effect on the molecules structure) [4].

molecular weight of 1,004 after a sustained 35 minutes of sonication [5]. Whether this is indicative of some limit or not is another matter entirely.

Lubricating oils containing VIIs can be described as dilute solutions, where the VII concentration is such that they do not interact with one another; their nearest neighbours are rather base oil molecules. Some of the earlier research on the degradation of polymer molecules by shearing forces [31] in a concentric cylinder apparatus has shown that polymer breakdown had higher rate constants in dilute solutions with poor solvents than in good solvents. This is explained by the increased attraction between the polymer molecules in bad solvents and less interaction in good solvents. The research also revealed that the rate constant increases at lower temperatures. The same experiment could not, however, degrade a pure polymer sample. 
VII improved lubricating oils are suceptible to shear-thinning, a type of nonNewtonian behaviour, whereby viscosity decreases with increased shear rate. This can be of a temporary nature or of a permanent nature. Temporary viscosity loss is a result of the VII chain unfolding under shear and aligning with the flow. This effect is illustrated at the top of Figure 2.5, before the molecule is shown to break. In the case of permanent viscosity loss, the polymer molecule is effectively halved as discussed previously, and can be easily detected by measuring the viscosity after stressing the lubricant. Further evidence of this can be found by analyzing the resulting molecular weight distribution of the lubricant after stressing and comparing it to the pre-stress distribution.

\subsection{Experimental Methods in the Mechanical Degradation of Polymers}

Transforming a material into a more useful form can be achieved through chemical reactions. For example, branching, bonding with different atoms, the appearance of double and triple bonds, and the location of these bonds along the carbon backbone all contribute to the change in physico-chemical behaviour of a given molecule or material.

Chemical reactions can be driven in several ways; the familiar thermo-oxidative degradation reaction discussed in the previous section is a well known example. Some of these reactions are specific to lubricating oils and fall under the tribochemistry 
umbrella. Heavy loads and high sliding velocities in contact zones combine to generate high frictional heat. In addtion, it has been observed that sheared contacting surfaces emit electrons and produce nascent surfaces, while contacting surface asperities produce flash temperatures and charged particles. However these phenomena do not constitute what is formally defined as a mechanically-driven chemical reaction.

Mechanochemistry defines mechanically-driven chemical reactions as the breaking of intramolecular bonds by direct mechanical action followed by additional chemical reactions [30]. An example of a mechanochemical reaction is when flint stones are struck together to produce sparks. Sparks result from the reaction between the surface plasma and air. When oil molecules react with a freshly abraded metal surface, it is not the result of a mechanically induced chemical reaction but rather the aftermath. The mechano-chemical reaction is in fact the broken bonds of the metal surface which are now free to react with the surrounding products.

When the research for this thesis first began, a journal bearing had been considered as a possible means of stressing the oil. Its pros were that it was an actual mechanical contact used in lubrication, however, it had several cons. A journal bearing requires a heavy load to generate a shear rate on the order of $10^{6} \mathrm{~s}^{-1}$. This implies a thin fluid film, the generation of high frictional heat due to high rotating speeds, and a further increase in the likelihood that the chemical reactions that were just discussed in the previous paragraph will take place. When the research project reaches a certain maturity, chemical analysis will become necessary and therefore, limiting the number of undesirable chemical species in the lubricating oil is also an experimental objective.

For reasons based on experimental necessity, a method which would reduce or eliminate the presence of tribochemical reactions involving the surfaces is sought. 
This indeed rules out the use of boundary lubricated surfaces, elastohydrodynamic contacts as well because they are even more severe than the journal bearing that was considered.

In the previous section we saw that VII molecules preferentially break within range of the chains' mid-point. The brocken bond is a carbon-carbon single bond, it is the strongest carbon-carbon bond in a hydrocarbon molecule, and although it has not been observed to break in short base oil molecules, presumably, the polymers produced through lubricating oil oxidation are large enough to suffer such breakage. This observation leads us to consider shear experiments on other polymer systems as a guide to our experimental design.

A variety of experiments exploring the mechanical scission of high molecular weight polymers have been devised in the past. Such experiments include the use of turbulent flow fields, elongational fields, atomic force microscopy, single force microscopy, ultrasonic irradiation [5] and diesel injector nozzles [32-34]. However, these experiments are not without controversy. The use of ultrasonic irradiation is seen as controversial due to extreme heat produced by the collapse of cavitation bubbles. Research conducted on the internal flow of diesel injectors has provided conclusive evidence that the internal flow of an injector also cavitates. Further research on diesel injectors has demonstrated that by controlling the pressure of the receiving fluid atmosphere, the cavitation can in fact, be suppressed [35].

Nevertheless, there are strong arguments to support the idea that cavitation is in fact mechanically breaking the polymer molecules in ultrasonic irradiation fields or diesel injectors [5]. Chief among these arguments is the non-random nature of the bond breaking which is always located in the mid-sector of the polymer chain. 
Cavitation does not only produce high temperatures but also a strong localised acceleration field. Cavitation bubbles are created when the pressure inside a liquid drops below its vapor pressure. In the case of lubricating oils, the base oil molecules undergo this phase change, presumably because their vapor pressure is higher than that of the polymers, thus forming the cavitation bubbles. As the cavity collapses, polymer chains that are close by will undergo a strong acceleration at the end that is closest to the cavity. Figure 2.6 demonstrates the concept well. At the top of the Figure, a cavitation bubble in maximum expansion is shown on the left. Because the collapse is extremely quick, the acceleration gradient is large and the tangled polymer molecule on the right is pulled in by the end closest to the collapsing cavity. The polymer molecule cannot untangle itself quickly enough to cope with the force acting upon it in the collapsing bubble's vicinity. In the second frame, the polymer is shown to have a longer untangled portion of its chain getting closer to the collapsing cavity and finally at the bottom of the Figure, when the cavity is almost collapsed, the polymer chain is broken.

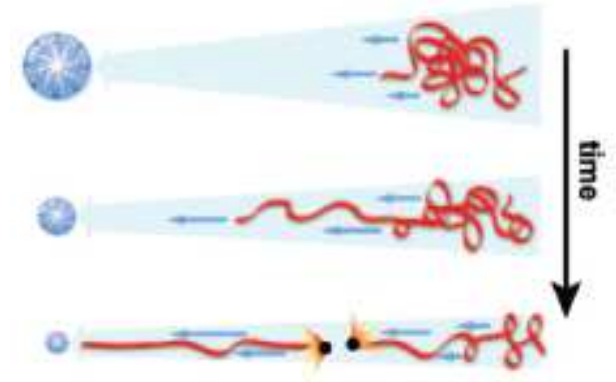

Figure 2.6: Theoretical representation of a polymer molecule breaking in the vicinity of a collapsing cavitation bubble. The topmost sketch represents the start of the collapsing event at time zero. As time marches forward (shown going down on the Figure), the bubble completely collapses and causes the polymer molecule to break [5].

The diesel fuel injector came to be an accepted method of determining the shear stability of polymers by the American Society of Testing and Materials (ASTM). 
The method's designation is ASTM D6278-12 $2^{\epsilon 1}$, Standard Test Method for Shear Stability of Polymer Containing Fluids Using a European Diesel Injector Apparatus, in which a Bosch DN 8 S 2 - type pintle nozzle injector is used. As such, we have decided to develop a similar test apparatus for our experiments.

\subsection{Diesel Injector Shear Rate Estimation}

The use of diesel injector nozzles in the study of the shear stability of polymers surfaced in the late forties and early fifties [33]. At that time VIIs were already in use and their effectiveness over a prolonged period of time came in doubt. The exposure of VII molecules to high shearing stresses or high shear rates was immediately suspected of being the culprit. Diesel injectors are useful tools to impose high shear strain rates on lubricating oils containing VII. In order to accomplish this, standard, commercially available fuel injection equipment was put together by Wood [33]. The system simply consisted of an electric motor to drive a fuel injection pump, a reservoir, a diesel injector, deaerator and filter. Eventually it was developed into the ASTM standard cited in Section 2.2.

The variable of interest in such experiments is the shear rate produced by the nozzle. Schnurmann and Johnson [36] were among the first to study the effects of shear on the shear stability of VII augmented lubricants with capillary-type nozzles. The use of nozzles was selected as the generation of high shear rates could be achieved with minimal viscous heating of the fluid so long as certain conditions were met. In doing so, they analyzed several geometric configurations of converging/diverging nozzles. Their goal was to develop nozzles that would allow them to calculate the shear rate by making sure that the flow did not deviate from Poiseuille behaviour. This meant 
that they could calculate the shear rate using the analytical solution to the problem.

Using Poiseuille flow means that the constant diameter section of the capillary nozzle must be sufficiently long enough to allow for $95 \%$ parabolic velocity profile to be achieved. Achieving the $95 \%$ parabolic velocity profile condition was possible if the criterion, $L / D=0.032(R e)_{\max }$, that Schnurmann and Johnson derived from hydrodynamic theory was met. They found that having a length to diameter ratio of 2.5 or less and a Reynolds number of 10 ensured a negligible temperature rise and fully developed Poiseuille flow.

When the diesel injector apparatus was first suggested as a way to stress high molecular weight polymers blended in oil, Wood suggested that shear strain-rates on the order of $10^{7} \mathrm{~s}^{-1}$ would be produced [33]. Unfortunately, there was no theory to support this claim and no evidence that the temperature rise of the lubricant passing through the nozzle was of any importance. In spite of this, permanent viscosity loss was observed.

In an identical setup to Wood's, Mackenzie and Jemmett [32] calculated shear strain rates based on simple Poiseuille flow, for which $\dot{\gamma}$ takes the form

$$
\dot{\gamma}=\frac{4 Q}{\pi r_{c}^{3}}
$$

where $Q$ is the volume flow rate and $r_{c}$ is the radius of the capillary tube. This formula was also used elsewhere [34] but, in that case the apparatus respected the criteria established for flow through a capillary-type orifice with negligible kinetic energy conversion into heat. However, while this formula may be able to accurately evaluate the shear rate that was reached in the capillary, it may not be correct for a fuel injector operating at 13.8 MPa as were the ones used by Wood, and Mackenzie 
and Jemmett in spite of using a simple nozzle geometry. The flows investigated by Schnurmann did not exceed $100 \mathrm{KPa}$.

It was also unclear how the volume flow rate necessary to use in equation 2.2 was arrived at knowing that injector nozzle flow is unsteady [8] and that it cavitates [35]. A simple incompressible flow calculation is incorrect and making a proper measurement of the volume flow rate is difficult [6]. Normally, injector flow rates are characterised by a discharge coefficient, $C_{d}$. If incompressible flow is encountered, highly turbulent zones can develop and limit the volume flow rate that can be calculated analytically. Similary, cavitation causes mass flux choking making an analytical calculation for both the mass and volume flow rate incorrect. In other words, an estimate of the flow conditions using the Bernoulli equation will not suffice. The discharge coefficient corrects for this but in order to establish what $C_{d}$ is, a measurement of the volume flow rate or mass flow rate through the nozzle is necessary. No evidence of such steps were taken in the cases discussed in the previous paragraph.

The mass flow rate from a diesel injector nozzle always deviates down from that which is predicted by single-phase flow assumptions due to cavitation. Cavitation is the result of localised fluid vaporization within a liquid flow where the pressure drops below the fluid's vapor pressure. The cause is often a result of sudden accelerations around sharp corners. Although the flow is rarely cavitated entirely, the small vapor zones surrounding the fluid core do cause mass flux choking of the nozzle and the theoretical mass flow rate cannot be delivered as a result [37]. Figure 2.7 illustrates a cavitated flow. Two-phase flows cannot be solved analytically rendering the accurate prediction of a shear rate impossible.

Most injector related research appears directed to the combustion scientist, where 


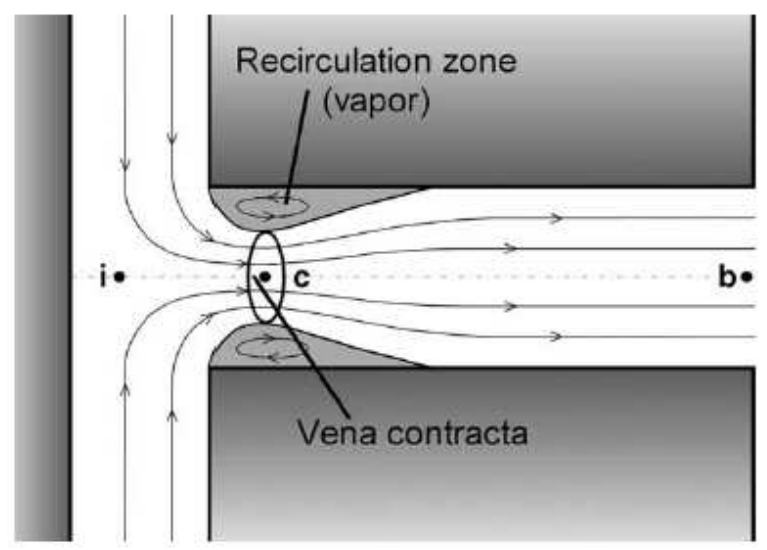

Figure 2.7: Partial mass flux choking of an injection nozzle caused by cavitation [6].

there is a marked interest in modeling the internal fluid dynamics. For combustion cavitation improves spray break-up and modifies the nozzle exit velocity. CFD modeling of such flows is complicated as it requires a very fine and well-defined mesh of the fluid domain. Single-phase flow simulations at fixed nozzle openings can identify possible cavitation sites [38]. Unfortunately, the flow model needs to be selected carefully [37] as common turbulence models such as $k$ - $\epsilon$ tend to overpredict flow rates and cause the pressure to drop well below atmosphere. Shear rates on the other hand are possibly not important to combustion scientists as they were never referenced in the consulted combustion literature.

It seems that without investing significant time in modelling the flow, estimating the shear rate based on an assumption of incompressible flow is the best solution in the short-term. The assumption of incompressible flow will likely lead to an over-estimation of the shear rate that will develop inside the nozzle. Cavitation, as shown in Figure 2.7, depending on its extent along the nozzle's walls will produce slip at the gas/liquid interface, thus reducing the shear rate. 


\section{Chapter 3}

\section{Test Plan \& Experimental Apparatus}

The goal of this research is to produce an experimental apparatus capable of imposing high shear rates on lubricating oil molecules. The literature review has shown how reactive a lubricating oil can be in the combined presence of heat and oxygen. A lubricating oil is used to reduce friction inside machine elements. At first glance, a roller element bearing, a boundary lubricated surface or even a journal bearing seemed like ideal candidates for the task as it is always more relevant to study a lubricant directly in its operating environment.

All of the lubrication modes discussed in Section 2.1.1 are excellent candidates (the journal bearing had been considered intially) with regard to the production of high shear rates. However, these different contacts generate a lot of frictional heat, thus requiring large lubricating oil flow rates to maintain the temperature inside the contacts to an appropriate level. Incidently, a disproportionate volume of oil relative to what is actually consumed (i.e. passes through the contact zone) is required. A high lubricating oil volume will lead to longer test times and mask the effects that shearing may have. High operating temperatures also mean that the rubbing surfaces are more chemically active and may have a catalytic effect on the oxidation reactions. This could complicate the future use and analysis of the experimental 
apparatus in the longterm.

After a close inspection of the literature on the mechanical degradation of VIIs, the diesel injector was selected as the apparatus of choice to shear the lubricating oils. It offered several advantages that other concepts did not. For one, the diesel injector can operate with a very small volume of oil. This also means that the entire fluid is exposed to shear stress because there is only one direction for it to go. Minimizing lubricating oil oxidation is easily achieved if the oil is injected into a chamber filled with the same fluid. Finally, there is very little sliding motion between the pintle and the nozzle opening, which means that the sliding surfaces implication in the reaction products should be minimal. The diesel injector should allow us to shear the oil in such a way that the mechanical degradation will dominate any other effect that will occur in parallel.

The literature has shown that mechanical degradation of base oil molecules due to shear is unlikely, but that as the oil ages, molecules of sufficient molecular weight to mechanically break may arise from oxidation. However, oxidizing a lubricating oil takes time, even if it is artificially accelerated, but more so if the oil was to simply run through a machine. To save time, instead of running the oil through the diesel injector until it is fully degraded, an artificial method of oxidizing the oil was used. Oils at different levels of oxidation were then cycled through the injector. Following these simple shear tests, viscosity measurements of the oils prior to shear and after were conducted to assess if there was any evidence of mechanical degradation.

The next sections will take the reader through the artificial oil oxidation method employed to prepare the samples for the diesel injector. Next, the diesel injector apparatus is fully detailed, followed by the verification performed on the rheometer 
used to measure the samples' viscosities, and finally, an estimate of the expected shear rate is provided.

\subsection{Accelerated Lubricating Oil Oxidation Method}

Lubricating oil oxidation in machinery is lengthy. It was not practical to fully degrade the lubricant by using the diesel injector until the oil was no longer usable. The goal of the research is to shear lubricating oils so that its effect on the lubricating oil degradation process can be investigated; this can be done provided that samples of differing oxidation levels are available. To do this, the lubricating oil is degraded artificially in a bench top reactor in order to save time. There are a variety of methods available to choose from [21].

Preparation of the lubricating oil samples necessary for use in the diesel injector was conducted by adapting a method based on the turbine oil oxidation test (TOOT) and the Ford modified oxidation test [28]. The selection was based on the test time and the availability of some experimental results [28] which could later serve as a guideline for sample quality control with some caution however as the oils used are different from the ones in the literature.

Figure 3.1 shows the bench-top oxidation apparatus in its final form, and lists the main components that will be discussed shortly. There is more to the air line (listed as item number 3 on the figure) than what could be shown. The entire experiment is setup in a fumehood to curtail harmful emissions from the oxidation process. 
The air line comes through the sidewall of the fumehood and is connected to the building's main compressed air supply line where it draws air through a Norgren, B73G-3AK-QD1-RMG pressure regulator, equipped with a water/particle filter, and an Omega FL-2012-SS, acrylic air-flow meter that is accurate to within $\pm 0.12 \mathrm{~L} / \mathrm{min}$. This ensures that the oil sample is supplied with a $1 \mathrm{~L} / \mathrm{min}$ flow rate of air at all times.

A 3 necked boiling flask was used as the reaction vessel and was set into a heating mantle. The neck on the centerline of the flask accomodates the dreschel head, a device that allows air flow delivery below the oil line to improve mixing and air diffusion, while at the same time allowing the excess air and oil vapors to escape the flask. On one of the side necks, a partial immersion glass bulb thermometer is installed to monitor the test temperature of the sample. Finally the other neck is capped with a glass plug and is used as a sampling port.

After a few attempts at producing samples with a heating mantle it became evident that maintaining an even temperature throughout the procedure was difficult to achieve manually. This is not surprising, knowing that the lubricant is changing on a molecular level while oxidizing, it is transforming into a different material from the original configuration. The viscosity, density, specific heat and other physical properties reflect that ongoing change and they likely affect its ability to transfer heat. Therefore, a more accurate control of the temperature was necessary due to the duration of the test (between 0 and 72 hours) especially when it was left unattended during the nighttime.

The heating mantle was discarded for a 2, $300 \mathrm{ml}$ capacity CG-1100-03, stainless steel oil bath with a 1200 Watt heating jacket capable of heating round bottom boiling flasks of up to $3,000 \mathrm{ml}$ in capacity. To improve heat transfer, the oil bath was set 
on a CG-1995-V-10 hot plate with magnetic stirrer. Only the magnetic stirrer was used as a means of circulating the bath oil.

Controlling the bath temperature was then performed with a 1/32 DIN Temperature Controller (CG-15001) to which a calibrated type J thermocouple is connected. Due to the catalytic effect of metals on lubricating oil degradation, the thermocouple was inserted into the oil bath rather than into the sample oil. In this fashion, the temperature control is still indirect because only the oil bath temperature is monitored by the controller and this is why the set-up still incorporates a partial immersion, liquid in glass thermometer (CG-3503-12) having an accuracy $\pm 2{ }^{\circ} \mathrm{C}$ to monitor the lubricating oil sample's temperature. To further stabilize the temperature of the sample, aluminum foil was wrapped around the boiling flask, covering the oil bath, but with enough care to avoid contact with the thermocouple.

Care was taken to center the boiling flask with respect to the oil bath as best as possible. The thermocouple linking the temperature of the oil bath to the controller was placed near, but not in contact with the edge of the boiling flask in order to get the most accurate reading possible while avoiding the largest temperature gradients generated by the heating jacket turning on and off. The thermocouple was inserted two thirds of the way down into the bath oil for best results. The heating jacket was attached to the outer periphery of the bath container. It was found that setting the temperature controller to $188^{\circ} \mathrm{C}$ gave a reading of $180^{\circ} \mathrm{C} \pm 2^{\circ} \mathrm{C}$ within the lubricating oil sample. The discrepancy between the control temperature and the actual lubricating oil sample's temperature was likely due to the heat transfer characteristics across the glass of the boiling flask, an insufficient amount of bath oil, the airflow rate and thus the flowing characteristics of the sample therein. 


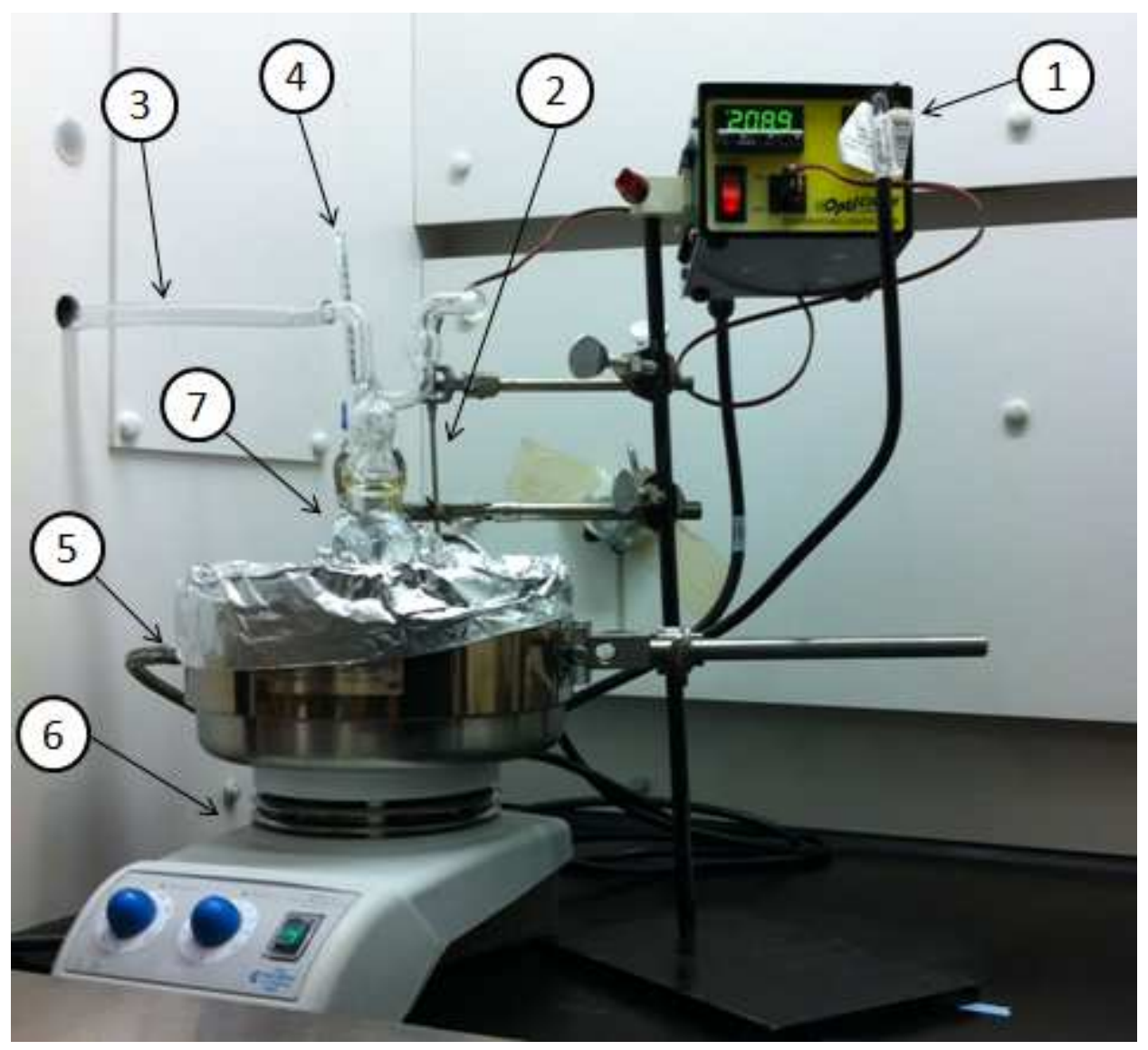

Figure 3.1: Bench-top oxidation testing apparatus. 1) Temperature Controller; 2) Thermocouple; 3) Air-Line; 4) Partial Immersion Thermometer; 5) Heating Jacket; 6) Hot Plate/Magnetic Stirrer; 7) Boiling Flask.

The test samples were produced from additive-free, light-viscosity mineral oil purchased from McMaster-Carr in lots of 1,000 ml, by degrading individual quantities of $250 \mathrm{ml}$, over a period of $8,12,16,24,32,40,48,56,60,64$ and 72 hours. Note that due to evaporation, only four quantities of $250 \mathrm{ml}$ were required to produce the 8 hour sample while a total of eight, $250 \mathrm{ml}$ samples had to be degraded to produce the 72 hours sample. A fraction of these samples was then used to cycle through the diesel injector. 


\subsection{Diesel Injector Apparatus Description}

A basic diesel injection system consists of an injection pump, a fuel pump, some high pressure fluid lines and a nozzle. For this experimental apparatus, the injection system used was taken from a diesel fuel Ignition Quality Tester, also known as an $\left(\mathrm{IQT}^{T M}\right)$, that had been previously used in combustion research. A custom designed and built atomization chamber is fitted to the nozzle outlet to collect the sample and reduce the occurence of oxidation.

In the following sections, a thorough description of the injection system, injection nozzle, atomization chamber, injection actuation program, installation, experimental program and estimated injector nozzle shear rates is made.

\subsubsection{Injection System}

Contrary to a typical fuel injection system, the IQT injection system shown in Figure 3.2 uses a pneumatically driven injection pump, designed to deliver a metered volume of fluid for injection. Fluid delivery through the injector depends on the air-pressure driving the system and it is also possible to change the mass of fluid injected by modifying the shim stack on the actuator [39] which controls the stroke length of the plunger. These shim stacks are mounted on all four spacers as shown in Figure 3.2. The injection pump was not modified from its as-received configuration for the experiments described in this thesis. 


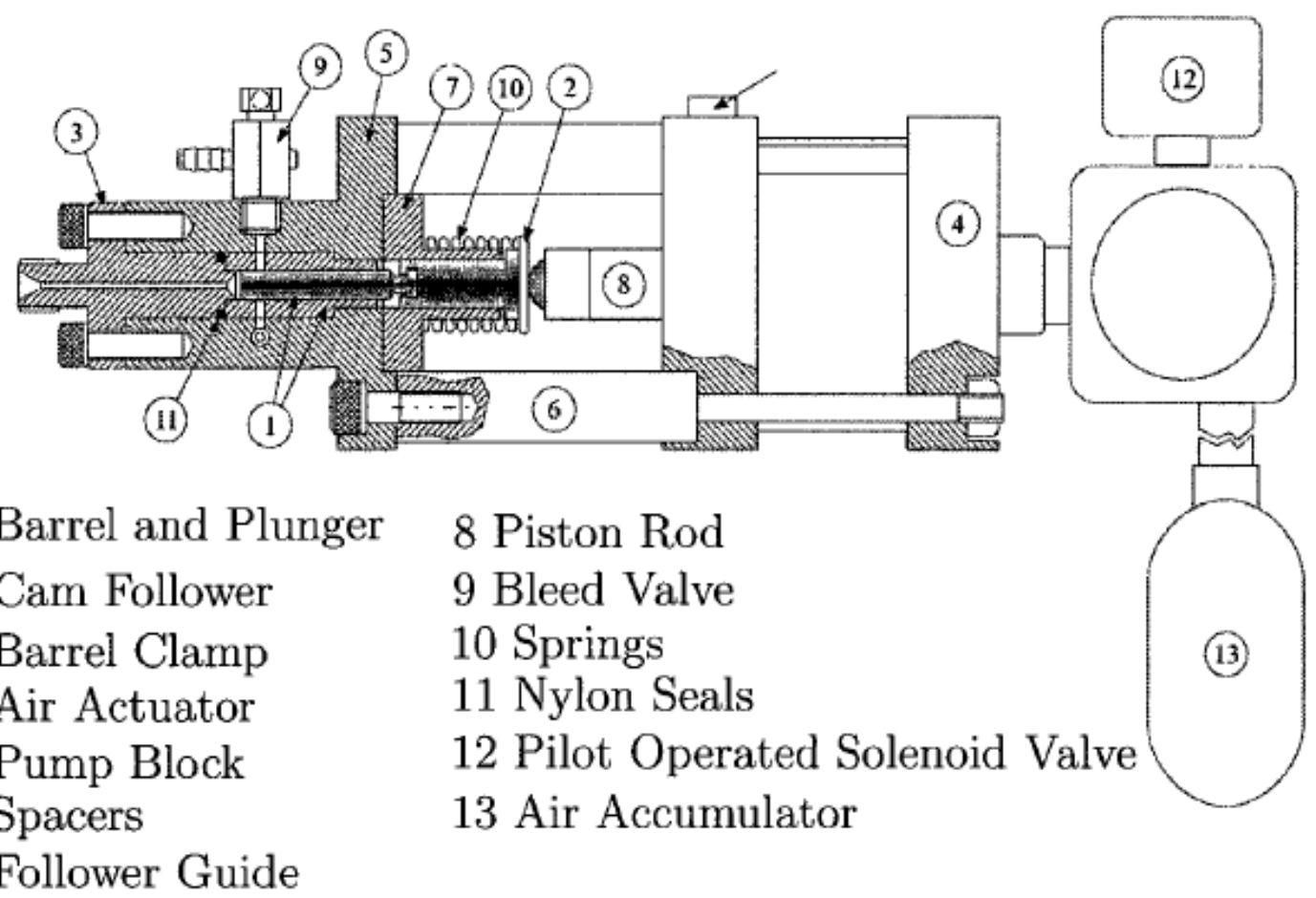

Figure 3.2: Injection Pump details [7].

The driving air pressure comes from two accumulators arranged in series with one Heskel( HAA31-2.5-N) air amplifier that is in turn connected to the main compressed air supply line. The air is then released to a pneumatically actuated piston through an ASCO 8316G14 solenoid valve. The valve is remotely triggered from a small program up-loaded from Matlab (with the Arduino package) or the Arduino 1.6.2 (IDE) software on an Arduino Mega 2560 micro-controller via a USB cable. The micro-controller is linked to a Grayhill 70GRCK4, 4 channel rack to which one 70G-OAC5 AC output/DC input module is used to trigger the solenoid valve on and off, thereby, controlling the injections.

For an injection to occur, the barrel chamber needs to be filled with fluid between each plunger stroke. This is done by pressurizing the injection tank with compressed 
air. The outlet of the air amplifier branches into a tee connector where one line feeds into the injection tank via a pressure regulator set to 75 psig. The injection fluid and air is separated by a polytetrafluoroethylene (ptfe) plunger with an o-ring around its circumference, ensuring a proper seal.

The plunger shown in Figure 3.2 (see bubble call-out number 1) pushes the fluid through the line to the injector nozzle. It is important not to run the pump dry, as the lubrication of the plunger comes from the injected fluid. Dry running will therefore result in damage to the pump. Additionally, the injection pump is fitted with two Swagelok, SS-BVM2 bleed valves which are used to dispense excess fluid or air in the system prior to conducting injections on a fresh tank of oil. One also serves to drain the bypass fluid lubricating the plunger.

The bleed valves outlets are fitted with clear, flexible, polymer tubing which are tied together and arranged to drip into a beaker where the bypass fluid is collected for disposal.

\subsubsection{Injection Nozzle}

The particular diesel injector nozzle that came with the IQT injection pump is a DN 12 SD 12 nozzle. This implies that the nozzle is a delay (or throttling) pintle-type nozzle. Pintle nozzles exist in different variations but they are all governed by the same, ISO 4010 [9] standard which fixes the internal geometry as shown in Figure 3.3. The exceptions are the angle on the conical tip (shown to have an $18^{\circ}$ angle) of the pintle and the length of the neck, which effectively makes the difference between a pintle-nozzle and a throttling pintle-nozzle. 


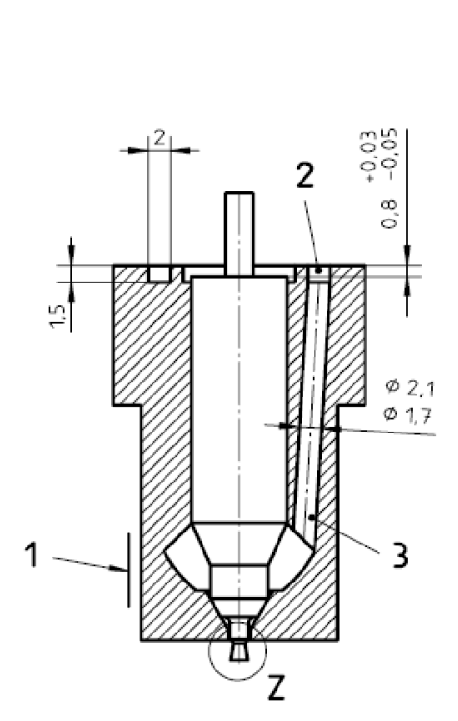

Dimensions in millimetres

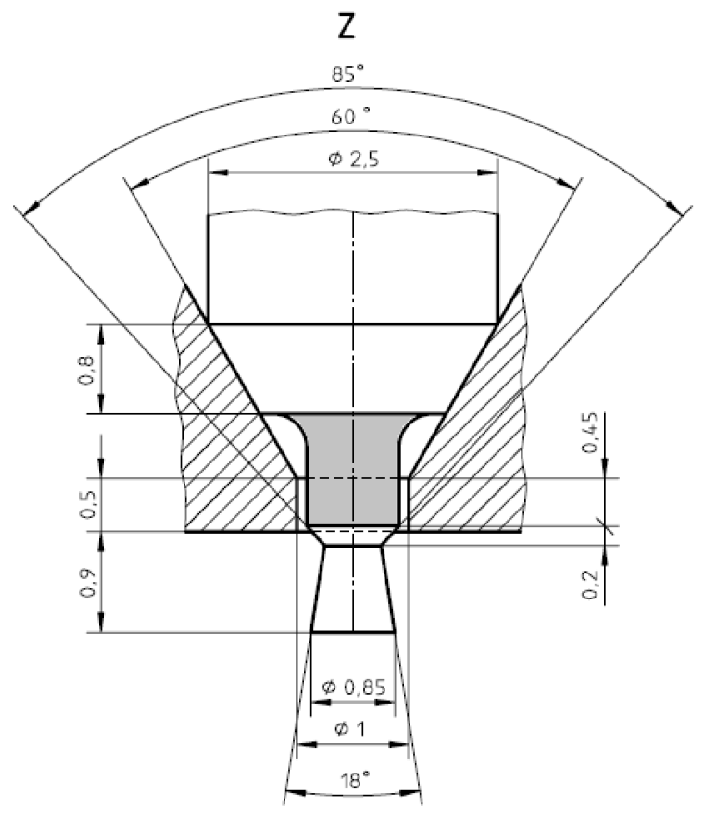

Figure 3.3: Nozzle and pintle geometry as specified by the ISO 4010 standard. Note the 'neck' of the pintle by the grayed-out area.

Nozzles are designed to open at a pre-set injection pressure. The top of the pintle sits against a stem which is in contact with a compression spring. This compression spring controls the nozzle opening pressure (NOP). Using a specialized diesel injector tester, the NOP can be set by tightening or loosening a threaded steel tube encasing and compressing the spring. In these experiments the NOP was set to $13.8 \mathrm{MPa}, \pm$ $68.9 \mathrm{KPa}$.

Oil enters the injector nozzle through the annular groove labelled by "2" on the cut-away view shown in Figure 3.3. It is then driven down through three galleries as labelled by "3", into the sac volume labelled by "1". Inside the sac volume the pressure builds and applies a vertical force component on the conical surface of the pintle shown in the sac volume. An injection takes place once the NOP threshold is 
breached.

\subsubsection{Atomization Chamber}

The injector nozzle holder is fixed to a circular interface with an atomization chamber (see Appendix A.1 for a detailed engineering drawing) bolted to the opposite side as shown in Figure 3.4. In a combustion process, the fuel is injected into the combustion chamber where it mixes with air. Unfortunately, this poses a problem for this application as injection into atmosphere would entrain air and promote the oxidation of the oil. The atomization chamber is designed to minimize the occurence of oxidation during injection cycles.

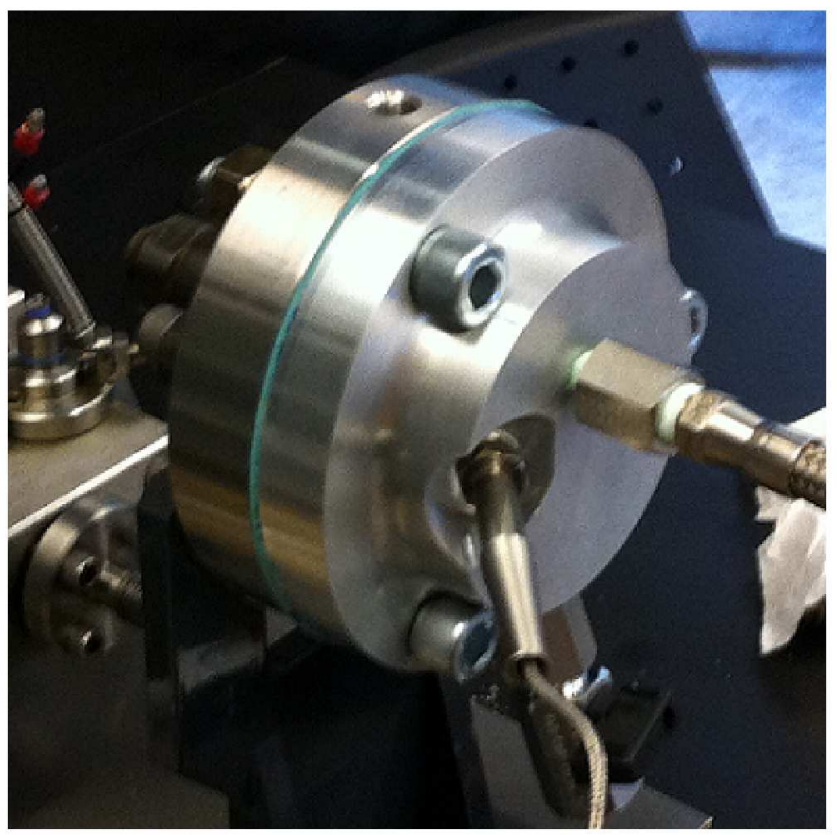

Figure 3.4: Atomization chamber mounted to diesel injector interface plate. The drain-hole, overflow outlet and thermocouple port are visible.

Oxidation is minimized by keeping the hemispherical cavity of the atomization 
chamber at the nozzle outlet filled with lubricating oil during injections [40]. By injecting into oil, air entrainment is curbed. The atomization chamber is equipped with a drain plug to empty the chamber and an overflow outlet to collect the sample in order to recirculate it into the injection tank. Note the overflow outlet at the top and the valve connected to the chamber drain hole at the bottom of the atomization chamber in Figure 3.4. The side hole is a thermocouple port but it is not used in these experiments.

\subsubsection{Injection Actuation Program}

Based on the research done in fuel spray analysis with the IQT [8] it seems that an injection requires a total of roughly $5 \mathrm{~ms}$ to complete or $3.5 \mathrm{~ms}$ if the secondary injection event is ignored as shown by the solid line indicating the relationship between needle lift and time in Figure 3.5.

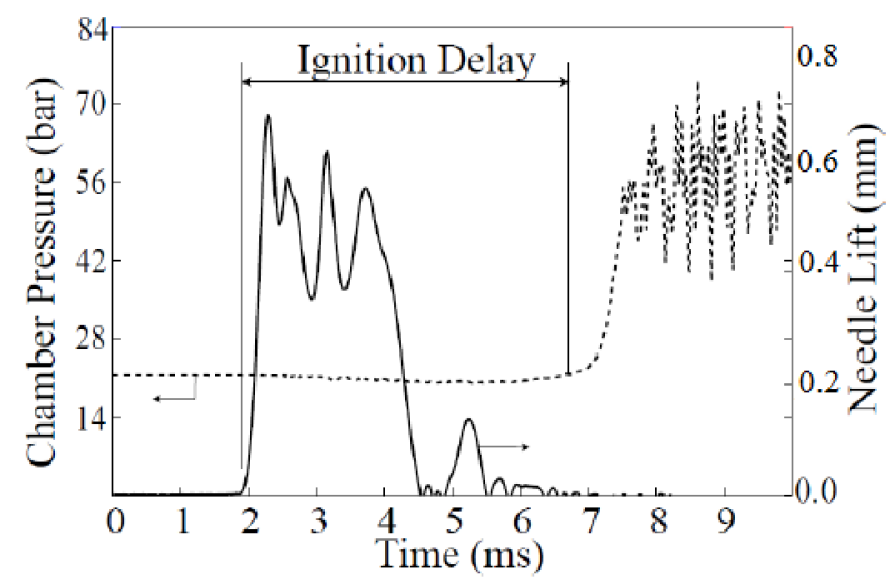

Figure 3.5: Diesel injector nozzle needle lift trace as a function of time (NOP:276 bars, back-pressure: 21.1 bars), modified from [8].

The secondary injection, along with the overall unsteadiness of the injection, is likely 
a result of a lack of damping on the actuator spring.

Using the described injection profile, a suitable injection time and delay were estimated. The simple code generated to control the solenoid valve is written here for convenience:

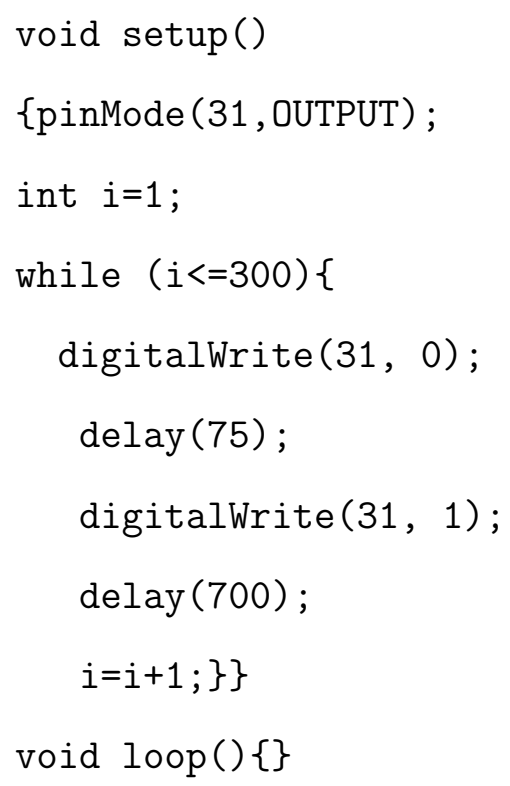

Using negative logic, the injection signal is written to pin 31 on the micro-controller and is outputted to the solid-state relay for $75 \mathrm{~ms}$ corresponding to the first delay line on the program. The next delay shuts-off the air-supply to the actuator allowing the accumulators to replenish their air-supply before the next injection cycle begins. The injection tank allowed for approximately 300 injections and is reflected as the counter limit used in the while loop.

\subsubsection{Diesel Injector Apparatus Installation}

The entire diesel injection apparatus is set-up on a mobile table built from modular 80/20 structural aluminum. Appendix A.2 shows the assembly drawing used to create 
the table. The apparatus is mounted to the table as can be seen in Figure 3.6. This Figure does not show the solenoid valve but a detailed schematic of the complete system is shown in Figure 3.7 where all the components that have been discussed also appear.

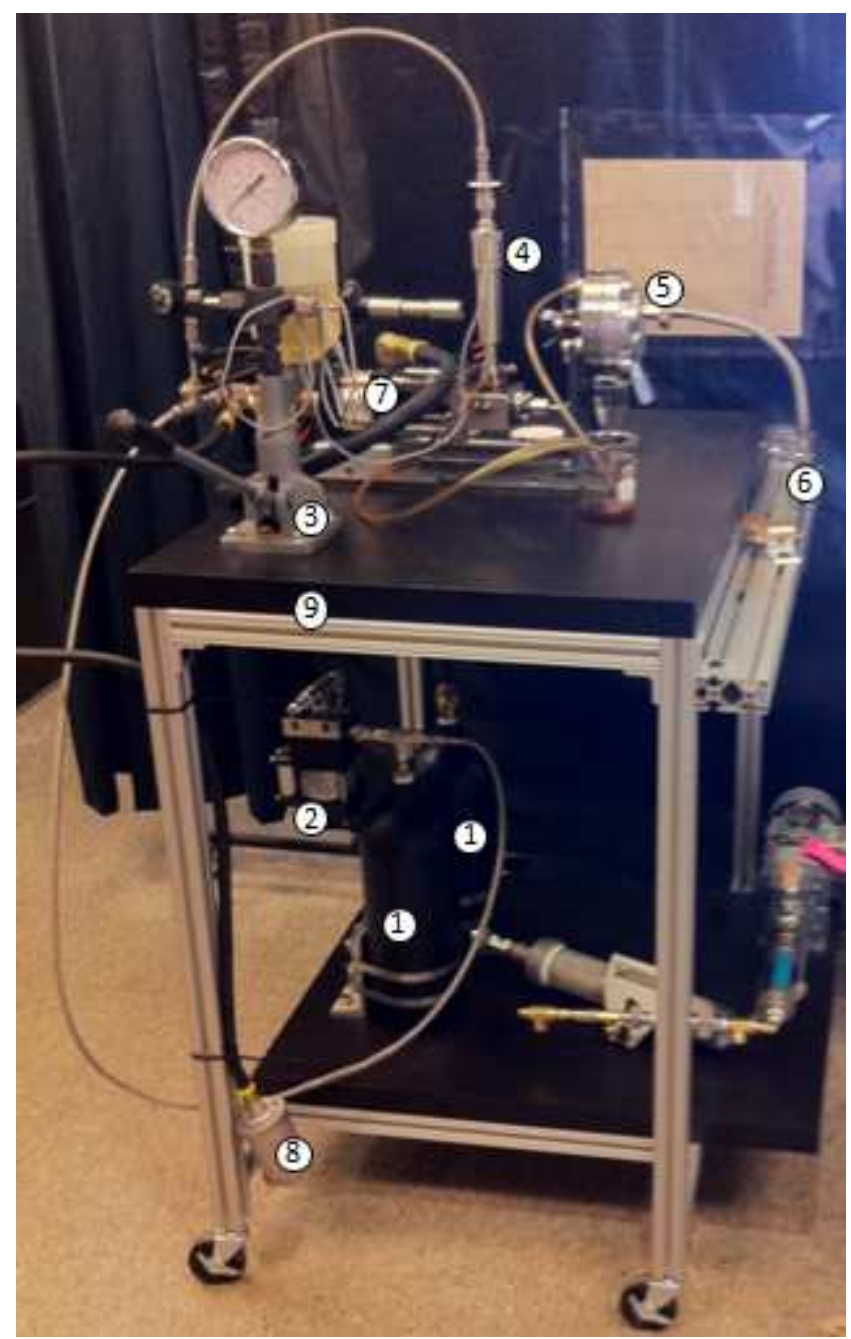

Figure 3.6: Experimental installation featuring: 1) Accumulators; 2) Air Amplifier; 3) Diesel Injector Calibrator; 4) Injection Tank; 5) Injector Nozzle/Atomization Chamber Assembly; 6) Sample Collection Jar; 7) Injection Pump; 8) Exhaust Muffler; 9) Mobile Table. 


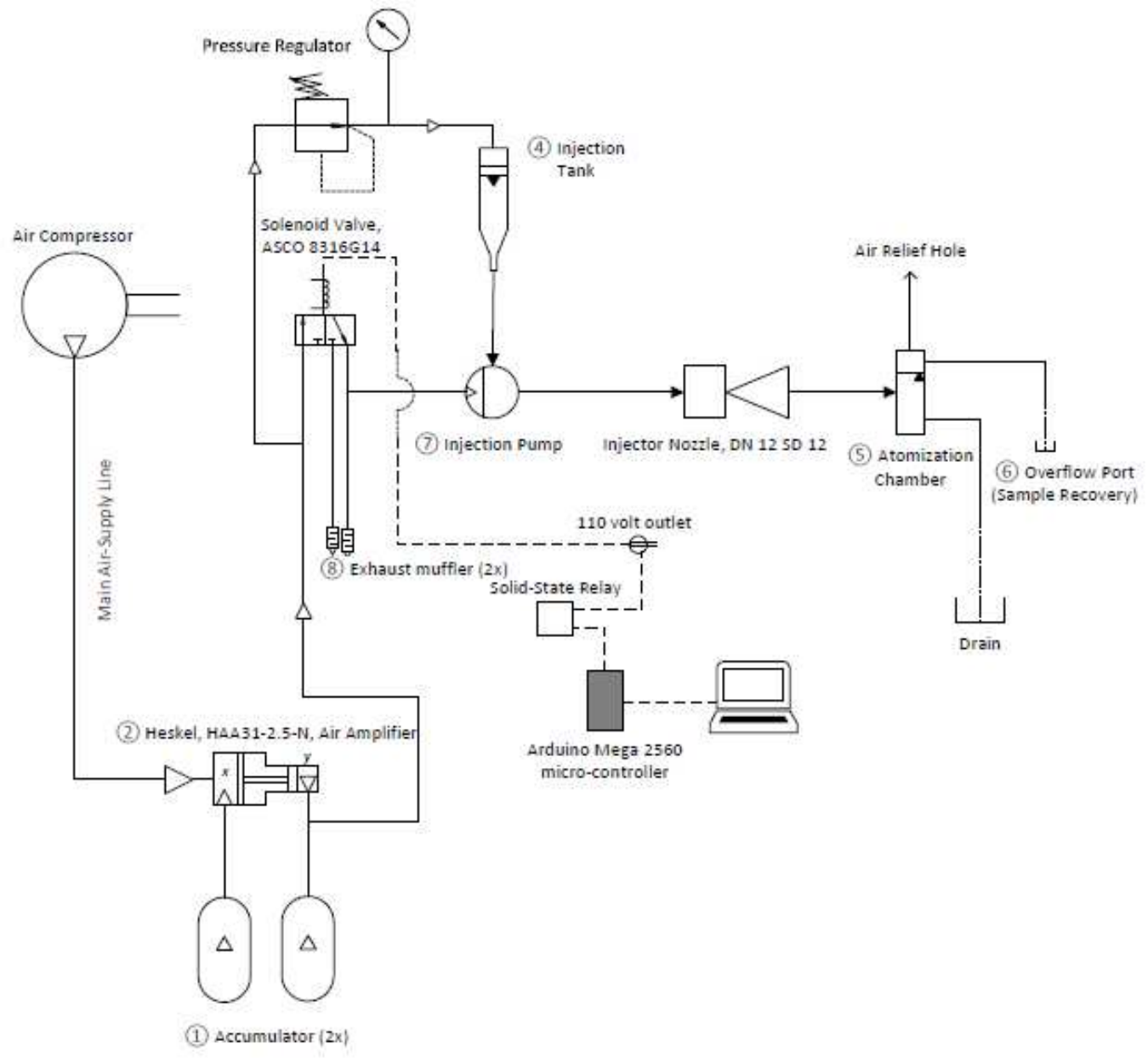

Figure 3.7: Schematic of diesel injector apparatus.

\subsubsection{Experimental Program}

All the oil samples intended for shearing were oxidized using the bench-top oxidation process for artificially degrading lubricating oils. These were then subjected to 12 cycles through the injector nozzle at an NOP of $13.8 \mathrm{MPa}$. The injection tank and atomization chamber have an oil capacity of $64 \mathrm{ml}$ and $35 \mathrm{ml}$ respectively. Since a little more than one tank is needed, and accounting for possible fluid losses during each test, two tanks worth of oil were sheared per sample. This required that each sample go through the injector 25 times to ensure that they were subjected to the intended 12 shearing cycles. After emptying each tank, it was re-filled with the oil 
collected at the overflow port exit shown as item number 6 in Figure 3.6.

Upon completing the injections, the atomization chamber, injection tank and interface plate were dismanteld for cleaning with acetone. Before re-assembly, the injection tank was filled with the next sample and run through the injector in order to flush the line of the previous sample. The injected flushing fluid was then discarded accordingly and the components were put together again for the next run. Prior to each new battery of tests, the atomization chamber was filled with sample via the overflow port.

Once the pre-shear and post-shear samples were prepared and collected, viscosity measurements were taken to determine the effect of shear on the sample.

To ensure adequate viscosity measurements, the calibration of a Physica MCR 301 rheometer from Anton-Paar, needed to be verified. Details on the DG42/Q1 measurement system used with the rheometer are available in Appendix D.1. To do this, viscosity standards are essential. First, degraded oil samples from a previous bench-top oil oxidation apparatus (see section 3.1), spanning from 0 to 48 hours of oxidation, were used to determine the expected range of viscosity within which the samples of interest would fit. From the viscosities shown in Figure 3.8, the oil samples' viscosities are expected to fall within $25 \mathrm{mPa} \cdot \mathrm{s}$ and $350 \mathrm{mPa} \cdot \mathrm{s}$. In this manner the rheometer's measurement accuracy could be verified at both extremes of the required measurement range.

Some of the samples produced for the actual experiment exceeded the maximum oxidation time of the preliminary samples by $24 \mathrm{hr}$. Anticipating that the maximum viscosity of the range would exceed that of the preliminary readings, two mineral oil 
viscosity reference standards intended for rotational viscometery were used. Both standards are produced by Paragon Scientific; RTM10 has a viscosity of $23.21 \mathrm{mPa} \cdot \mathrm{s}$ and RTM19 has a viscosity of $432.1 \mathrm{mPa} \cdot \mathrm{s}$ for a temperature of $22^{\circ} \mathrm{C}$.

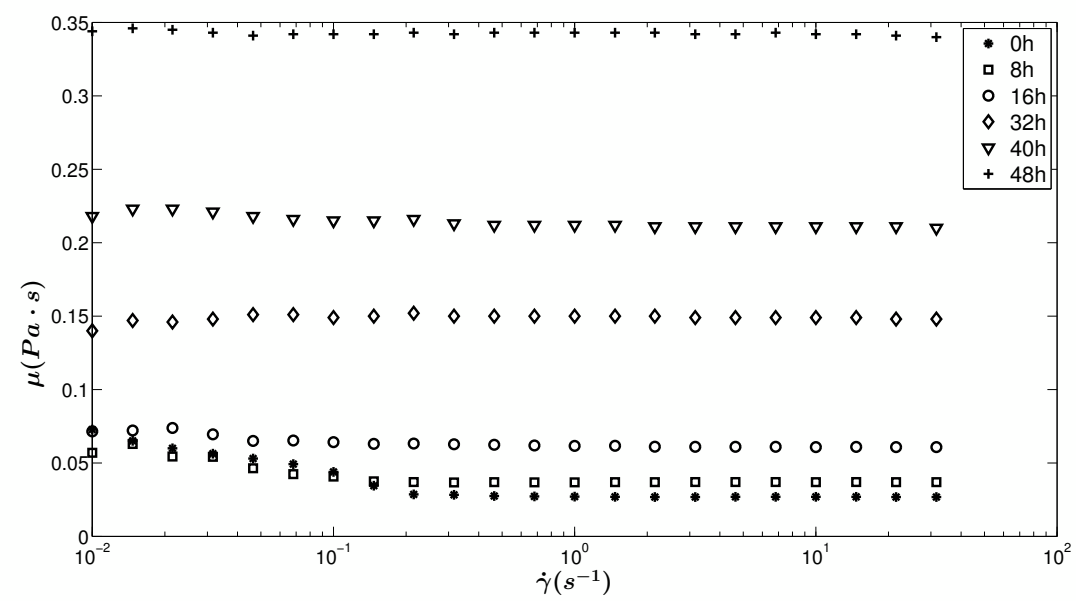

Figure 3.8: Expected viscosity of oil samples based on preliminary sample data. The legend denotes aging time in hours.

For each standard a total of three measurement curves, each totalling 31 measuring points at varying shear rates up to $1,000 \mathrm{~s}^{-1}$ were recorded. Owing to a lack of temperature control with the instrument, the standards' viscosity could not be measured at any of the temperatures provided on the calibration sheet. During testing the temperature was slowly incrementing during each trial and temperature readings were taken off the instrument's display panel. These yielded averaged test temperatures of $28.1^{\circ} \mathrm{C}$ and $28.52^{\circ} \mathrm{C}$ for the RTM10 and RTM19 respectively. The temperature varied by no more than $0.5^{\circ} \mathrm{C}$ for the thicker of the RTM19 and by no more than $0.2^{\circ} \mathrm{C}$ for the RTM10.

The resulting viscosity measurements for both standards are shown in Figure 3.9. 
Upon closer inspection of the plotted data there appears to be some abnormalities in the viscosity readings, for both standards, before a shear rate of $1 \mathrm{~s}^{-1}$. A vertical line was added to the plots in order to show the lower limit of valid shear rates for which this instrument can be used.

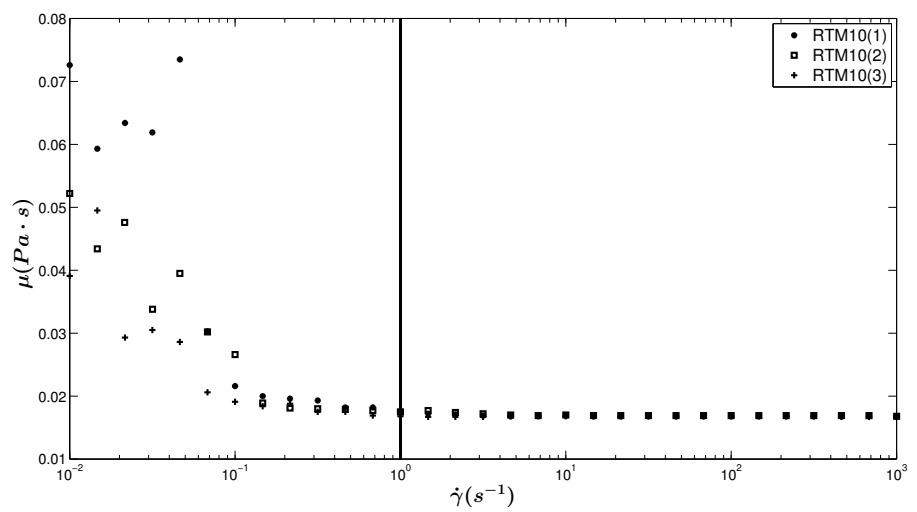

(a) RTM10

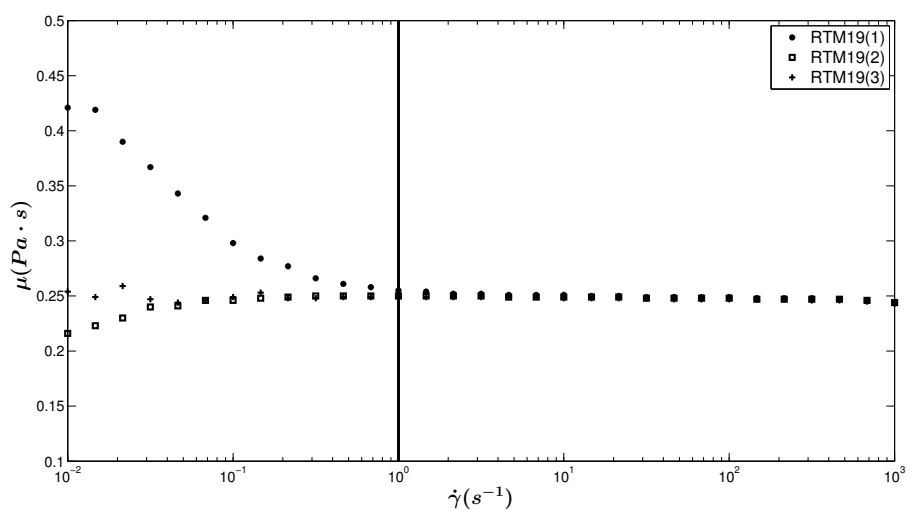

(b) RTM19

Figure 3.9: Plots of viscosity vs. shear rate for mineral oil viscosity standards RTM10 and RTM19, for 3 different tests on each.

After discarding the viscosity readings for shear rates below $1 \mathrm{~s}^{-1}$, the average value 
of viscosity for the RTM10 standard was found to be $16.8 \mathrm{mPa} \cdot \mathrm{s}$ and $247.5 \mathrm{mPa} \cdot \mathrm{s}$ for the RTM19 standard. Each standard was provided with a calibration table (see Figure 3.10 for the plotted table values) highlighting the product's viscosity values at different temperatures. This relationship between viscosity and temperature is perhaps not a linear one. However, given that the measurement temperatures were close to the tabulated values, indeed only a further $3.5^{\circ} \mathrm{C}$ from the last value on the calibration chart, it was deemed acceptable to use linear interpolation in order to find the expected viscosity of the standards at the corresponding average test temperatures. In this light, the calibration data for both standards was plotted with a basic linear fit producing an interpolation curve as shown in Figure 3.10. The equations for the fits also appear on the plots. In the end, viscosities of $17.2 \cdot \mathrm{s}$ and $244.9 \mathrm{mPa} \cdot \mathrm{s}$ were interpolated for RTM10 and RTM19.

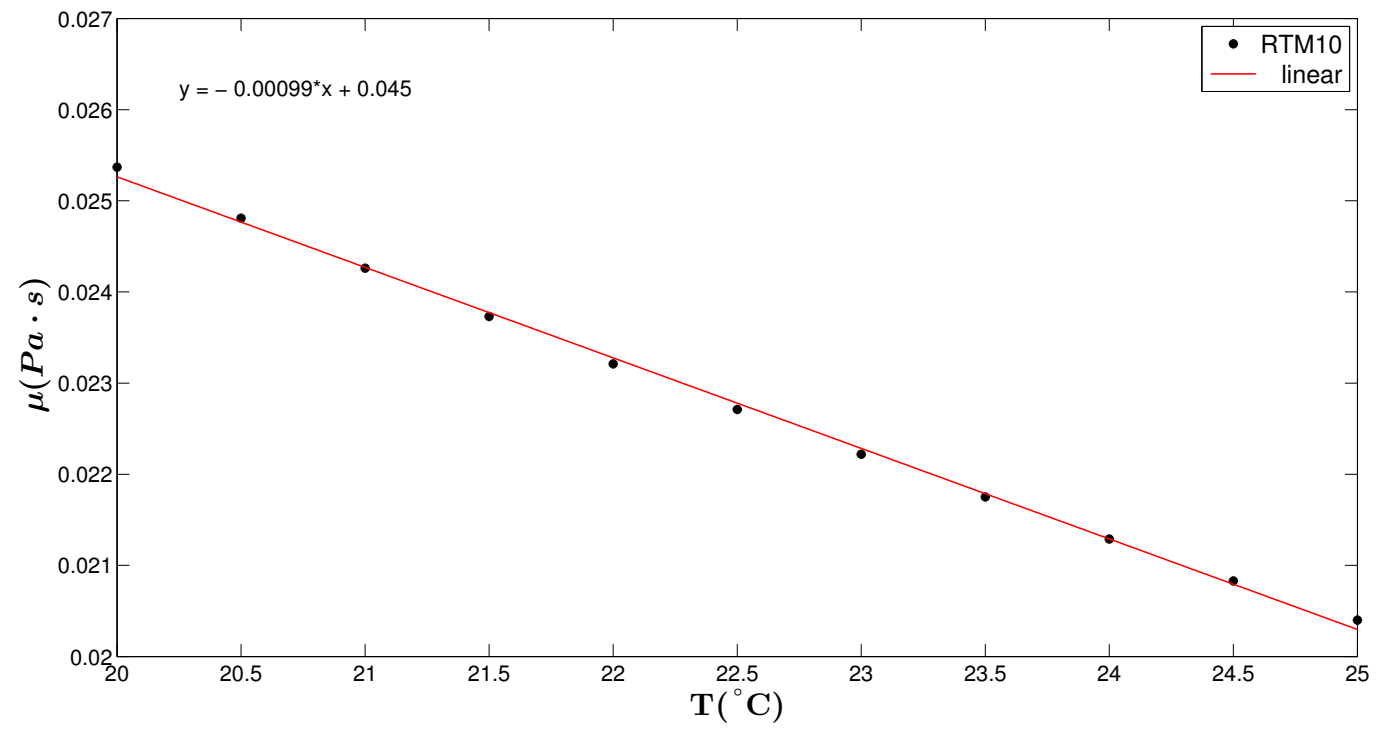

(a) RTM10 


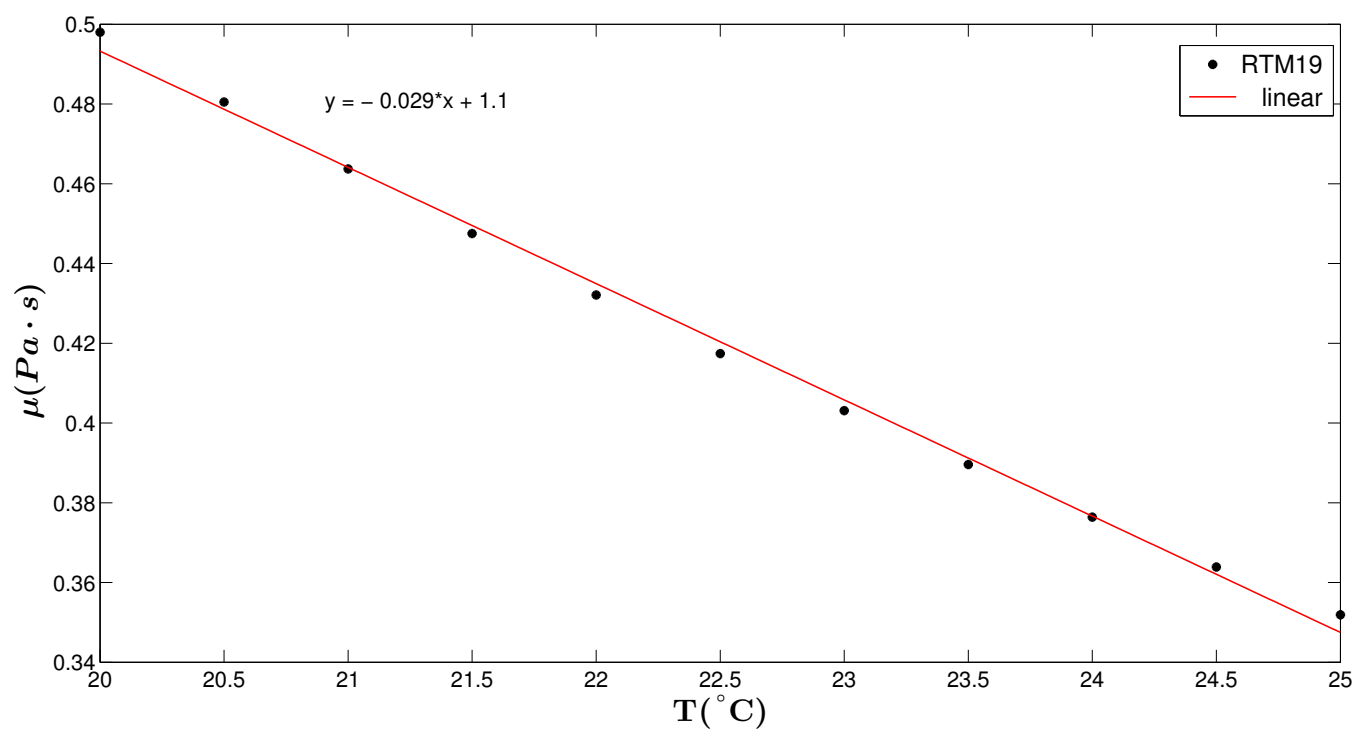

(b) RTM19

Figure 3.10: Calibration data for RTM10 and RTM19 with corresponding linear fits for interpolation.

At most, it represents a $2.3 \%$ deviation between measured and predicted values thus indicating that there is good agreement, and the instrument is well-calibrated.

\subsubsection{Injector Nozzle Flow and Shear Rates}

As discussed in section 2.3, there is no analytical solution for the internal flow of the geometry being considered. However, a simple laminar incompressible flow solution for Hagen-Poiseuille flow through an annulus will provide an order of magnitude for the shear-rates that are encountered by the fluid within the nozzle. As indicated in the previous section, an injection event is short and unsteady, making it highly transient in nature. As the pintle lifts or settles, the minimum flow area changes location based on the needle position inside the 
nozzle, Figure 3.11 illustrates for a $0.3 \mathrm{~mm}$ lift (a), $0.6 \mathrm{~mm}$ lift (b) and $0.8 \mathrm{~mm}$ lift (c).

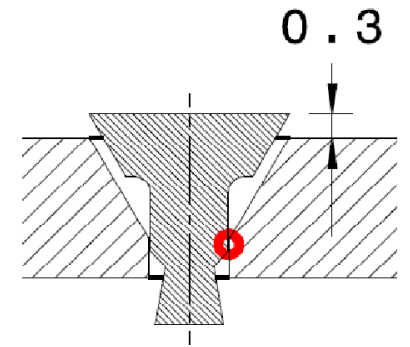

(a) $0.3 \mathrm{~mm}$ needle

lift.

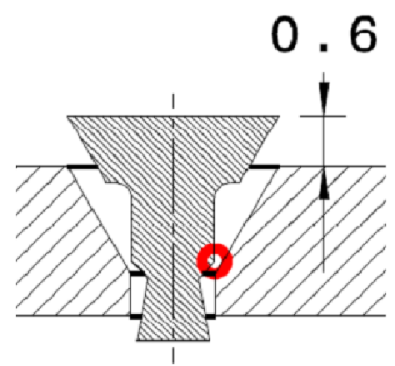

(b) $0.6 \mathrm{~mm}$ needle lift.

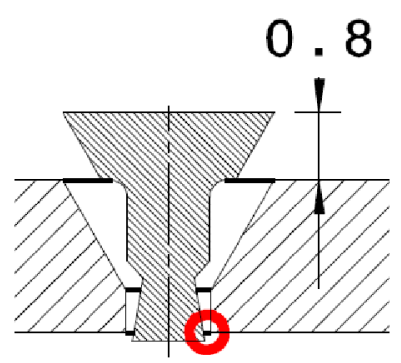

(c) $0.8 \mathrm{~mm}$ needle

lift.

Figure 3.11: Minimum flow area (circled) encountered by injection fluid at various needle-lift positions.

When these nozzles are calibrated, air is pulled through the nozzle at fixed needle lift positions using a vacuum pump until the flow is choked. Figure 3.12 shows how the flow rate of air varies with respect to the needle-lift position. 


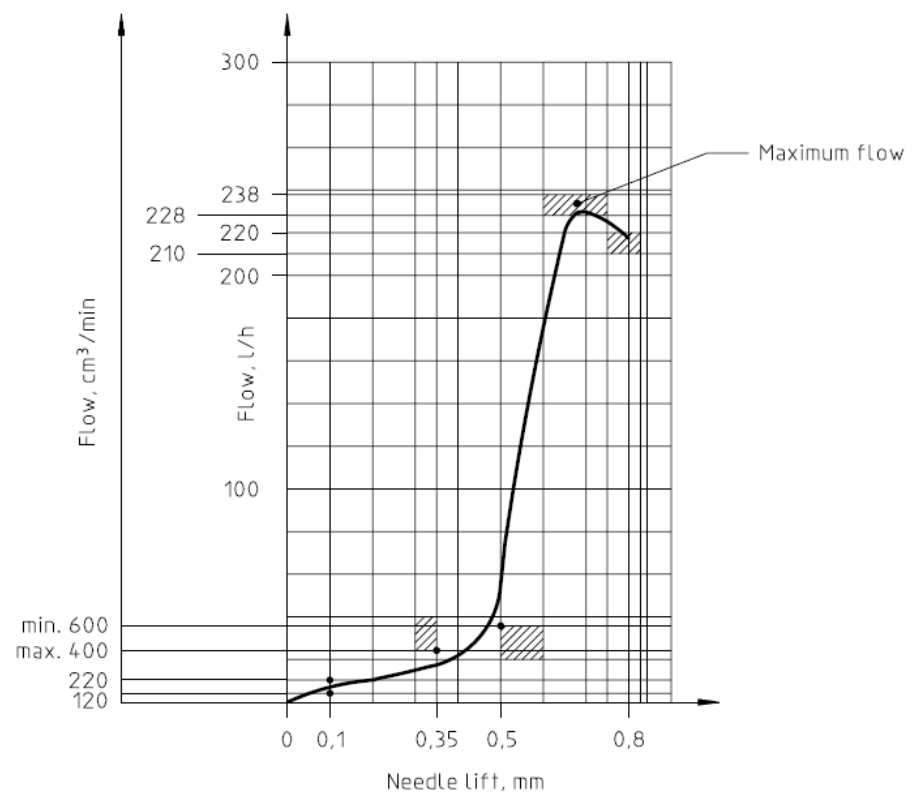

Figure 3.12: Typical air flow rate curve for a calibrated pintle-type injector nozzle [9].

For the purpose of the shear-rate estimate, an assumed needle-lift position of $0.8 \mathrm{~mm}$ (fully opened) is used. At this position, if the nozzle cavitates at all, it is likelier to occur at the nozzle-exit and it will probably make the shear-rate estimate a little more realistic. The assumption of incompressibility immediately satisfies the continuity equation and the general form of the equation governing incompressible Poiseuille flow [41] reduces to the momentum equation where, $\mu$ is the oil's viscosity, $u$ is the $x$-component of velocity, $\partial^{2} u / \partial y^{2}$ and $\partial^{2} u / \partial z^{2}$ represent the diffusion of momentum according to the $y$ and $z$-components, balancing out $d \hat{p} / d x$ (the pressure gradient) to give:

$$
\mu\left(\frac{\partial^{2} u}{\partial y^{2}}+\frac{\partial^{2} u}{\partial z^{2}}\right)=\frac{d \hat{p}}{d x}
$$


Note that in this case the direction of the flow is arbitrarily assumed to be along the $x$-coordinate.

For a radially-symmetric annulus, the velocity anywhere between the inner cylinder and outer tube can be expressed with respect to some radial distance as

$$
u(r)=\frac{1}{4 \mu} \frac{-d \hat{p}}{d x}\left[a^{2}-r^{2}+\left(a^{2}-b^{2}\right) \frac{\ln (a / r)}{\ln (b / a)}\right]
$$

where $r$ is a distance from the center of the annulus, confined to the inner and outer-walls. The variables $a$ and $b$ are constants and are the radii of the outer tube and inner cylinder respectively; Figure 3.13 illustrates.

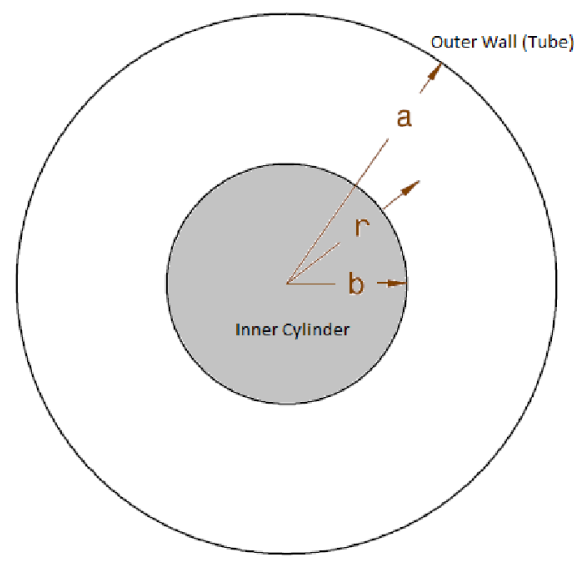

Figure 3.13: Schematic representation of important dimensions in annular flow.

Taking the derivative (see Appendix C for full derivation) of Equation 3.2 with respect to $r$, shows the shear strain rate to be

$$
\frac{d u(r)}{d r}=\frac{1}{4 \mu} \frac{-d \hat{p}}{d x}\left[-2 r-\frac{1}{r} \frac{\left(a^{2}-b^{2}\right)}{\ln (b / a)}\right]
$$


At maximum needle-lift, the inner radius of the minimum flow area, $b=0.4092 \mathrm{~mm}$ and the outer radius, $a=0.5 \mathrm{~mm}$. The NOP of the injector nozzle corresponds was set to $13.79 \mathrm{MPa}$. The nozzle length is approximately $1.8 \mathrm{~mm}$, giving a pressure gradient of $7.66 \mathrm{~Pa} / \mathrm{mm}$. Finally, setting the viscosity, $\mu=25 \mathrm{mPa} \cdot \mathrm{s}$ which is that of the unoxidized mineral oil at $20^{\circ} \mathrm{C}$, an estimated shear strain rate of $13.5 \times 10^{7}$ $\mathrm{s}^{-1}$ is developed inside the nozzle.

Of course, this particular shear rate is somewhat large but within the estimated range set-forth by Wood [33]. Because of the pressure and possible temperature rise inside the nozzle, the viscosity of the fluid would vary in addition to potential cavitation effects.

Another means by which the shear rate can be estimated is to eliminate the viscosity from Equation 3.3. This is easily done knowing that the volume flow rate, $Q$, for an annulus is given by

$$
Q=\frac{\pi}{8 \mu} \frac{-d \hat{p}}{d x}\left[a^{4}-b^{4}-\frac{\left(a^{2}-b^{2}\right)^{2}}{\ln (a / b}\right] .
$$

As mentioned in Section 2.3 the actual mass flow rate through the injector cannot be predicted from a simple application of the Bernoulli equation but it can be easily estimated. After carefully measuring the mass of oil injected after 10 injections, it was possible to average-out the mass per injection to $0.0878 \mathrm{~g} / \mathrm{inj}$. Estimating the time per injection from the needle-lift curve shown in Figure 3.5, it is possible to obtain an average mass flow rate of $0.025 \mathrm{~kg} / \mathrm{s}$. From there, 
assuming that the oil's density remains constant, the volume flow rate can be determined. Finally, by substituting the pressure gradient term in Equation 3.3 with a rearranged form of Equation 3.4 an estimated shear rate of $7,880,000 \mathrm{~s}^{-1}$ is obtained.

Undoubtedly the fluid properties vary inside the nozzle and the actual shear-rate must lie between the two calculated values, within the confines of the assumptions that have been made. In fact, it is likely that the shear rate is better approximated by the second estimate since the volume flow rate is based on a measured quantity from the nozzle. Owing to the pintle's unsteady motion (see Figure 3.5 and eccentricity [41] the shear rate is very likely higher than $7,880,000 \mathrm{~s}^{-1}$. Eventually, a full treatment of the injector nozzle flow will be required, but at this time it is not a priority. 


\section{Chapter 4}

\section{Results \& Discussion}

Completing the experimental program has allowed us to commission the designed and built diesel injector apparatus. By utilizing the bench-top oxidation apparatus for artificially degrading mineral oil, oxidized samples of the mineral oil were prepared over periods of $8,12,16,24,32,36,40,48,56,60,64$ and 72 hours. After collecting a sufficient volume of sample from each period, approximately $120 \mathrm{ml}$ of the total was inserted into the diesel injector apparatus to undergo shearing. For these tests the nozzle opening pressure (NOP) was set to 2,000 psi or $13.79 \mathrm{MPa}$. The fluid was cycled through the injector 25 times but, due to the necessary volume of oil required in the atomization chamber itself, each fluid molecule was subjected to at least 12 cycles.

\subsection{Preliminary Results}

Viscosities of the samples before and after injection were measured over 35 measuring points, up to $5,000 \mathrm{~s}^{-1}$ when the thickness of the lubricating oil allowed for it. The more oxidized (thicker) lubricating oil samples caused the rheometer to reach the motor's torque limit of $200,000 \mu \mathrm{N} \cdot \mathrm{m}$. Regardless, the measurements were repeated three times for each sample. The full results are displayed in plot form in 
Appendix B.1. The data considered for analysis is confined to that from a shear strain rate of $1 \mathrm{~s}^{-1}$ (As explained in section 3.2.6) on up to the limiting shear strain rate just before the torque limit of the motor is reached. These limits are shown by vertical lines on the plots. Also, due to the lack of a temperature control device, there was no effective way to record the test temperatures. As such, the temperatures at the beginning and at the end of the tests were recorded from the instrument's display panel and averaged. These can be found in Appendix B.2, but note that overall the temperature difference was small, only $0.5^{\circ} \mathrm{C}$ for the thicker samples and $0.1^{\circ} \mathrm{C}$ for the thinnest, less oxidized samples.

To assess whether or not the diesel injector apparatus was able to break down lubricating oil molecules, a comparative plot (Figure 4.1) showing the average viscosities, $\bar{\mu}$ of the oxidized-unsheared samples and oxidized-sheared samples was generated. It demonstrates that in the early stages of degradation, the viscosities between the sheared and unsheared samples are practically unnoticeable. However, a trend starts to develop at the 36 hour mark, where a clear distinction between the sheared and unsheared samples can be observed. With increasing oxidation times, noticeable differences start to appear, of which the largest is $0.043 \mathrm{~Pa} \cdot \mathrm{s}$ at the 72 hour mark. For added clarity, refer to Table 4.1 where the plotted data shown in Figure 4.1 has been tabulated. The significance of the viscosity change at the 72 hour mark is best appreciated after seeing the percent change in viscosity as shown in Figure 4.2. 


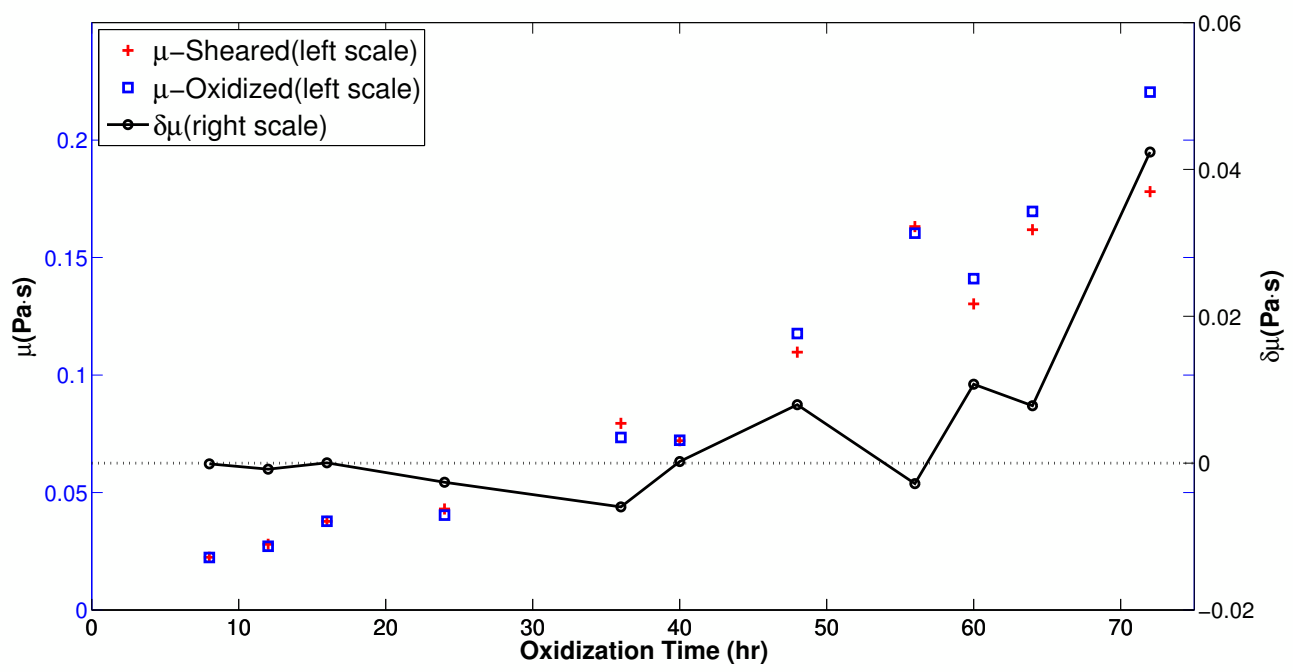

Figure 4.1: Plot showing the viscosity difference between the sheared and unsheared oxidized lubricating oil samples.

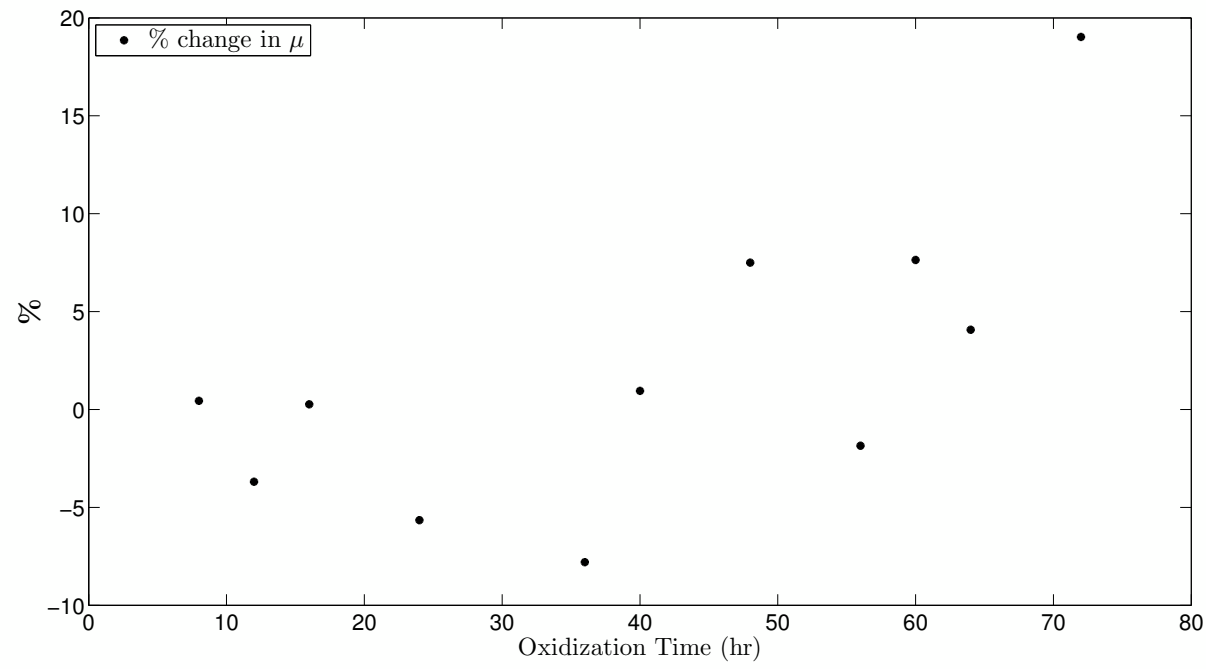

Figure 4.2: Plot showing the $\%$ viscosity change in viscosity. It clearly singles out the influence of shear on oil viscosity after 72 hours of oxidation where a $19 \%$ change was observed. 
Table 4.1: Tabulated average viscosities $(\bar{\mu})$ of oxidized-unsheared samples, oxidizedsheared samples and their difference $(\delta \bar{\mu})$ according to their respective oxidation times.

\begin{tabular}{|c|c|c|c|}
\hline Oxidation & Unsheared & Sheared & Unsheared - Sheared \\
Time, hrs & $\bar{\mu}(\mathrm{Pa} \cdot \mathrm{s})$ & $\bar{\mu}(\mathrm{Pa} \cdot \mathrm{s})$ & $\delta \bar{\mu}(\mathrm{Pa} \cdot \mathrm{s})$ \\
\hline 8 & 0.0226 & 0.0225 & 0.001 \\
12 & 0.0271 & 0.0281 & -0.0010 \\
16 & 0.0380 & 0.0379 & 0.0001 \\
24 & 0.0407 & 0.0430 & -0.0023 \\
36 & 0.0744 & 0.0802 & -0.0058 \\
40 & 0.0734 & 0.0727 & 0.0007 \\
48 & 0.1200 & 0.111 & 0.0090 \\
56 & 0.1620 & 0.165 & -0.0030 \\
60 & 0.1440 & 0.1330 & 0.0110 \\
64 & 0.1720 & 0.1650 & 0.0070 \\
72 & 0.2260 & 0.1830 & 0.0430 \\
\hline
\end{tabular}

Clearly, some of the measurements shed doubt over the trend. At the 36 hour mark, the sheared sample has a higher viscosity than the unsheared sample but, at the 40 hour mark, both measurements are the same and both are again nearly identical at the 56 hour mark. The shearing procedure was rigorously followed and it is unlikely that the error might have originated from there. However, all possibilities must be considered. One possibility is that the bench top oxidation process was not sufficiently controlled.

The bench top oxidation method used to artificially degrade the lubricating relied on the building's main air supply. The samples needed to be prepared over extended periods of time, leaving the result vulnerable to air-supply variations. This could explain the near identical viscosities of the 36 hour and 40 hour samples. In the cases where the sheared sample's viscosity was observed to be higher than the oxidized 
sample, two additional possibilities present themselves. The less speculative one is that the measurements find themselves within one another's standard deviation thus, meaning that the result is not significant within experimental uncertainty. Finally, given the duality of the diesel injector wherein the internal flow is partially incompressible and cavitated, there is a possibility that if the lubricating oil's molecular weight was not high enough, that the injector promotes the thermo-oxidative process instead, thus encouraging polymerization rather than breaking-up the products of oxidation.

Figure 4.3 shows the average viscosities of the oxidized-sheared and oxidizedunsheared samples along with the errorbars that result from taking the standard deviation, $S_{N}$, given by

$$
S_{N}=\sqrt{\frac{1}{N} \sum_{i=1}^{N}\left(\mu_{i}-\bar{\mu}\right)^{2}}
$$

for each sample's measurement set. Upon a closer inspection of the plot, the 64 hour samples' standard deviations may be a little too close to make a call by visual inspection. Comparing the tabulated standard deviations in Table 4.3 to the average viscosities presented in Table 4.1, it becomes obvious that there is clearly no overlap for the samples at the 36, 48, 60 and 72 hour mark, indicating that the result is not random. The results are strongly conclusive that there is evidence of shear break down of the lubricating oil samples. 


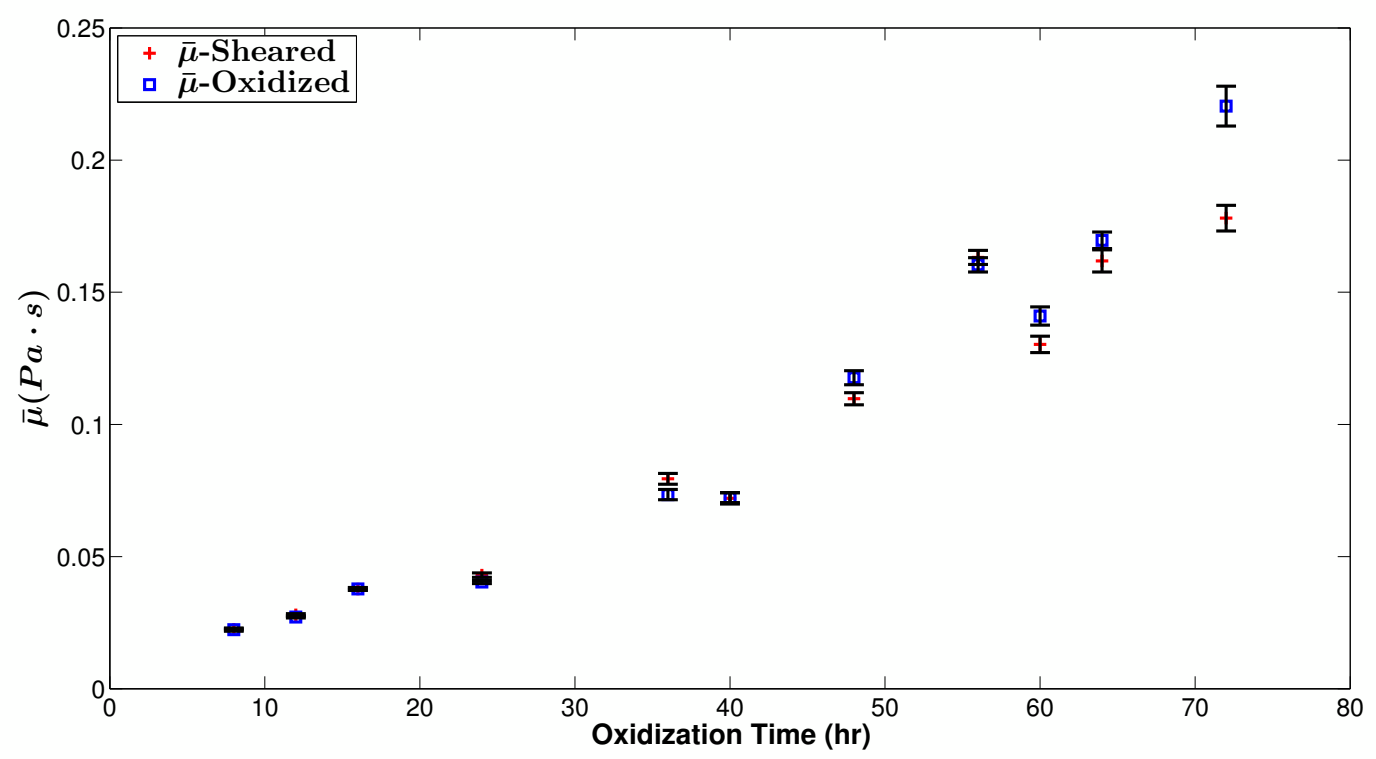

Figure 4.3: Plot showing the viscosity difference between the sheared and unsheared oxidized lubricating oil samples.

Table 4.3: Average starting and final temperatures of each viscosity tests.

\begin{tabular}{|c|c|c|}
\hline Oxidation & Unsheared & Sheared \\
Time, hrs & Standard Deviation, & Standard Deviation, \\
& $S_{N}-\mu(\mathrm{Pa} \cdot \mathrm{s})$ & $S_{N}-\mu(\mathrm{Pa} \cdot \mathrm{s})$ \\
\hline 8 & \pm 0.0006 & \pm 0.0003 \\
12 & \pm 0.0004 & \pm 0.0004 \\
16 & \pm 0.0006 & \pm 0.0005 \\
24 & \pm 0.0006 & \pm 0.0008 \\
36 & \pm 0.0020 & \pm 0.0020 \\
40 & \pm 0.0018 & \pm 0.0022 \\
48 & \pm 0.0026 & \pm 0.0023 \\
56 & \pm 0.0027 & \pm 0.0027 \\
60 & \pm 0.0034 & \pm 0.0031 \\
64 & \pm 0.0031 & \pm 0.0042 \\
72 & \pm 0.0075 & \pm 0.0049 \\
\hline
\end{tabular}


Further support concerning the measurements comes from the fact that rotational viscometers are known to be accurate within a margin of $3-5 \%$ [14]. A z-test was performed using the 72 hour sample's mean viscosity. It was found that the probability of finding the mean viscosity of the sample at $\pm 5 \%$ from the true mean of the sample fell outside of the $95 \%$ confidence interval, indicating the robustness of the measured quantity and the consistency of the rheometer. 


\section{Chapter 5}

\section{Future Work}

The literature review revealed that the potential effects of shear were likelier with high molecular weight compounds such as the ones found in oxidized lubricating oils. As a result, an experimental diesel injector apparatus was created to impart shear strain rates on samples degraded through a secondary experimental apparatus meant to artificially oxidize additive-free mineral oil. The commissioning of the diesel injector experiment proved successful in breaking highly oxidized mineral oils, but improvements to both experiments have been identified as well as a new direction for the continuation of this research.

The section that follows will first focus on the artificial aging process of the lubricating oil in order to produce better samples for investigation through the diesel injector apparatus. The more important topic of what is next with the diesel injector apparatus will then be discussed. Rig improvements to automate or facilitate operation of the diesel injector apparatus will be presented in order to perform longterm experiments. Finally, the new research direction is presented. 


\subsection{Artificial Oxidation Method - Suggested Im- provements}

Some inconsistencies in the results have highlighted the need for improvements in the experimental setup used to artificially age the lubricating oil samples. One would have expected the viscosity to increment monotonically, but some samples such as the 56 hour one, have shown a higher viscosity than both of their immediate neighbours, which seems incorrect. The plausible cause is likely down to the process used to make the samples to begin with. Some of the contributing issues could be the lack of direct temperature control of the sample and a lack of a proper air-supply for the duration of the experiment. A few easy fixes are available however, as discussed next.

Because of the catalyzing effect that metals have on the oxidation process, it was thought prudent to insert the thermocouple into the oil bath rather than inside the flask with the mineral oil sample. This technique brought sufficent temperature control provided that it was monitored in the first few minutes after starting a new sample. To better control the oxidation temperature, the thermocouple should be inserted inside the boiling flask, into the oil sample itself instead. For this, a type-J thermoucouple with a quartz glass sheath could be used and inserted directly into the oil sample. Quartz-glass is chemically resistant and can be used up to a temperature of $500^{\circ} \mathrm{C}$.

Another item that could have contributed to poor sample quality is an unexpected shut-off of the air supply or a reduced flow rate. The longer the oxidation time, the more probable either of these events could have occured. Each sample was produced in batches of 1,000 ml, through the degradation of individual $250 \mathrm{ml}$ samples. In an 
attempt to average-out inconsistencies, the samples were mixed together to produce the required 1,000 ml. This averaging was not the same for all samples as there was less evaporation at the lower oxidation times. The 8 hour batch was produced from 4 samples while the 72 hour batch required a total of 8 samples.

To produce better samples, a form of quality control based on the TAN would be useful. Ofunne [28] provides a plot of TAN vs. oxidation time in his paper for mineral base oils. Obviously the oil used in this experiment is certainly from a different oil field than the ones his oils came from, but the plot can be used as a baseline of what to expect.

\subsection{Experimental Diesel Injector Apparatus - Im- provements \& New Research Direction}

In its current form, the diesel injector apparatus is semi-manually operated to conduct the shearing tests. The injections themselves were handled through the micro-controller but the operator still had to collect the lubricant and fill the injection tank before moving on to the next set of injections. The diesel injector has shown itself capable of breaking down heavily oxidized mineral oils after they have been subjected to 12 injection cycles. Another important question is what happens to these same oxidized samples over longterm exposure to shearing stresses.

Automating the diesel injector will allow the experiments to run over an extended period of time. This goal can be achieved in two different ways. One is to re-route the outlet from the injection pump to the injector in order to directly inject into a 
custom built, pressurized injection tank, with the addition of a filter in case longterm testing produces any metal particles. This is the simplest method of automation as only the number of injections need to be configured into the micro-controller injection program. This also has the advantage of keeping the required amount of sample small. It provides an intrisic, back-pressure control (to be discussed further in the following paragraph) since the injection tank needs pressurization. Automation could also be successfully implemented by using a separate pump to circulate the oil from the nozzle outlet back to the injection tank, albeit this would be a little more involved than the method that was first suggested above.

The experimental setup, with or without the improvements, will also help further the research in different areas. The experimental results have shown a few outliers, of which the significance is most likely resulting from the quality of the oxidized samples themselves. However, there is a duality with the injector. The injector produces both high shear rates and partially cavitated flow conditions. Under normal injection operating conditions, one is not mutually exclusive from the other, but as section 2.1.5 has shown there is a strong case made for cavitation's role in the mechanical degradation of VIIs. This duality exists because of the high injection pressure relative to the ambient pressure at the outlet of the nozzle. Herein lies an opportunity to investigate the influence of cavitated and non-cavitated flow. That is, one can investigate the effects of pure shear versus those of mixed or combined shearing and cavitation effects. This would be easily done by controlling the pressure on the nozzle outlet as Jia's [35] simulations suggest.

The diesel injector experiments have shown that as oil oxidizes, mechanical components like roller element bearings, journal bearings and boundary lubricated contacts probably have a contribution in retarding the overall thickening of the lubricant. 
It has also revealed that this effect is prevalent when the lubricating oil is about ready for a change as discussed in section 2.1.3. The mechanical degradation of the oxidized lubricating oil may come too late in the lubricant's life cycle to be of value if we recall the main objective stated in section 1 . To know the full extent of the effects however, additional longterm measurements will be needed. These will involve cycling the oil through the injector for, 25, 50, 100, 300 cycles and more.

Section 2.1.5 also indicated the propensity of VIIs to break under shear. Recalling that oils are selected based on their viscosities, an early breakdown of these molecules could be detrimental. VIIs are used in oils to improve the stability of their viscosity at higher temperatures. This is a critical function. Because of the size of the VII molecules in general, they are susceptible to shear degradation instantly. Characterizing and understanding VII shear degradation behaviour based on their size and concentration in the lubricant is the way forward for this research. It will also be important to examine the evolution of the viscosity-temperature relationship as the VIIs molecular weight is reduced. The literature indicates that these molecules are large, but how large do they need to be to fulfill their function, and in what concentration?

Eventually, the research will mature to a point where the inclusion of the internal nozzle flow effects will need to be resolved and tied into the observed mechanical degradation of the VIIs but for now, with the diesel injector experiment working, the focus should be on confirming the observed trend with the oxidized mineral oils and investigate the various factors influencing VII bond breaking along with its relationship to lubrication. Shearing VIIs and comparing to available shear stability data is a priority. 


\section{Chapter 6}

\section{Conclusion}

Two experimental apparatuses have been successfully built to study the effects of shear rate on the degradation of lubricating oils. One is a bench-top oxidation apparatus to artificially accelerate and degrade the lubricating oils, the other is a diesel injector apparatus to shear the oxidized mineral oil samples prepared with the former apparatus.

This research sought out to answer whether or not the shear-rate could have an effect on the degradation of lubricating oils. A literature review on the subject has hinted at the absence of such phenomena taking place on fresh base oils but there was substantial evidence that shear rate does mechanically break high molecular weight polymers such as the VIIs used in modern lubricating oils and the oxidation products found in aged mineral oil. After considering several experiments to observe mechanical degradation, the diesel injector was settled upon.

The diesel injector was selected because it produces high shear rates; there is very little movement between rubbing or contacting surfaces and it minimizes the chance of metal catalysis. More importantly, however, is that the entire sample volume has to go through the nozzle allowing a minimization of the necessary sample volume 
used and an increase in the concentration of mechanically degraded products on a per volume basis. Their concentration is important as it makes it easier to detect their presence through visocisity measurements such as those performed here.

With this knowledge, a pneumatically activated injection pump, coupled with a DN 12 SD 12 injector nozzle was put together. To minimize the occurence of oxidation, an atomization chamber was designed to hold a small volume of sample into which the injector discharged. Injections were actuated by a program running through an Arduino Mega 2560 micro-controller.

Samples for injection were prepared over periods up to 72 hours in a bench-top oxidation apparatus and then fed into the diesel injector apparatus for a combined total of 12 cycles. The research has concluded that as the oil oxidizes, its molecular structure changes. Under oxidizing conditions, hydrocarbons polymerize to form larger molecules that may be susceptible to shear induced chain scissions. By artificially degrading additive-free mineral oil, then cycling it through a diesel injector nozzle, subsequent viscosity measurements of the samples before and after shearing have shown that older lubricating oils become more susceptible to permanent viscosity loss (a strong indicator that molecular bonds have been broken), while fresh oil remains unaffected.

More results are needed to confirm the observed trend and in that regard improvements to the bench-top oxidation process have been identified, namely using direct temperature control of the oil sample under oxidation and adding TAN analysis as a quality control mechanism. As for the diesel injector apparatus it can be operated in its current form but it would be more versatile if automated operation is made possible for longterm shear experiments. 


\section{List of References}

[1] G. Drouin, Éléments de machines. Éditions de l'École polytechnique de Montréal, 1986.

[2] J. H. Arakeri and K. R. Sreenivas, "Hydrodynamic lubrication," Resonance, vol. 1, no. 9, pp. 51-58, 1996.

[3] M. F. Spotts and T. E. Shoup, Design of Machine Elements. Prentice-Hall, 1998.

[4] R. M. Mortier, M. F. Fox, and S. T. Orszulik, Chemistry and Technology of Lubricants. SpringerLink: Springer e-Books, Springer, 2011.

[5] M. M. Caruso, D. a. Davis, Q. Shen, S. a. Odom, N. R. Sottos, S. R. White, and J. S. Moore, "Mechanically-induced chemical changes in polymeric materials.," Chemical reviews, vol. 109, pp. 5755-98, Nov. 2009.

[6] R. Payri, J. M. García, F. J. Salvador, and J. Gimeno, "Using spray momentum flux measurements to understand the influence of diesel nozzle geometry on spray characteristics," Fuel, vol. 84, no. 5, pp. 551-561, 2005.

[7] S. G. Daviault, "Characterization of the Fuel Injection Process within the Ignition Quality Tester (IQT ${ }^{\mathrm{TM}}$ )," MASc thesis, Carleton University, 2011.

[8] S. G. Daviault, E. A. Matida, M. M. Karakolis, and G. D. Webster, "Droplet Size and Velocity Characteristics of the Ignition Quality Tester ( IQT TM ) Fuel Spray," SAE Paper, vol. c, pp. 279-286, 2011.

[9] International Organization for Standardization, "Iso 4010: Diesel Engines - Calibration Nozzle, Delay Pintle Type," ISO Standard, 1998.

[10] B. J. Hamrock and S. R. Schmid, "Fundamentals of Fluid Film Lubrication Second Edition," 2004.

[11] S. S. M. Hsu and R. S. Gates, "Boundary lubricating films: formation and lubrication mechanism," Tribology International, vol. 38, pp. 305-312, Mar. 2005. 
[12] S. Bair, M. Khonsari, and W. O. Winer, "High-pressure rheology of lubricants and limitations of the Reynolds equation," Tribology International, vol. 31, no. 10, pp. 573-586, 1998.

[13] A. Basu, A. Berndorfer, C. Buelna, J. Campbell, K. Ismail, Y. Lin, L. Rodriguez, and S. S. Wang, "Smart sensing" of Oil Degradation and Oil Level Measurements in Gasoline Engines," SAE Technical Paper Series, no. 724, 2000.

[14] L. V. Markova, V. M. Makarenko, M. S. Semenyuk, and a. P. Zozulya, "On-line monitoring of the viscosity of lubricating oils," Journal of Friction and Wear, vol. 31, pp. 433-442, Jan. 2011.

[15] S. M. Hsu, "Molecular basis of lubrication," Tribology International, vol. 37, pp. 553-559, July 2004.

[16] R. L. Rudnick, Leslie R and Shubkin, "Highly Refined Mineral Oils," in Synthetic Lubricants And High-Performance Functional Fluids, ch. 17, pp. 393-411, CRC Press, 1999.

[17] W. R. Murphy, D. A. Blain, A. S. Galiano-Roth, and P. A. Galvin, "Benefits of synthetic lubricants in industrial applications," Journal of Synthetic Lubrication, vol. 18, pp. 301-325, Jan. 2002.

[18] N. Mosey, T. Woo, M. Kasrai, P. Norton, G. Bancroft, and M. Müser, "Interpretation of experiments on ZDDP anti-wear films through pressure-induced cross-linking," Tribology Letters, vol. 24, pp. 105-114, Oct. 2006.

[19] M. M. Khonsari and E. R. Booser, Applied Tribology: Bearing Design and Lubrication. Tribology in Practice Series, Wiley, 2008.

[20] E. Höglund, "The relationship between lubricant shear strength and chemical composition of the base oil," Wear, vol. 130, no. 1, pp. 213-224, 1989.

[21] G. Stachowiak and A. W. Batchelor, Experimental Methods in Tribology. Tribology and Interface Engineering, Elsevier Science, 2004.

[22] P. Cann, "In-Contact Molecular Spectroscopy of Liquid Lubricant Films," MRS Bulletin, vol. 33, no. December, pp. 1151-1158, 2008.

[23] M. Lahtela, M. Linnolahti, T. a. Pakkanen, and R. L. Rowley, "Computer simulations of branched alkanes: The effect of side chain and its position on rheological behavior," The Journal of Chemical Physics, vol. 108, no. 6, p. 2626, 1998. 
[24] S. Bair, "The shear rheology of thin compressed liquid films," Proceedings of the Institution of Mechanical Engineers, Part J: Journal of Engineering Tribology, vol. 216, pp. 1-17, Jan. 2002.

[25] R. I. Taylor, "The inclusion of lubricant shear thinning in the short bearing approximation," Proceedings of the Institution of Mechanical Engineers, Part J: Journal of Engineering Tribology, vol. 213, pp. 35-46, Jan. 1999.

[26] L. Mikeska, "Chemical structure of lubricating oils," Industrial \& Engineering Chemistry, vol. 28, pp. 970-984, Aug. 1936.

[27] D. F. Calef, "Diffusion-Controlled Reactions," vol. 34, pp. 493-524, Oct. 1983.

[28] G. C. Ofunne, A. U. Maduako, and C. M. Ojinnaka, "High temperature oxidation stability of automotive crankcase oils and their base oils," Tribology International, vol. 23, no. 6, pp. 407-412, 1990.

[29] S. Blaine and P. E. Savage, "Reaction pathways in lubricant degradation. 2. nHexadecane autoxidation," Industrial \& engineering chemistry research, vol. 30, no. 9, pp. 2185-2191, 1991.

[30] G. Kaupp, "Mechanochemistry: the varied applications of mechanical bondbreaking," CrystEngComm, vol. 11, no. 3, pp. 388-403, 2009.

[31] A. A. M. Basedow, K. H. Ebert, and H. Hunger, "Effects of mechanical stress on the reactivity of polymers: Shear degradation of polyacrylamide and dextran," Die Makromolekulare Chemie, vol. 180, no. 2, pp. 411-427, 1979.

[32] K. Mackenzie and A. E. Jemmett, "Polymer shear stability," Wear, vol. 17, pp. 389-398, May 1971.

[33] L. G. Wood, "The Change of Viscosity of Oils containing High Polymers when Subjected to High Rates of Shear," British Journal of Applied Physics, vol. 1, pp. 202-206, Aug. 1950.

[34] R. E. Harrington and B. H. Zimm, "Degradation of Polymers by Controlled Hydrodynamic Shear," The Journal of Physical Chemistry, vol. 69, no. 1, pp. 161$175,1965$.

[35] M. Jia, M. Xie, H. Liu, W.-H. Lam, and T. Wang, "Numerical simulation of cavitation in the conical-spray nozzle for diesel premixed charge compression ignition engines," Fuel, vol. 90, pp. 2652-2661, Aug. 2011. 
[36] R. Schnurmann and R. S. Johnson, "Poiseuille Flow in Jet Viscometer Orifices," Proceedings of the Royal Society A: Mathematical, Physical and Engineering Sciences, vol. 303, pp. 429-451, Mar. 1968.

[37] D. P. Schmidt and M. L. Corradini, "The internal flow of diesel fuel injector nozzles: a review," International Journal of Engine Research, vol. 2, no. 1, pp. 1$22,2005$.

[38] M. Gavaises, S. Tonini, a. Marchi, a. Theodorakakos, D. Bouris, and L. Matteucci, "Modelling of internal and near-nozzle flow of a pintle-type outwardsopening gasoline piezo-injector," International Journal of Engine Research, vol. 7, no. 5, pp. 381-397, 2006.

[39] M. M. Karakolis, "Experimental analysis of the fuel injection system of the ignition quality tester (IQT)," MASc thesis, 2009.

[40] A. American and N. Standard, "Standard Test Method for Shear Stability of Polymer Containing Fluids Using a European Diesel Injector Apparatus 1," vol. 05, pp. 1-9, 2002.

[41] F. White, Viscous Fluid Flow. McGraw-Hill international edition, McGraw-Hill Education, 2005. 


\section{Appendix A}

\section{Manufacturing Drawings}

Note that all the dimensions shown on the next drawings are in inches. 


\section{A.1 Atomization Chamber}

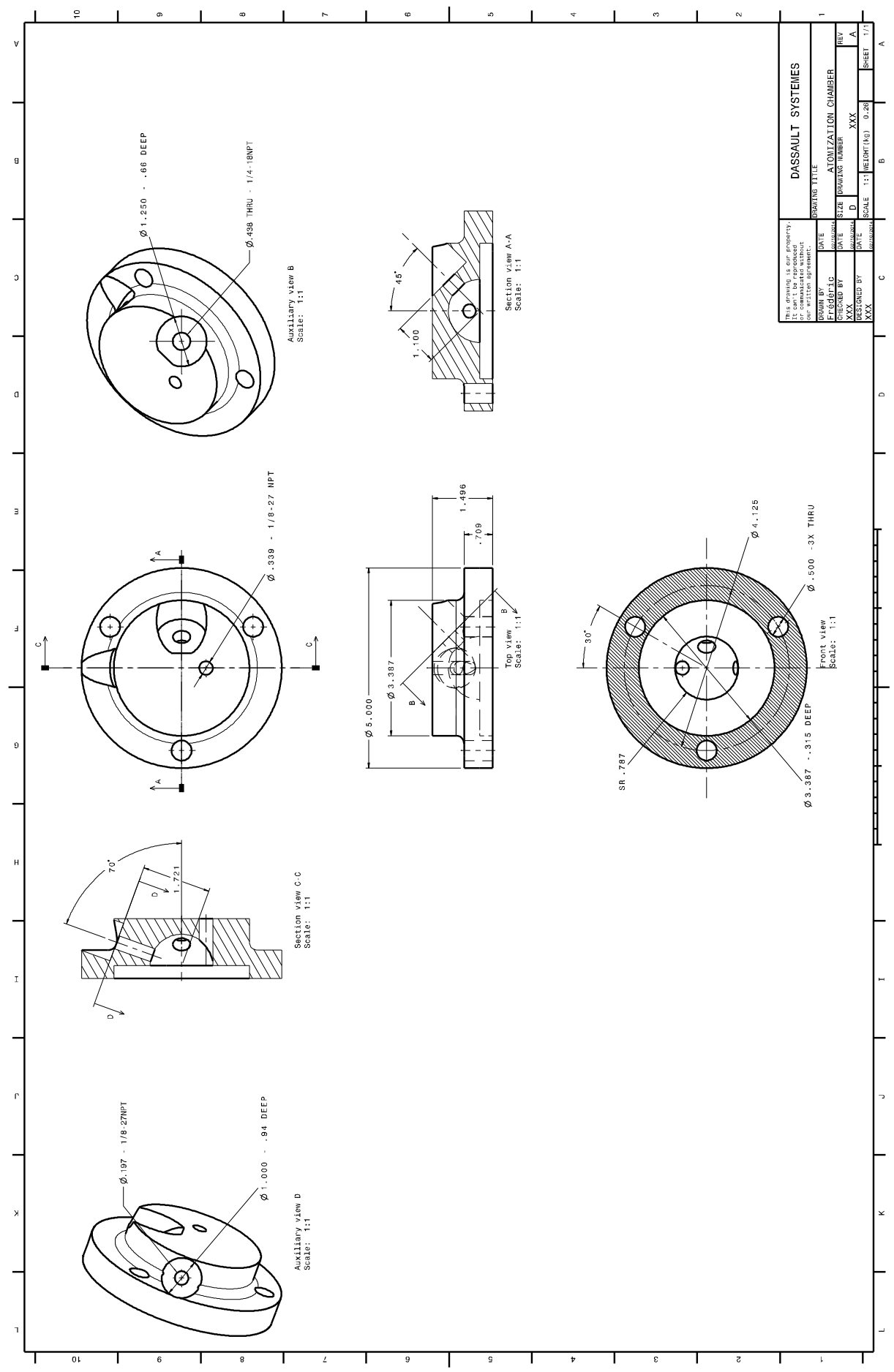




\section{A.2 Injector Rig Mobile Table}

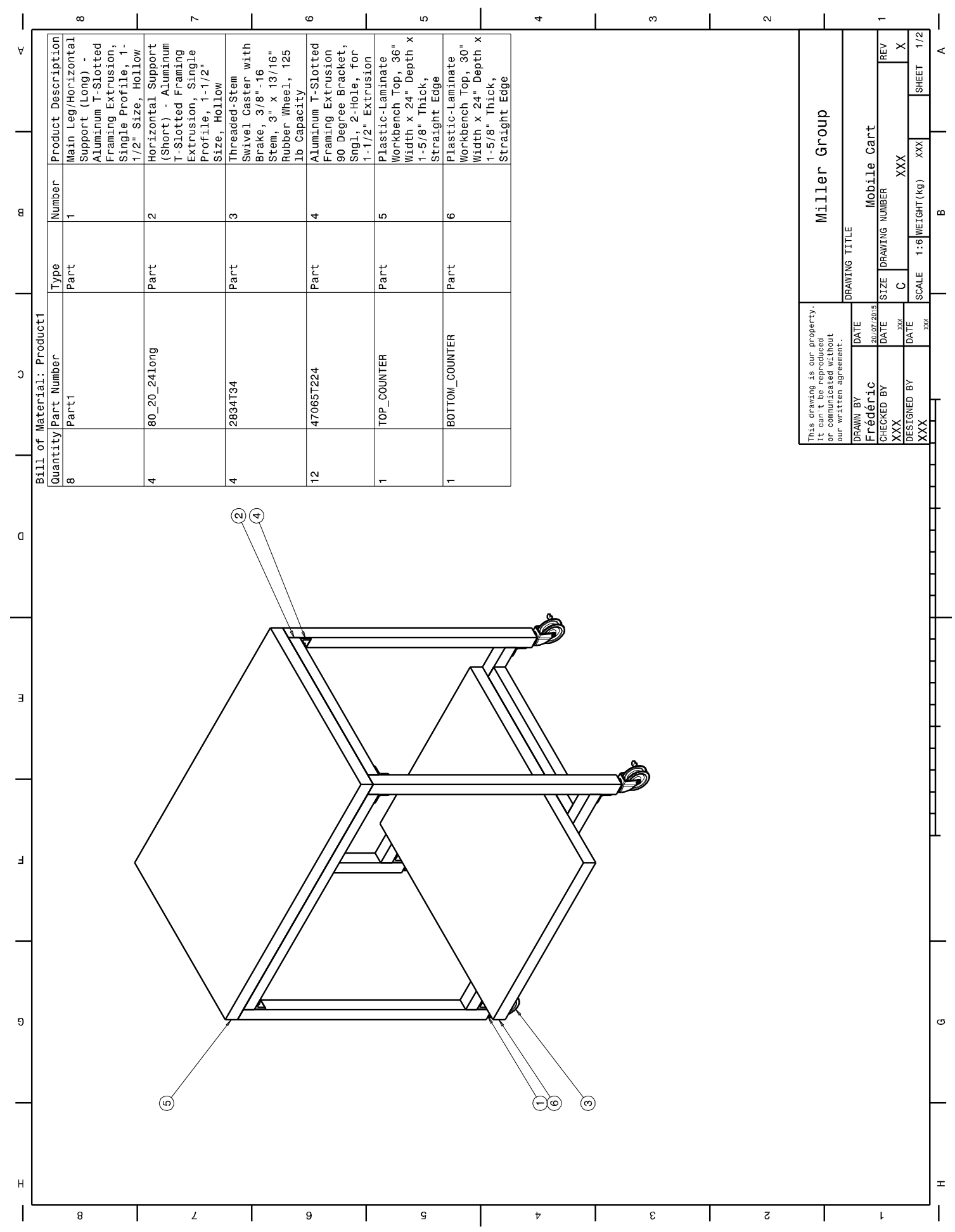




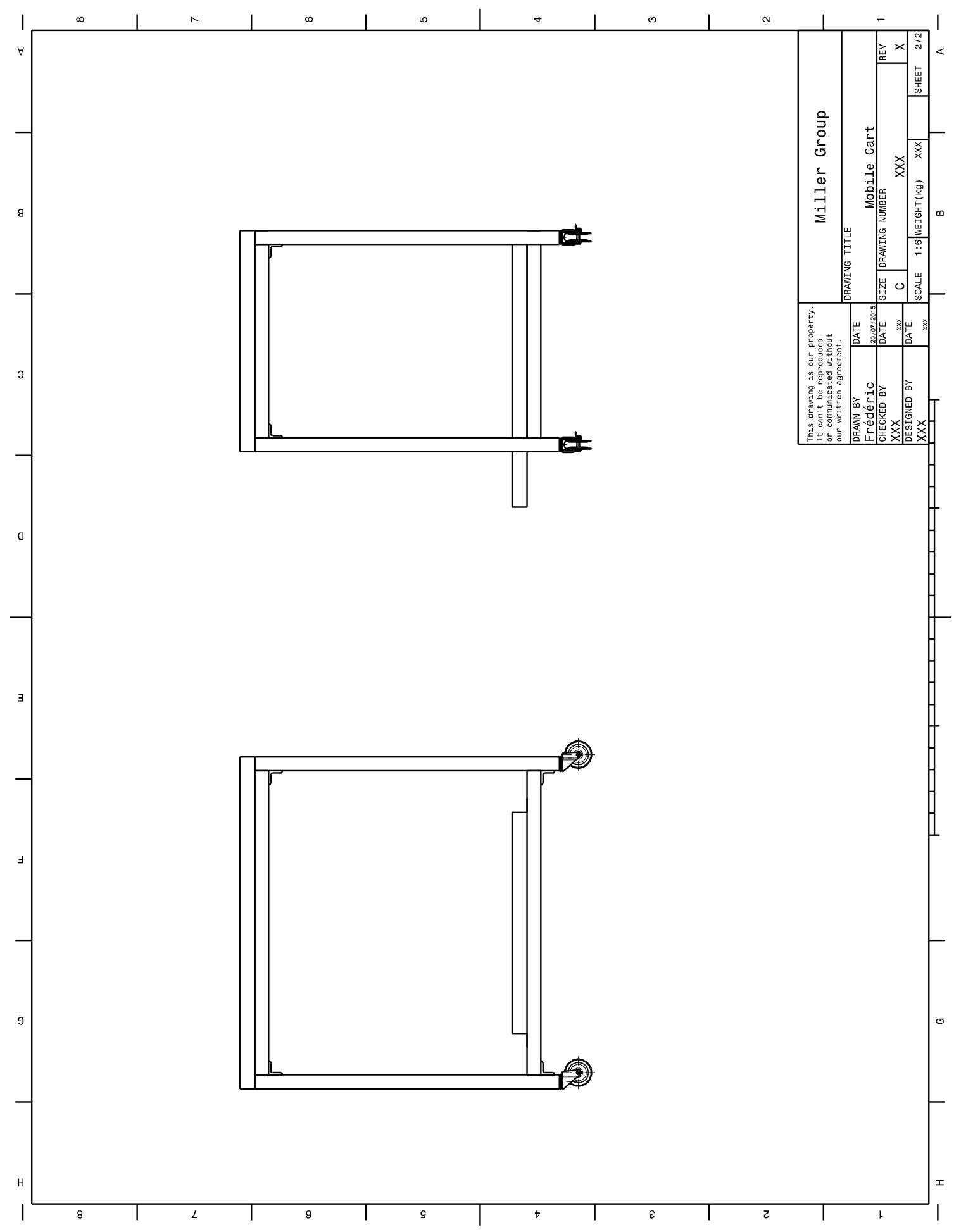




\section{Appendix B}

\section{Experimental Data}

This section presents the viscosity and shear stress data for the oxidized and oxidized/sheared lubricating oil samples, the average rheometry testing temperatures of each sample and the least squares curve fit of both mineral oil viscosity standards, RTM10 and RTM19. 


\section{B.1 Viscosity and Shear Stress Data}

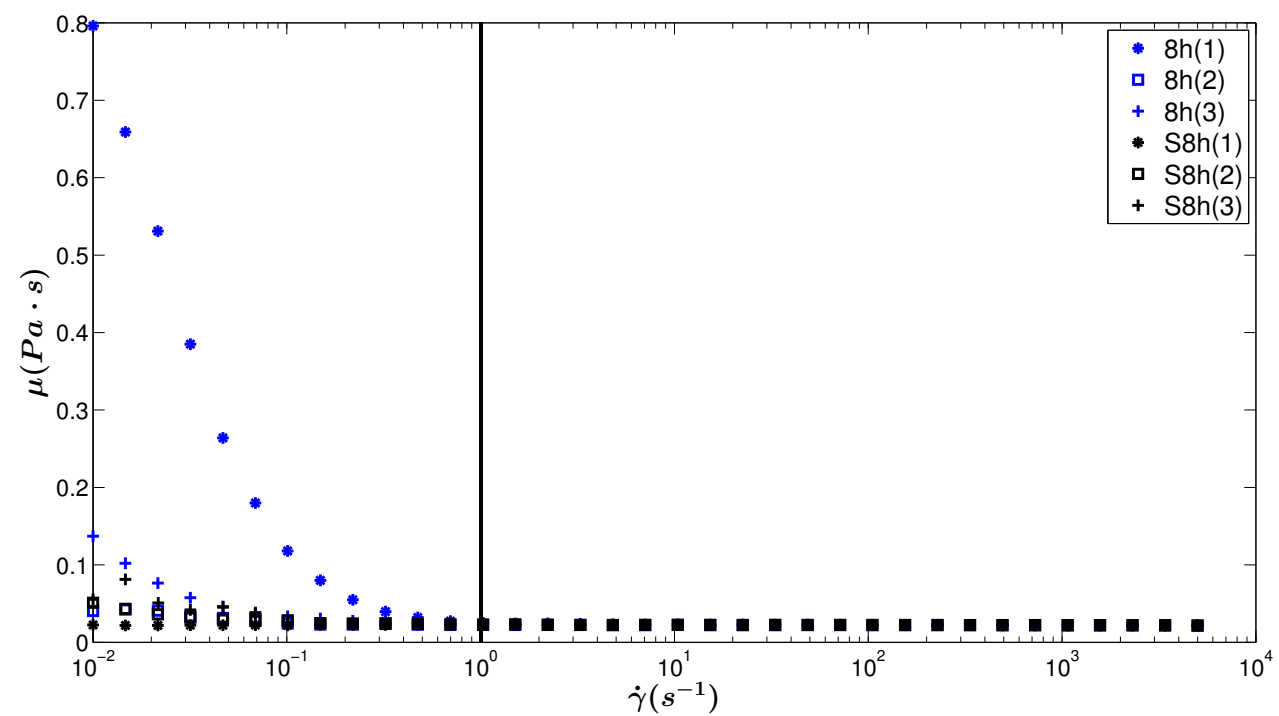

(a) Viscosity vs. shear strain rate

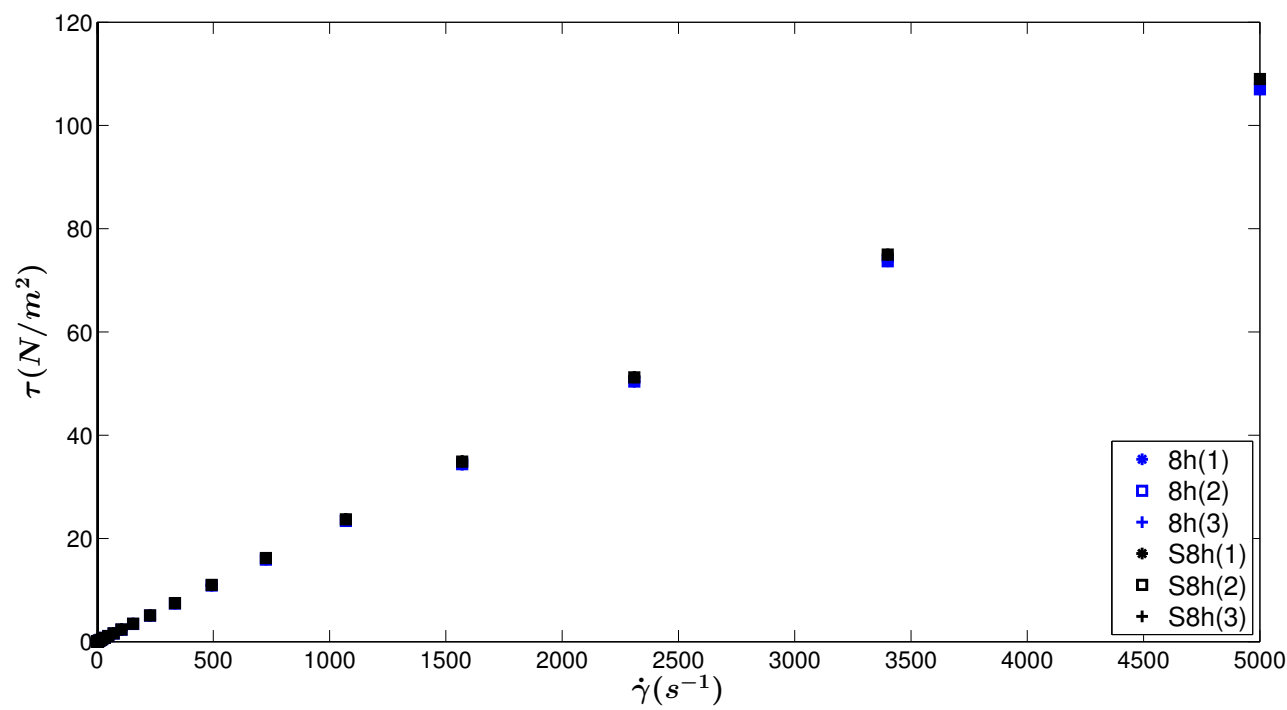

(b) Shear Stress vs. shear strain rate

Figure B.1: Viscosity and shear stress data plotted against the shear strain rate for oxidized and oxidized \& sheared samples after 8 hours of oxidization. 


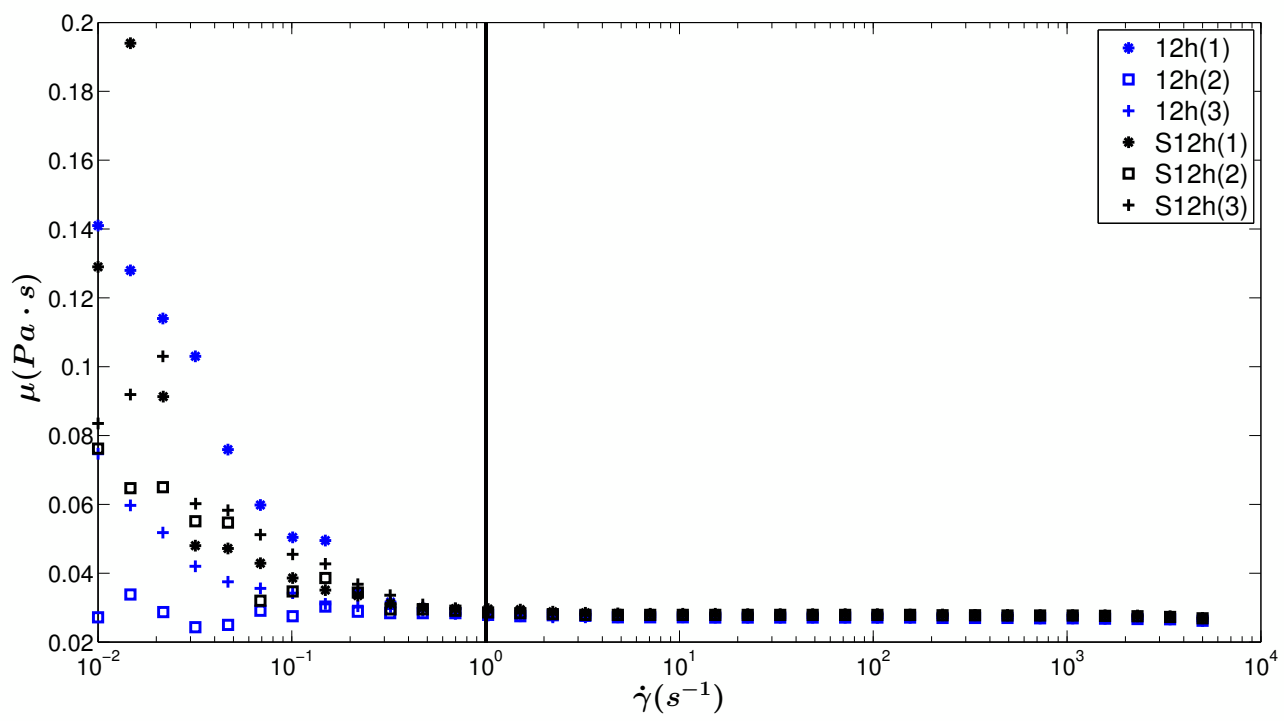

(a) Viscosity vs. shear strain rate

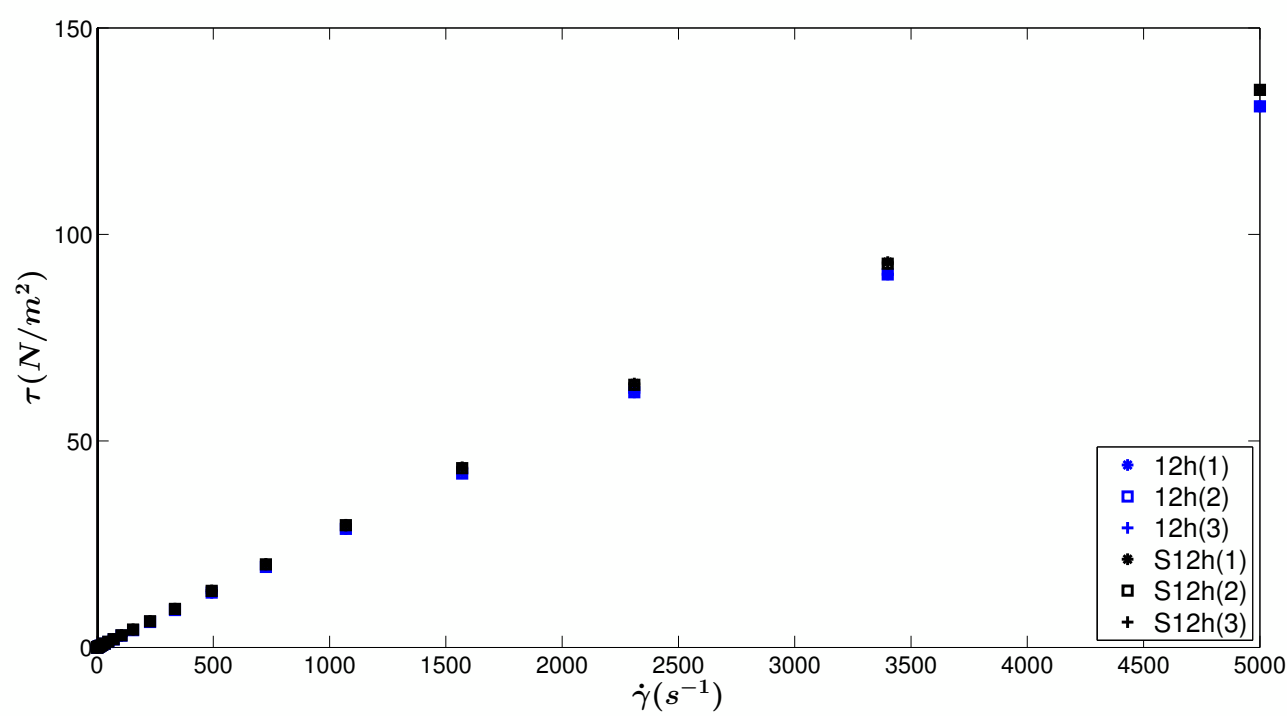

(b) Shear Stress vs. shear strain rate

Figure B.2: Viscosity and shear stress data plotted against the shear strain rate for oxidized and oxidized \& sheared samples after 12 hours of oxidization. 


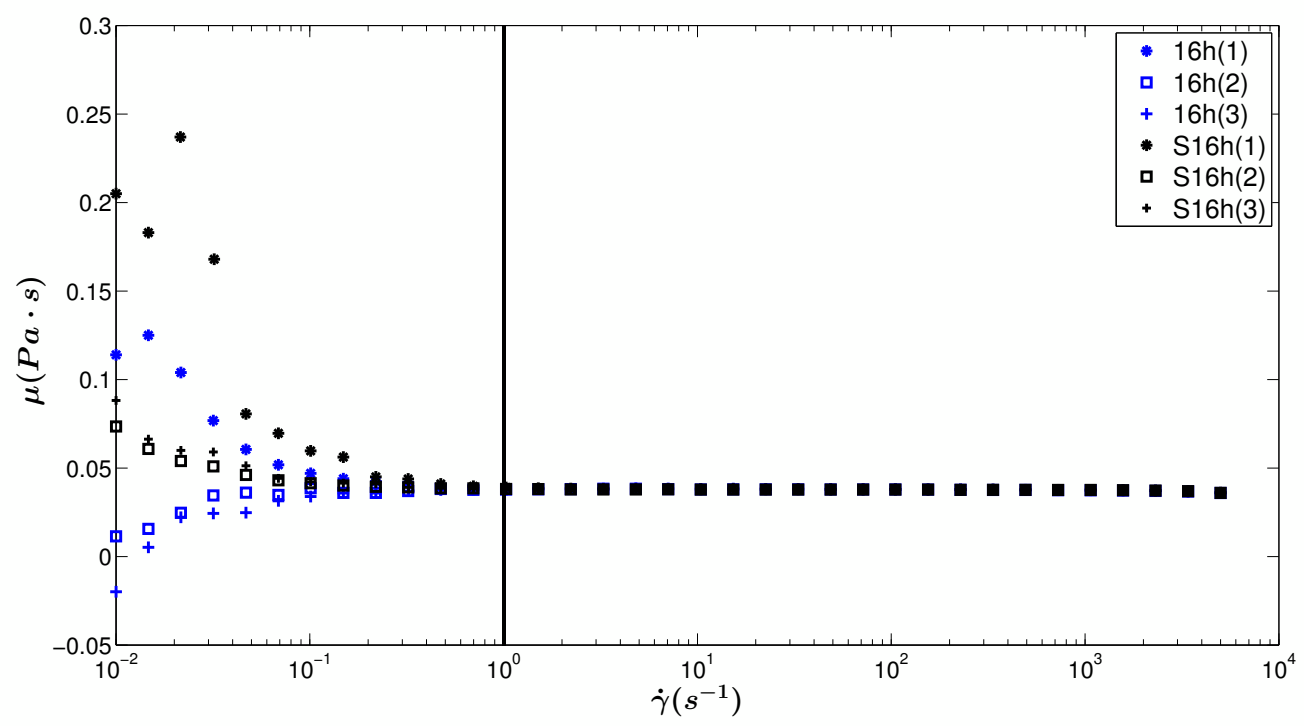

(a) Viscosity vs. shear strain rate

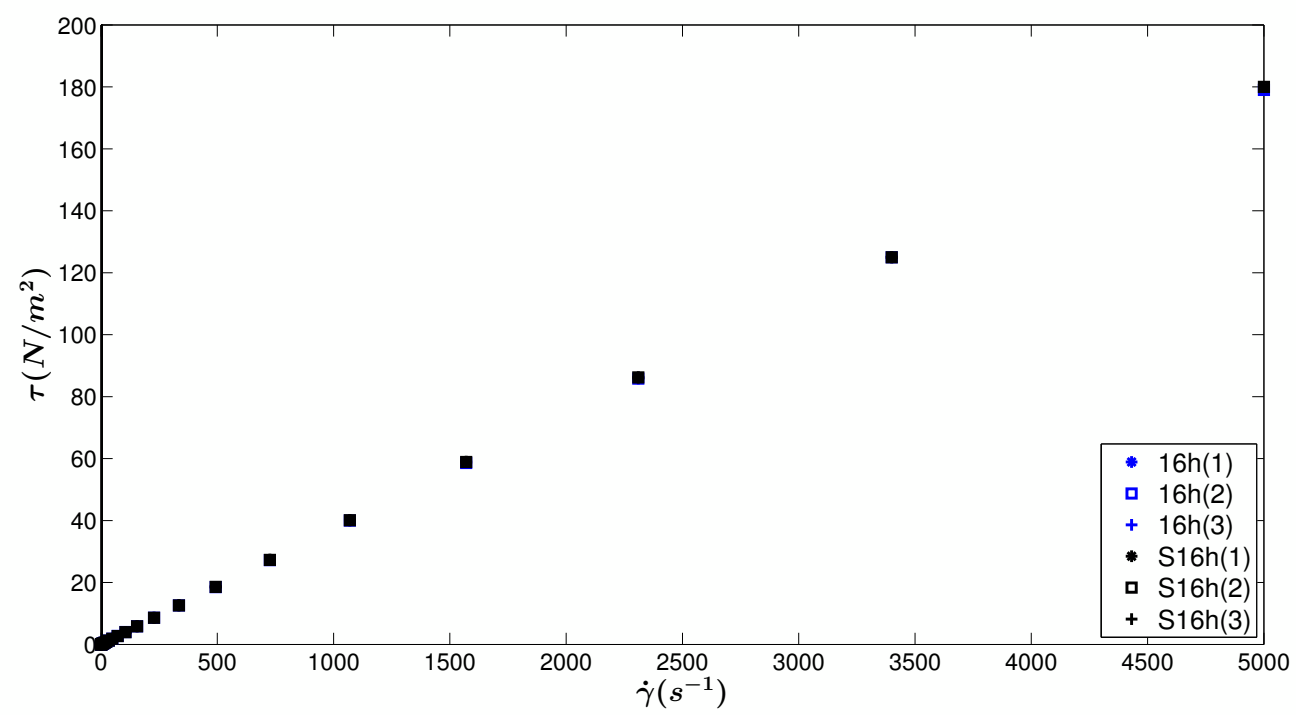

(b) Shear Stress vs. shear strain rate

Figure B.3: Viscosity and shear stress data plotted against the shear strain rate for oxidized and oxidized \& sheared samples after 16 hours of oxidization. 


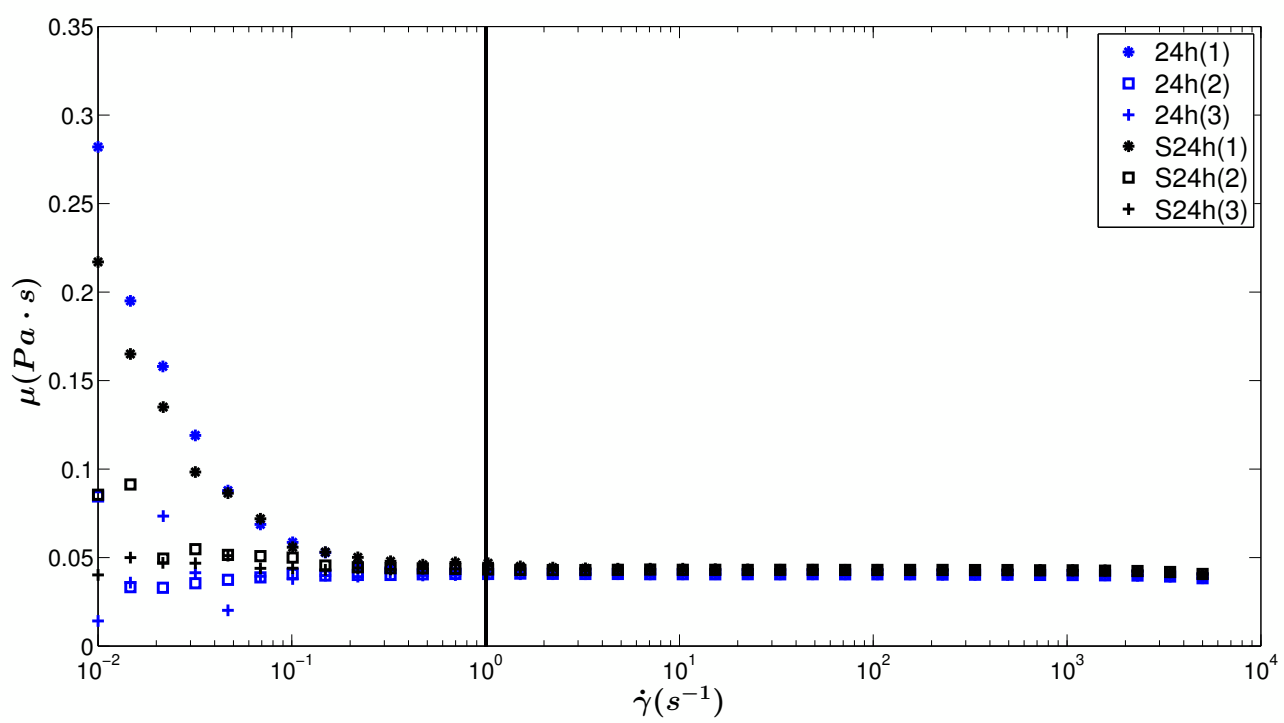

(a) Viscosity vs. shear strain rate

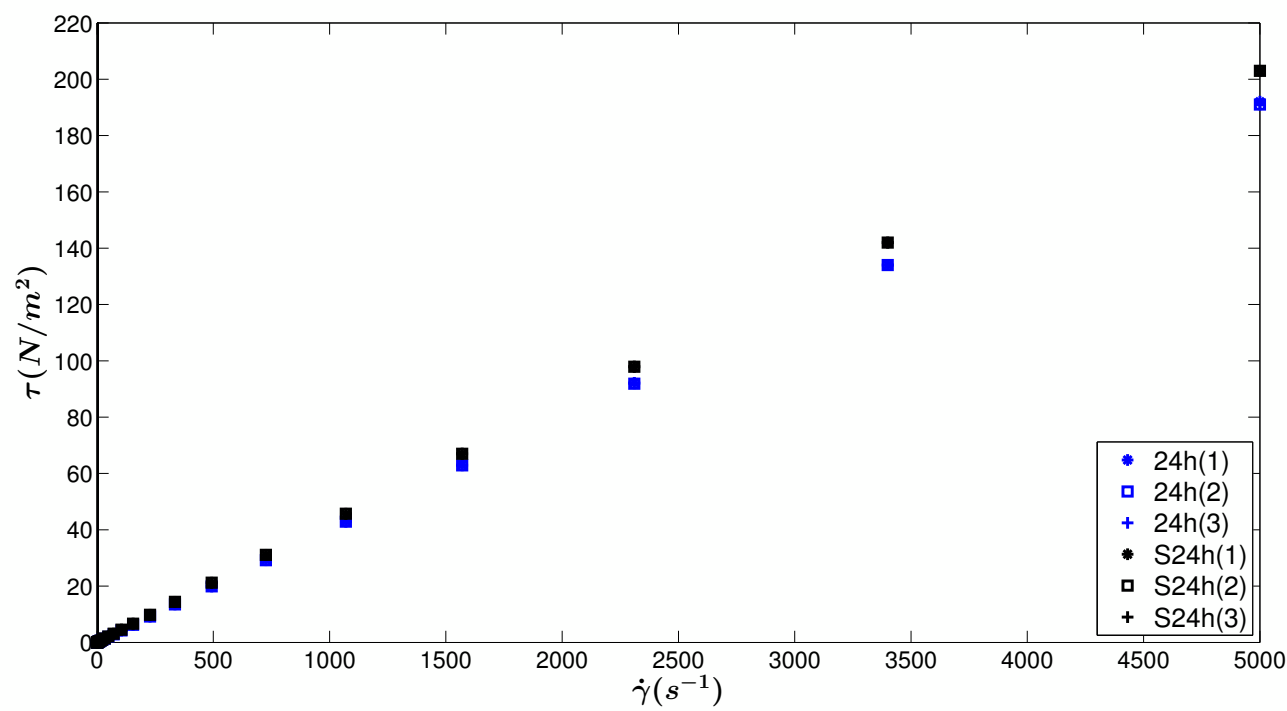

(b) Shear Stress vs. shear strain rate

Figure B.4: Viscosity and shear stress data plotted against the shear strain rate for oxidized and oxidized \& sheared samples after 24 hours of oxidization. 


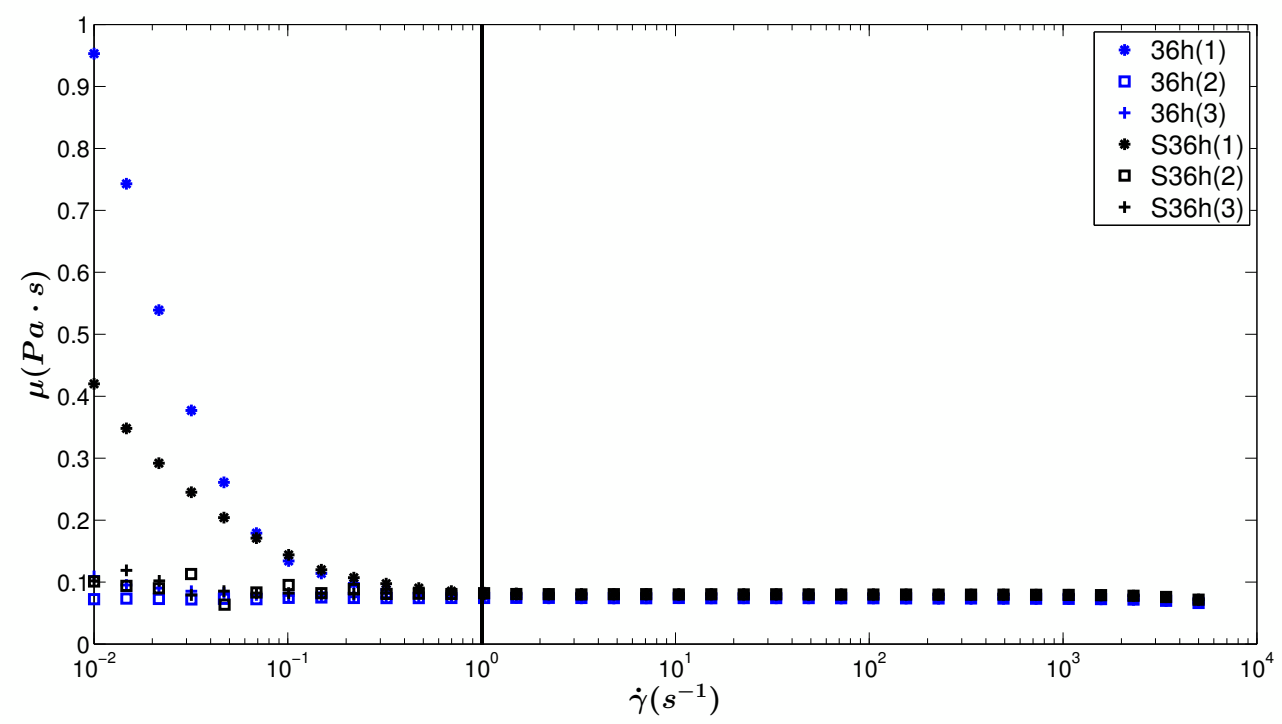

(a) Viscosity vs. shear strain rate

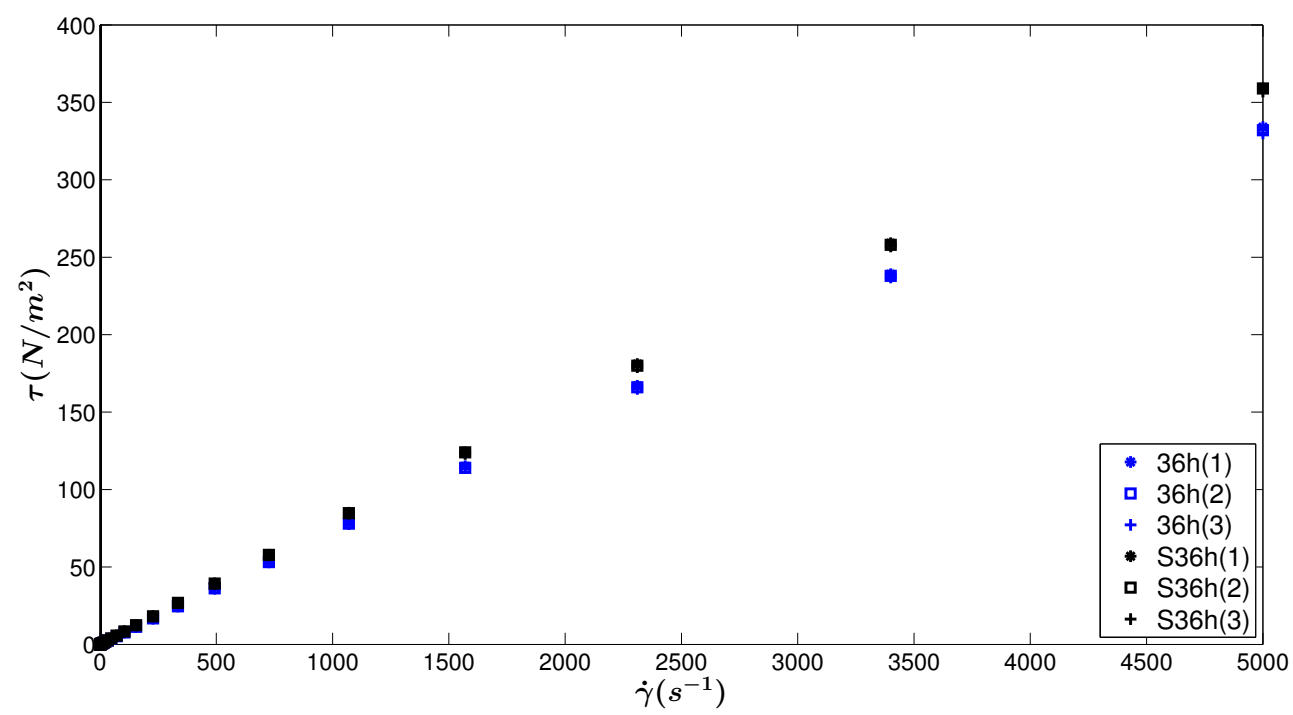

(b) Shear Stress vs. shear strain rate

Figure B.5: Viscosity and shear stress data plotted against the shear strain rate for oxidized and oxidized \& sheared samples after 36 hours of oxidization. 


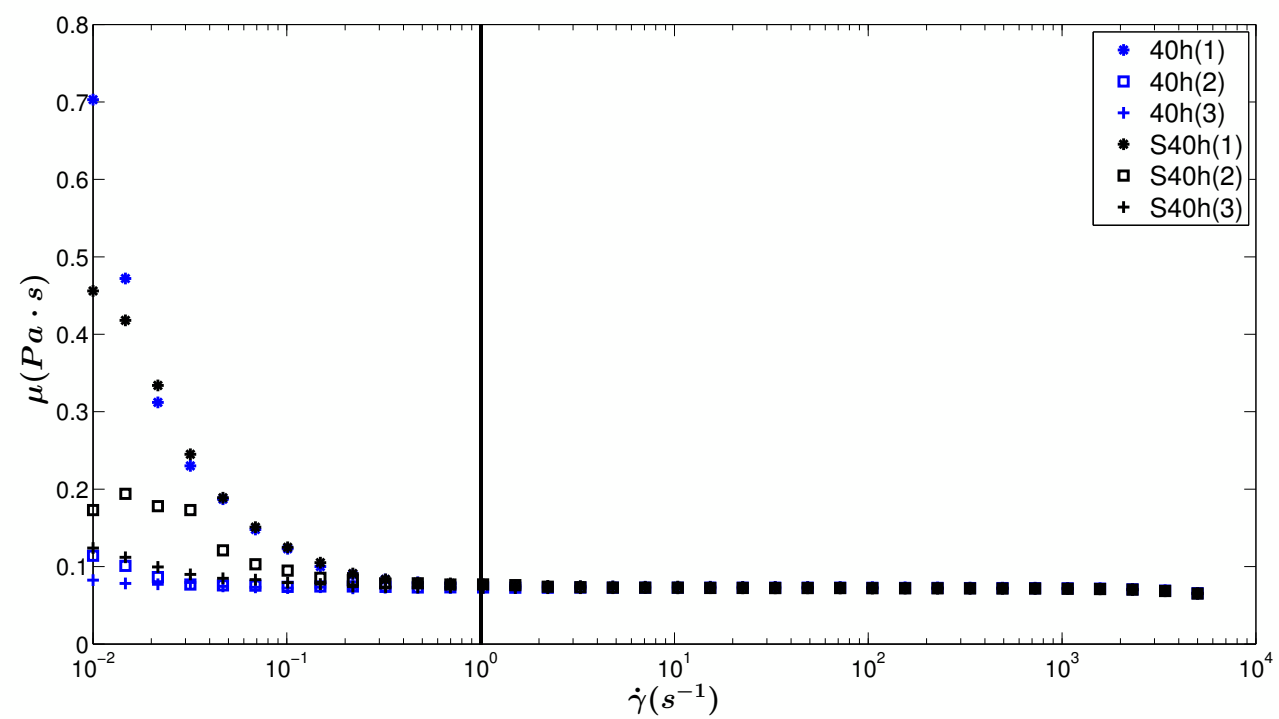

(a) Viscosity vs. shear strain rate

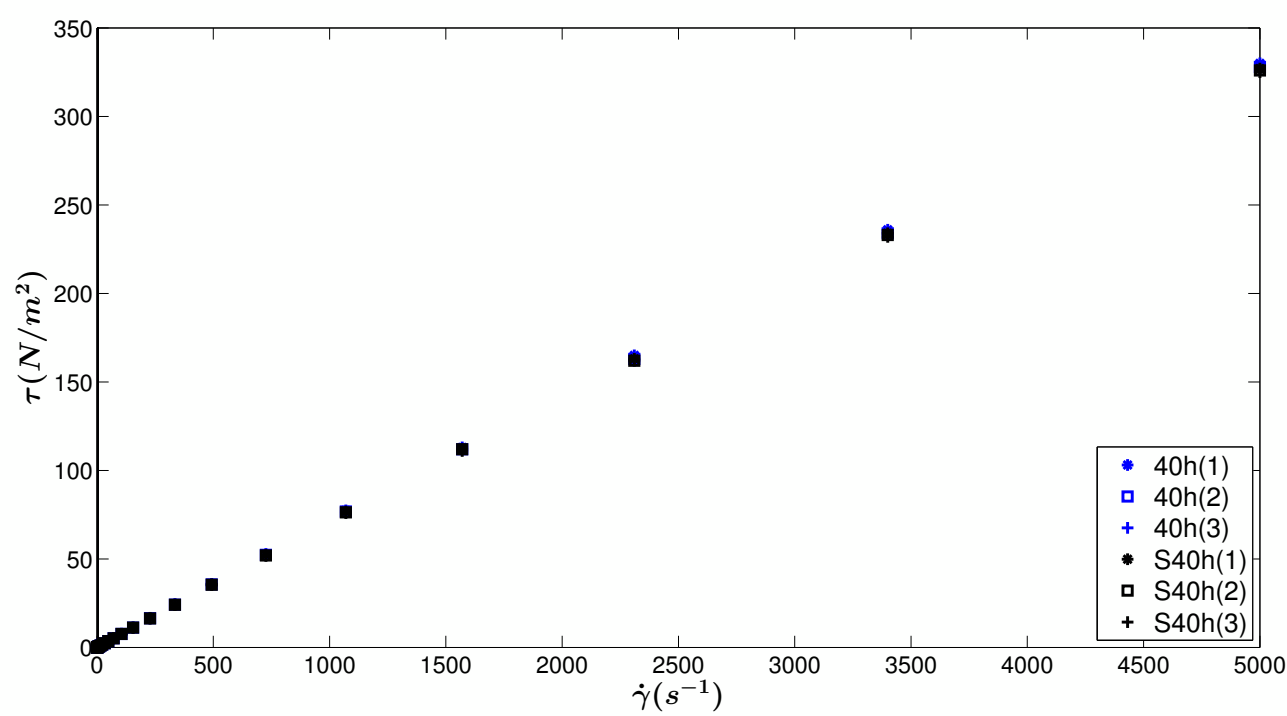

(b) Shear Stress vs. shear strain rate

Figure B.6: Viscosity and shear stress data plotted against the shear strain rate for oxidized and oxidized \& sheared samples after 40 hours of oxidization. 


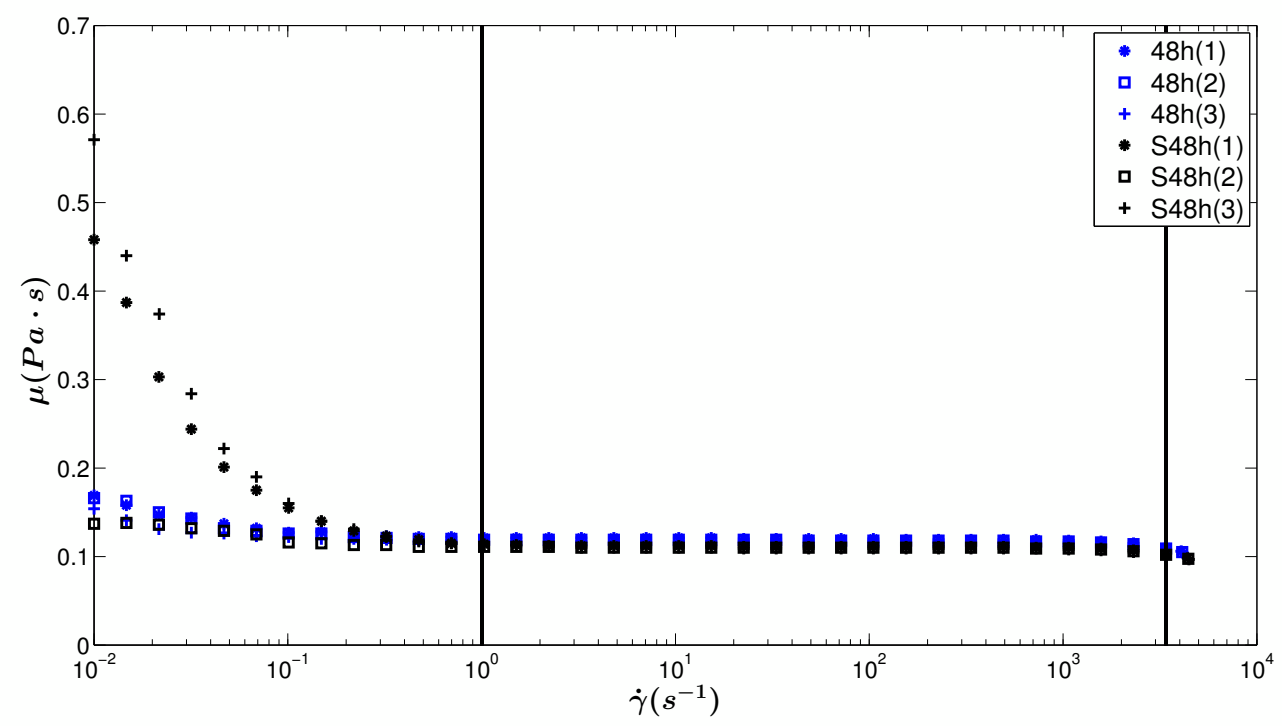

(a) Viscosity vs. shear strain rate

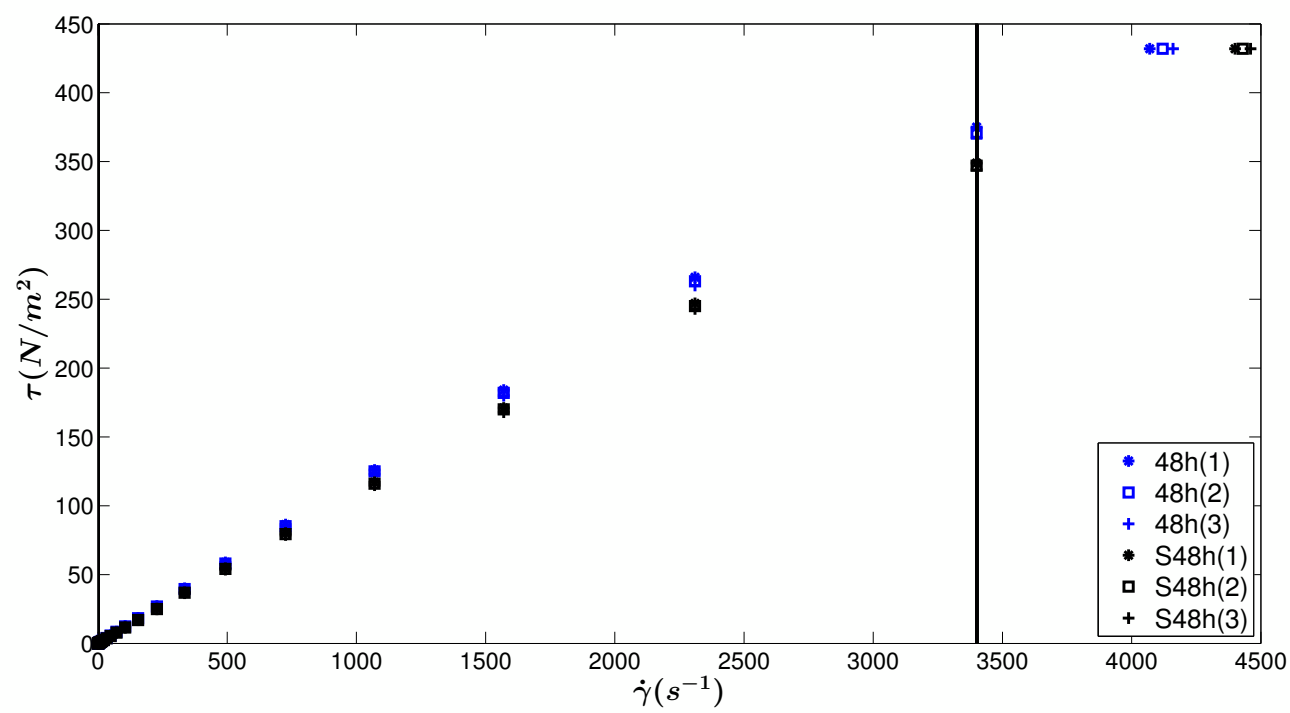

(b) Shear Stress vs. shear strain rate

Figure B.7: Viscosity and shear stress data plotted against the shear strain rate for oxidized and oxidized \& sheared samples after 48 hours of oxidization. 


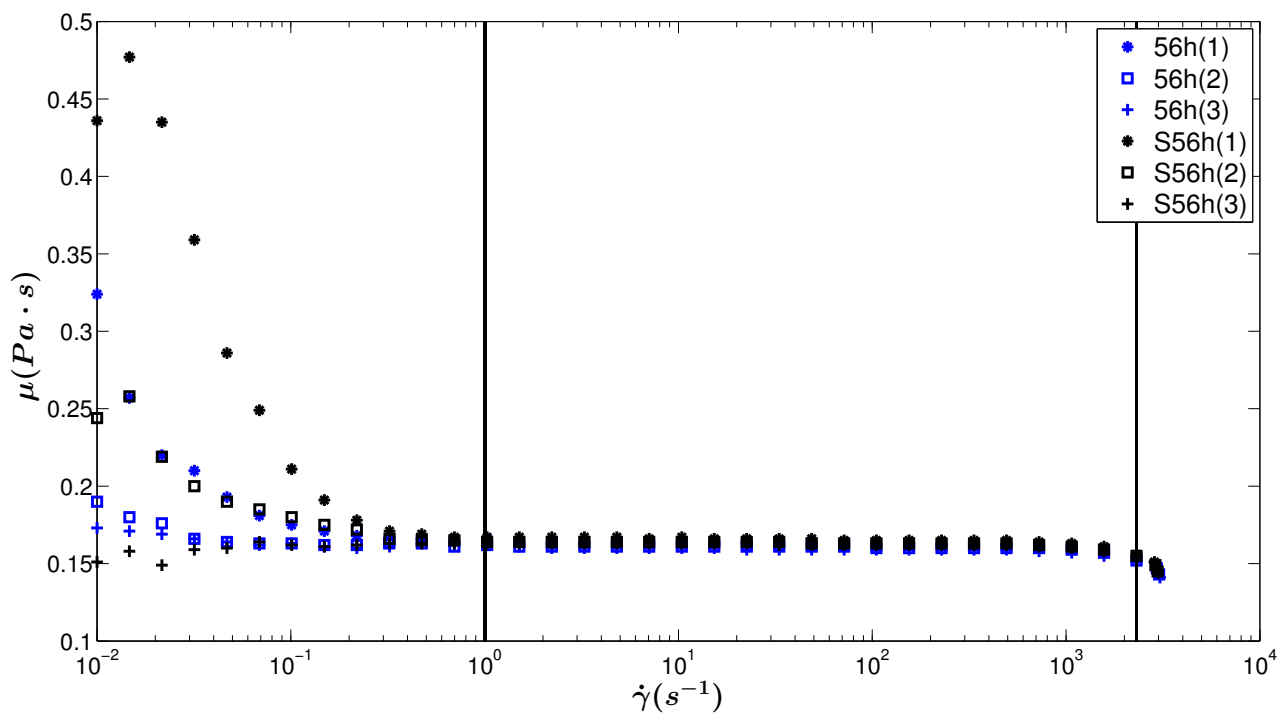

(a) Viscosity vs. shear strain rate

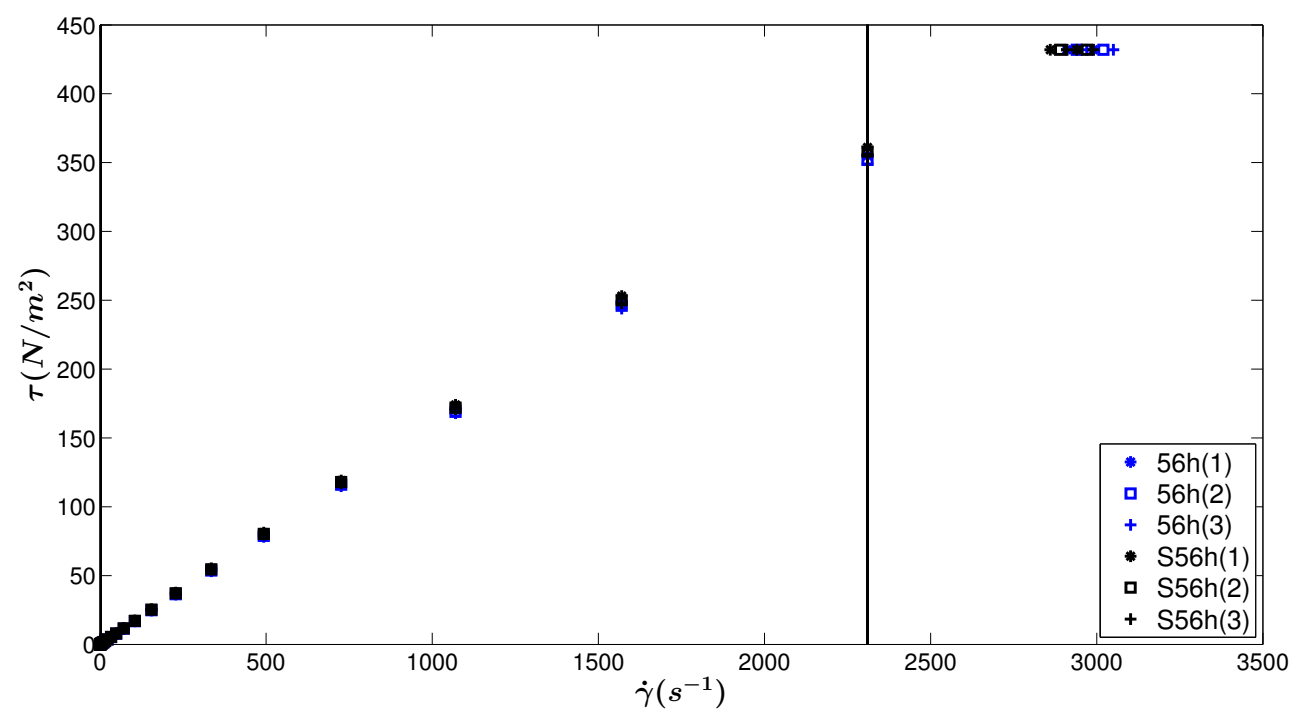

(b) Shear Stress vs. shear strain rate

Figure B.8: Viscosity and shear stress data plotted against the shear strain rate for oxidized and oxidized \& sheared samples after 56 hours of oxidization. 


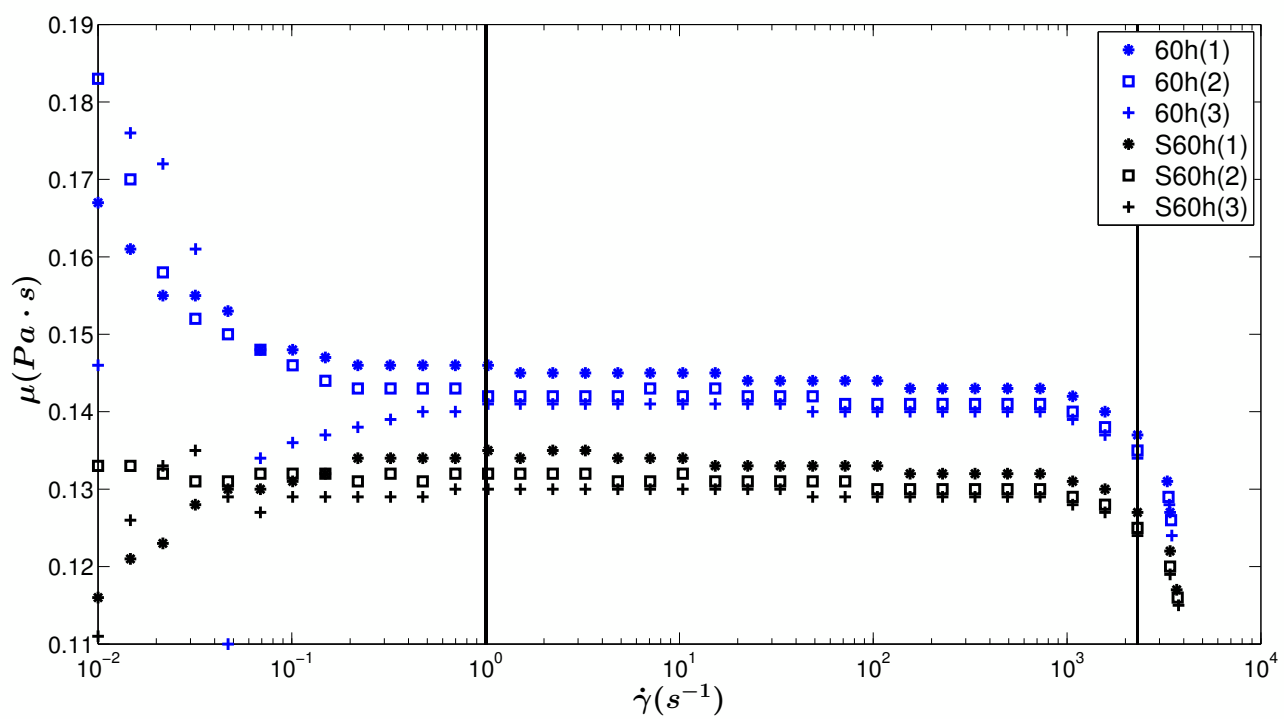

(a) Viscosity vs. shear strain rate

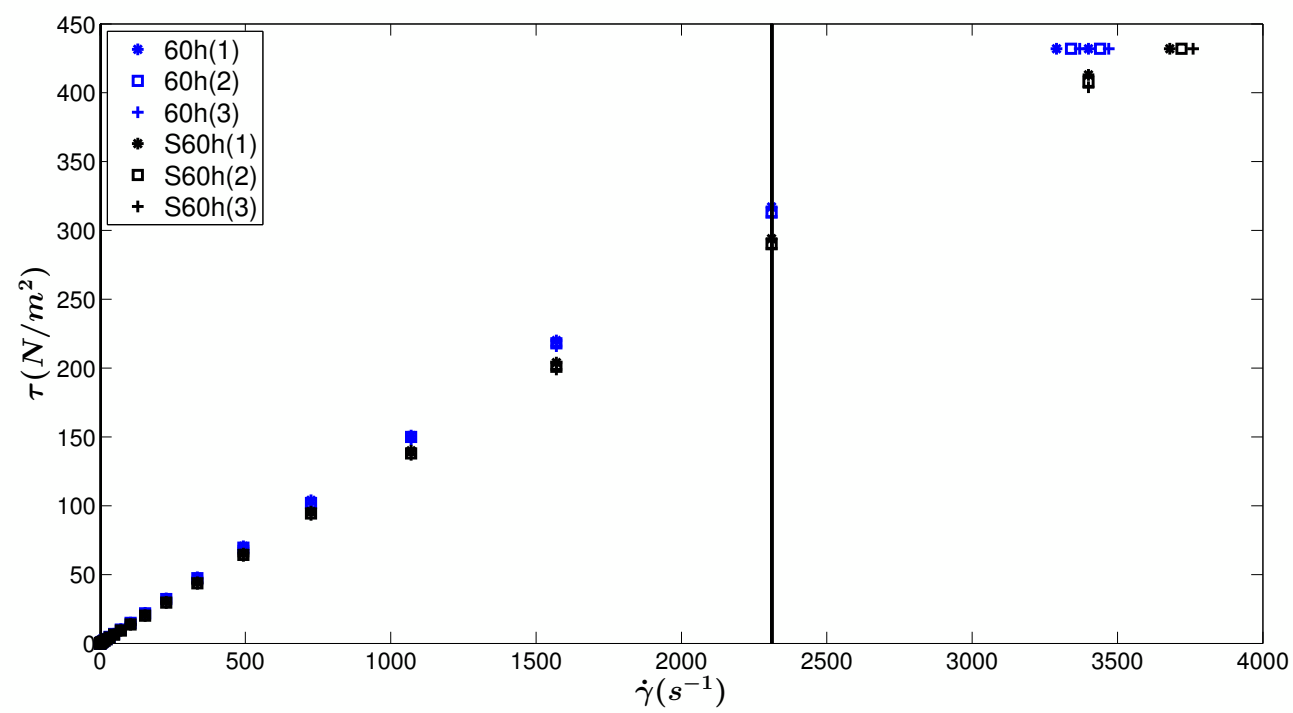

(b) Shear Stress vs. shear strain rate

Figure B.9: Viscosity and shear stress data plotted against the shear strain rate for oxidized and oxidized \& sheared samples after 60 hours of oxidization. 


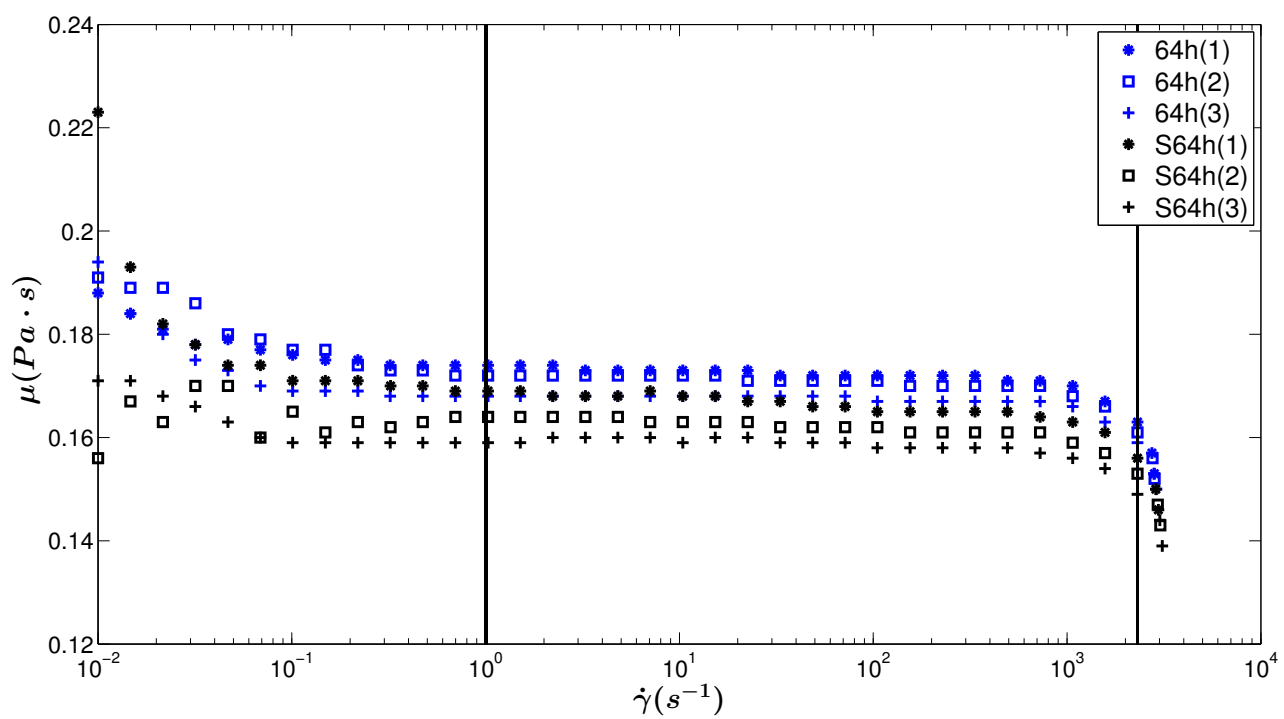

(a) Viscosity vs. shear strain rate

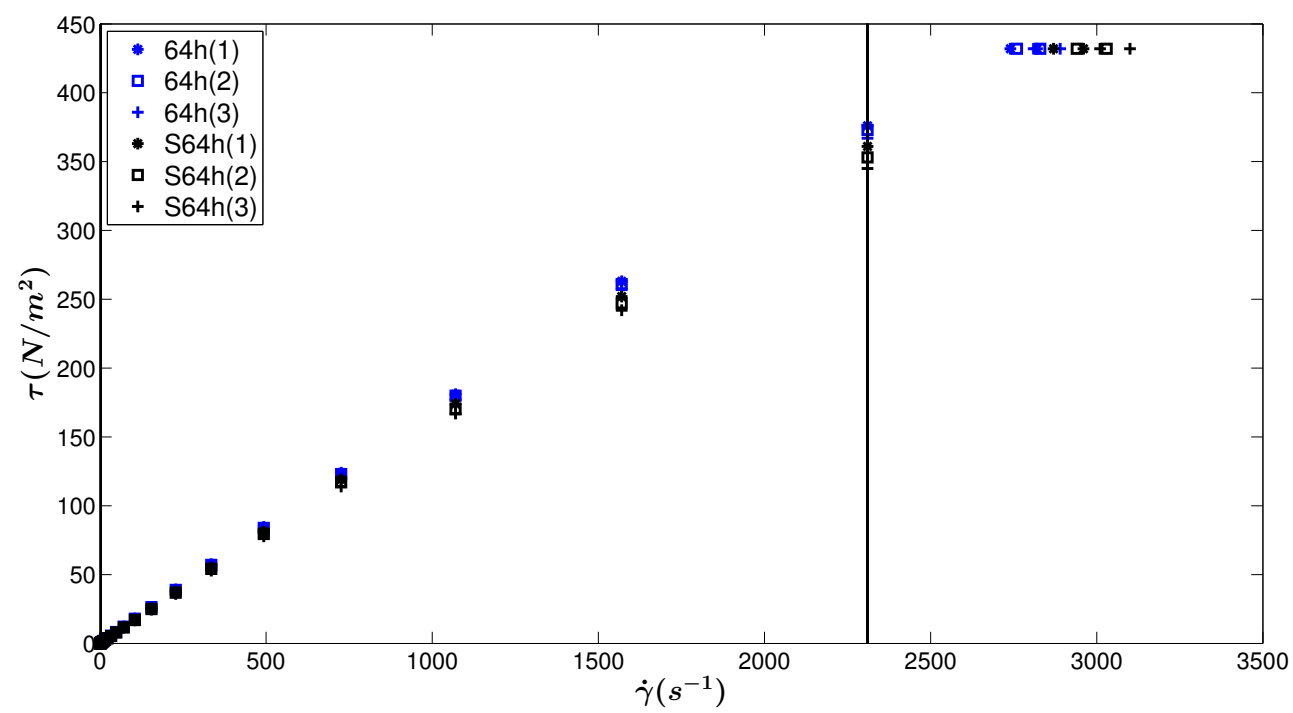

(b) Shear Stress vs. shear strain rate

Figure B.10: Viscosity and shear stress data plotted against the shear strain rate for oxidized and oxidized \& sheared samples after 64 hours of oxidization. 


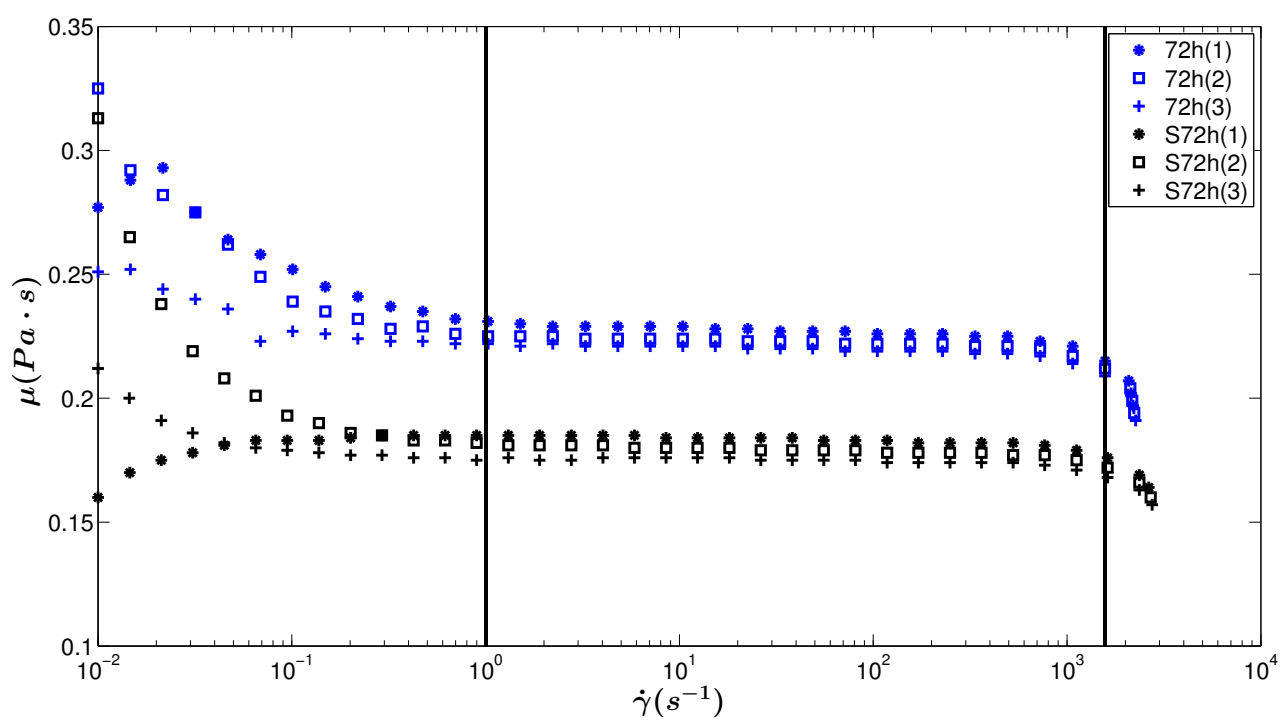

(a) Viscosity vs. shear strain rate

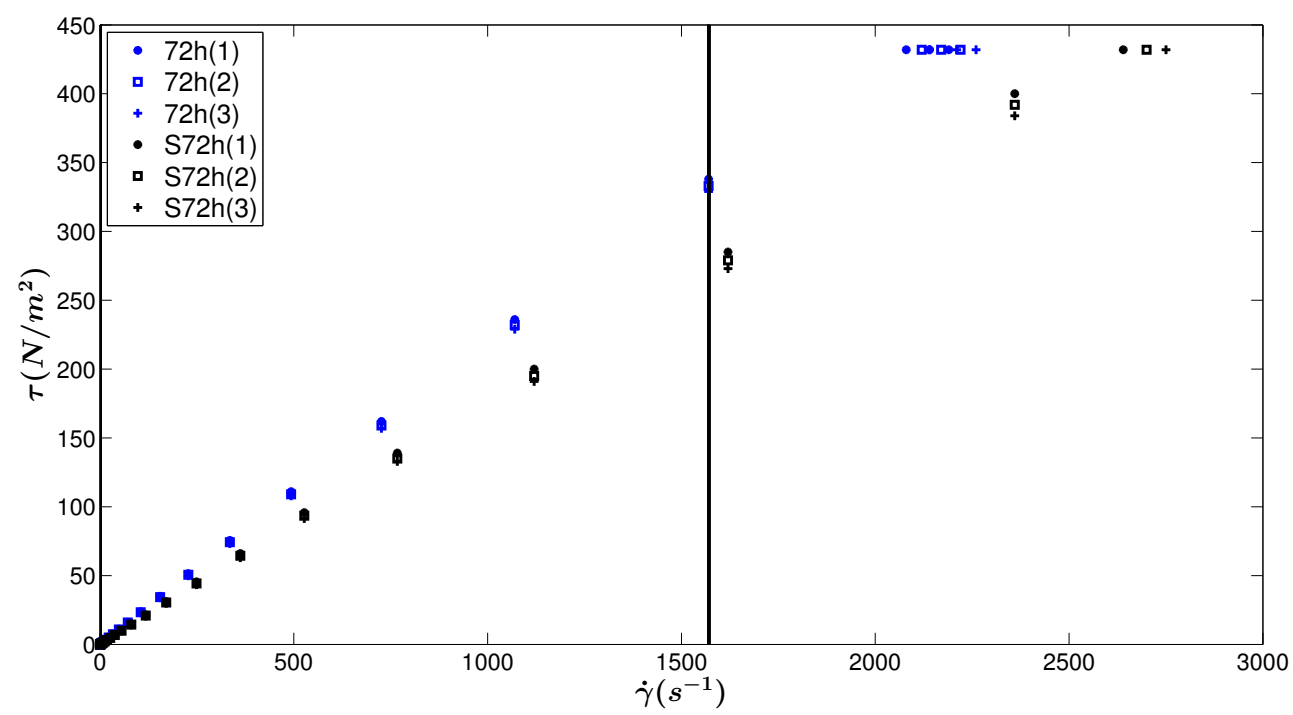

(b) Shear Stress vs. shear strain rate

Figure B.11: Viscosity and shear stress data plotted against the shear strain rate for oxidized and oxidized \& sheared samples after 72 hours of oxidization. 


\section{B.2 Rheometry Testing Temperatures}

Table B.1: Average starting and final temperatures of each viscosity tests.

\begin{tabular}{|c|c|c|}
\hline Sample & Starting Temperature, $\mathrm{T}_{s}\left({ }^{\circ} \mathrm{C}\right)$ & Final Temperature, $\mathrm{T}_{f}\left({ }^{\circ} \mathrm{C}\right)$ \\
\hline MO_8h & 29.19 & 29.2 \\
\hline MO_SH_8h & 29 & 29.05 \\
\hline MO_12h & 29.52 & 29.55 \\
\hline MO_SH_12h & 29.31 & 29.35 \\
\hline MO_16h & 29.7 & 29.76 \\
\hline MO_SH_16h & 29.62 & 29.70 \\
\hline MO_24h & 30.09 & 30.17 \\
\hline MO_SH_24h & 29.88 & 29.93 \\
\hline MO_36h & 30.37 & 30.6 \\
\hline MO_SH_36h & 30.2 & 30.34 \\
\hline MO_40h & 30.3 & 30.47 \\
\hline MO_SH_40h & 30.3 & 30.48 \\
\hline MO_48h & 30.71 & 30.92 \\
\hline MO_SH_48h & 30.77 & 31.04 \\
\hline MO_56h & 30.66 & 30.91 \\
\hline MO_SH_56h & 30.31 & 30.65 \\
\hline MO_60h & 30.66 & 30.91 \\
\hline MO_SH_60h & 30.5 & 30.81 \\
\hline MO_64h & 29.42 & 29.67 \\
\hline MO_SH_64h & 29.8 & 30.25 \\
\hline MO_72h & 28.94 & 29.3 \\
\hline MO_SH_72h & 28.64 & 29.17 \\
\hline
\end{tabular}




\section{Appendix $\mathrm{C}$}

\section{Derivation of Equation 3.2}

Obtaining the shear strain rate in an incompressible Poiseuille annular flow requires the derivation of the equation [41] describing the velocity, $u(r)$ through an annular section with respect to the radial distance, $r$ :

$$
\frac{d u(r)}{d r}=\frac{d\left(\frac{1}{4 \mu} \frac{-d \hat{p}}{d x}\left[a^{2}-r^{2}+\left(a^{2}-b^{2}\right) \frac{\ln (a / r)}{\ln (b / a)}\right]\right)}{d r} .
$$

The pressure gradient, $d \hat{p} / d x$ and the viscosity, $\mu$ are constants and can be excluded

from the term needing differentiation on the right-hand side. The differentiation then reduces to

$$
\frac{d u(r)}{d r}=\frac{1}{4 \mu} \frac{-d \hat{p}}{d x} \frac{d\left[a^{2}-r^{2}+\left(a^{2}-b^{2}\right) \frac{\ln (a / r)}{\ln (b / a)}\right]}{d r} .
$$

After applying the power rule, product rule and quotient rule of derivation, we obtain

$$
\frac{d u(r)}{d r}=\frac{1}{4 \mu} \frac{-d \hat{p}}{d x}\left(-2 r+\left[\left(a^{2}-b^{2}\right)\left[\frac{\ln (b / a)(-1 / r)}{\ln (b / a)^{2}}\right]\right]\right) .
$$

Further rearranging, the equation for shear strain rate reduces to:

$$
\frac{d u(r)}{d r}=\frac{1}{4 \mu} \frac{-d \hat{p}}{d x}\left[-2 r-\frac{1}{r} \frac{\left(a^{2}-b^{2}\right)}{\ln (b / a)}\right]
$$




\section{Appendix D}

\section{Measurement System}

The measurement system used on the Anton-Paar, Physica MCR-301 is the DG42/Q1, a concentric double-gap cylinder. All of the measurements were made according to the equations and parameter list indicated through Anton-Paar's proprietary Rheoplus software. 


\section{D.1 DG42/Q1}

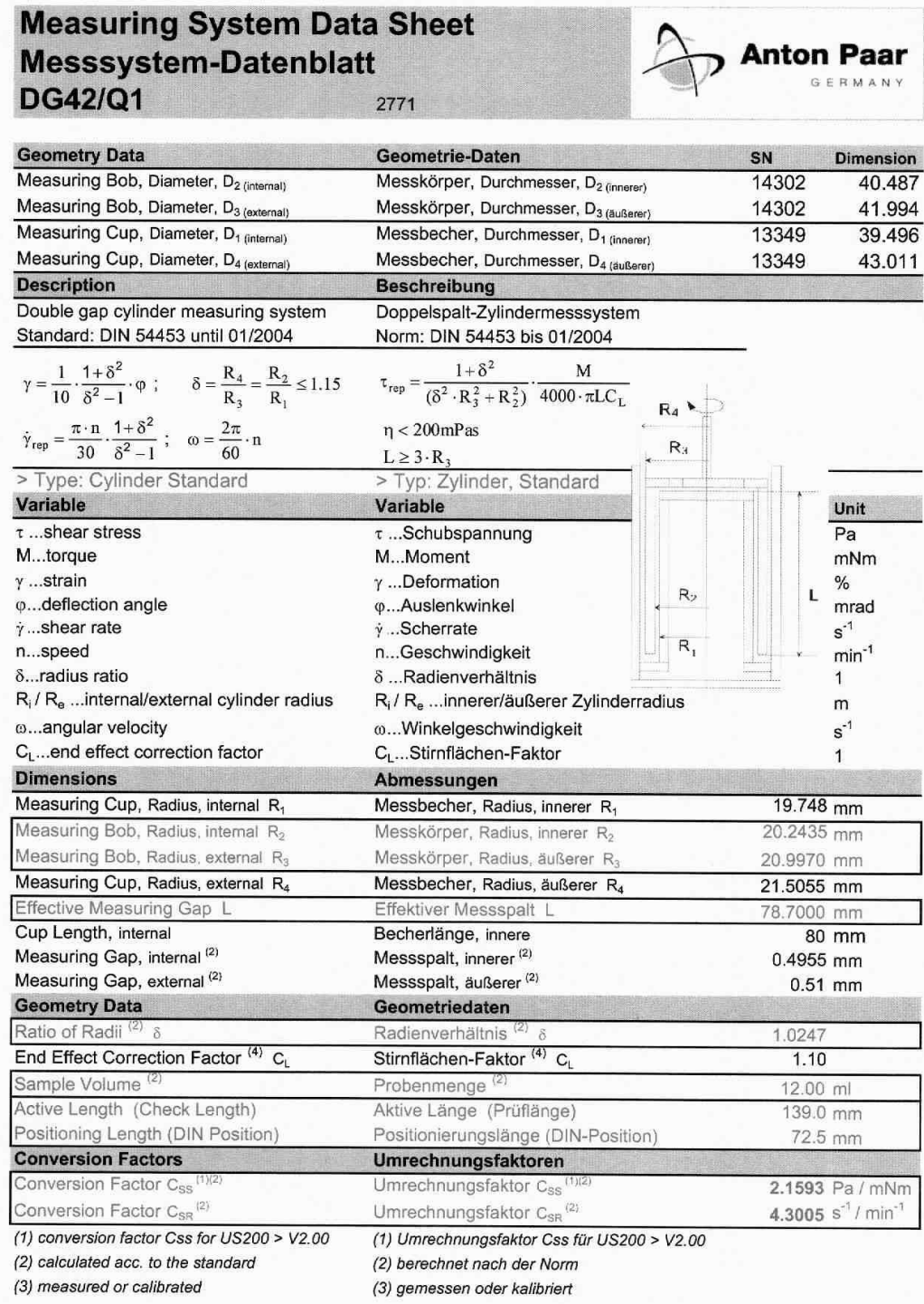


Measuring System Data Sheet Messsystem-Datenblatt DG42/Q1

2771

\section{S Anton Par}

\begin{tabular}{|c|c|c|}
\hline ...Additional Data & ...Zusätzliche Daten & \\
\hline Conversion Factor $C_{S D}$ & Umrechnungsfaktor $C_{s o}$ & $4.1067 \% / \mathrm{mrad}$ \\
\hline Conversion Factor $C_{S O}$ [SI-Unit] & Umrechnungsfaktor $C_{S O}$ [SI-Einheit] & $41.06671 / \mathrm{rad}$ \\
\hline Conversion Factor $C_{S S}$ [SI-Unit] & Umrechnungsfaktor $C_{\text {ss }}$ [SI-Einheit] & $2159.3 \mathrm{~Pa} / \mathrm{Nm}$ \\
\hline Conversion Factor [relative] $C_{s s}{ }^{\text {(4) }}$ & Umirechnungsfaktor $C_{S S}$ [relativ] $^{(4)}$ & $0.107963 \mathrm{~Pa} / \%$ \\
\hline Conversion Factor $C_{S R}$ [SI-Unit] & Umrechnungsfaktor $C_{S R}$ [SI-Einheit] & $258.0298 \mathrm{~s}^{-1} / \mathrm{s}^{-1}$ \\
\hline$\rightarrow$ Calculated Values & $\rightarrow$ berechnete Werte & \\
\hline (4) Conversion Factor Css for US200 < V2.10 & (4) Umrechnungsfaktor Css für US200 < V2.10 & \\
\hline Calculation / Conversion Factors & Berechnung / Umrechnungsfaktoren & \\
\hline$\overline{\mathrm{C}_{\mathrm{SS}}}$ & $\tau=\mathrm{C}_{\mathrm{SS}} \cdot \mathrm{M}$ & \\
\hline $\mathrm{C}_{\mathrm{SD}}$ & $\gamma=\mathrm{C}_{\mathrm{SD}} \cdot \varphi$ & \\
\hline $\mathrm{C}_{\mathrm{SR}}$ & $\dot{\gamma}=\mathrm{C}_{\mathrm{SR}} \cdot \mathrm{n}$ & \\
\hline Recommended for & Empfohlen für & \\
\hline low viscous fluids & edrigviskose Flüssigkeiten & \\
\hline
\end{tabular}

(4) Empirical value 